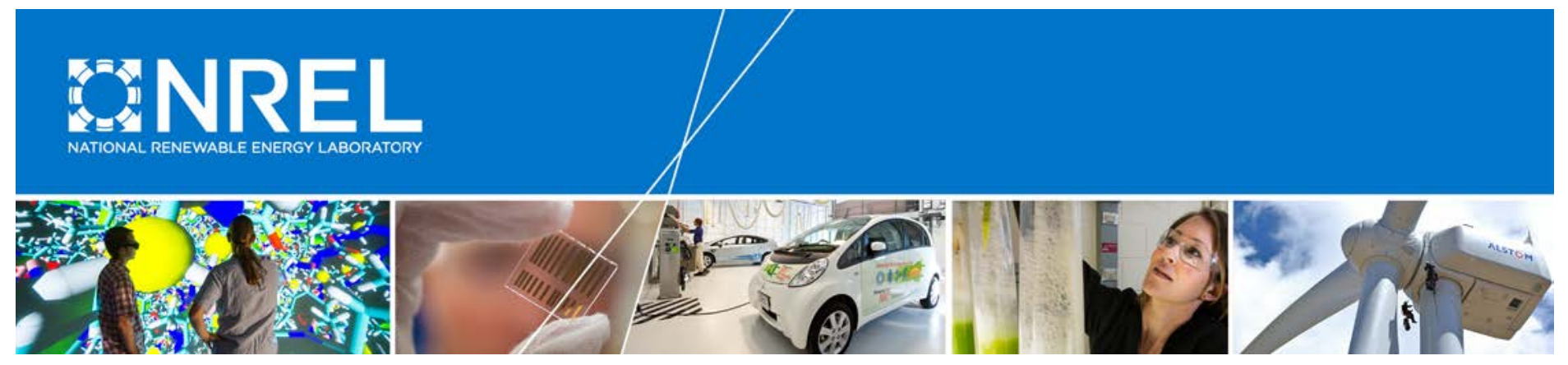

\title{
Fort Carson Building 1860 Biomass Heating Analysis Report
}

Randolph Hunsberger, Gregg Tomberlin, and Chris Gaul National Renewable Energy Laboratory

NREL is a national laboratory of the U.S. Department of Energy Office of Energy Efficiency \& Renewable Energy Operated by the Alliance for Sustainable Energy, LLC

This report is available at no cost from the National Renewable Energy Laboratory (NREL) at www.nrel.gov/publications.

\section{Technical Report}

NREL/TP-5D00-64887

September 2015 


\section{Fort Carson Building 1860 Biomass Heating Analysis Report}

Randolph Hunsberger, Gregg Tomberlin, and Chris Gaul

National Renewable Energy Laboratory

Prepared under Task No. WFGG.1000

NREL is a national laboratory of the U.S. Department of Energy

Office of Energy Efficiency \& Renewable Energy

Operated by the Alliance for Sustainable Energy, LLC

This report is available at no cost from the National Renewable Energy Laboratory (NREL) at www.nrel.gov/publications.

National Renewable Energy Laboratory 15013 Denver West Parkway

Golden, CO 80401

303-275-3000 • www.nrel.gov

\section{Technical Report}

NREL/TP-5D00-64887

September 2015

Contract No. DE-AC36-08GO28308 


\title{
NOTICE
}

This report was prepared as an account of work sponsored by an agency of the United States government. Neither the United States government nor any agency thereof, nor any of their employees, makes any warranty, express or implied, or assumes any legal liability or responsibility for the accuracy, completeness, or usefulness of any information, apparatus, product, or process disclosed, or represents that its use would not infringe privately owned rights. Reference herein to any specific commercial product, process, or service by trade name, trademark, manufacturer, or otherwise does not necessarily constitute or imply its endorsement, recommendation, or favoring by the United States government or any agency thereof. The views and opinions of authors expressed herein do not necessarily state or reflect those of the United States government or any agency thereof.

This report is available at no cost from the National Renewable Energy Laboratory (NREL) at www.nrel.gov/publications.

Available electronically at SciTech Connect http:/www.osti.gov/scitech

Available for a processing fee to U.S. Department of Energy and its contractors, in paper, from:

\author{
U.S. Department of Energy \\ Office of Scientific and Technical Information \\ P.O. Box 62 \\ Oak Ridge, TN 37831-0062 \\ OSTI http://www.osti.gov \\ Phone: 865.576.8401 \\ Fax: 865.576.5728 \\ Email: reports@osti.gov
}

Available for sale to the public, in paper, from:

\author{
U.S. Department of Commerce \\ National Technical Information Service \\ 5301 Shawnee Road \\ Alexandria, VA 22312 \\ NTIS http://www.ntis.gov \\ Phone: 800.553 .6847 or 703.605 .6000 \\ Fax: 703.605.6900 \\ Email: orders@ntis.gov
}




\section{Forward}

As part of the Army Net-Zero Energy Installation program, the Fort Carson Army Base requested that NREL evaluate the feasibility of adding a biomass boiler to the district heating system served by Building 1860. NREL previously performed a review of biomass heating at the same location for an ECIP proposal in 2013.

This report starts with the results of our analysis, followed by detailed sections that provide more detail on specific aspects of the analysis:

- Chapter 1-Introduction and Background

- Chapter 2-Building 1860 Heating Loads ${ }^{1}$

- Chapter 3-Biomass Supply and Cost Summary

- Chapter 4-Biomass System Sizing Methodologies

- Chapter 5-Economic Analysis

- Chapter 6-Schematic Design and Building Details

- Chapter 7-Fort Carson Environmental \& Regulatory Analysis

- Chapter 8-Development of a Biomass Decision Support Tool Model

- Appendix A Potential Wood Contaminants

- Appendix B System Size Vs. Load Served-Representative Examples

The following supplements are unpublished, at the request of the potential suppliers.

- Supplement 1-Biomass resource assessment (Antares)—unpublished

- Supplement 2-Rocky Top Quote-unpublished

We have also developed an Excel-spreadsheet-based decision support tool-specific to the historic loads served by Building 1860 — with which users can perform what-if analysis on gas costs, biomass costs, and other parameters. At the time of this writing, the current version of the tool is v1.0.

\footnotetext{
${ }^{1}$ Building 1860 houses a district heating system that serves a number of buildings on the Fort Carson campus, thus the loads referred to are all of those served by this system.
} 


\section{Executive Summary}

Contrary to the conclusions of the NREL ECIP review from 2013 (discussed in Chapter 1), we do not recommend adding a biomass system to the Building 1860 district heating system at this time. This is due primarily to the low cost of natural gas and relatively high costs for-as well as high supply uncertainty of-biomass (see Chapter 3 for details).

The previous analysis included the assumption that 10,000 tons per year of biomass collected at Fort Carson would be available for handling costs of about \$20 per ton. It turns out that this material is no longer available.

The 2013 analysis was based on a natural gas cost of $\$ 6.39$ per million Btu. The most recent utility data shows the price of gas for Building 1860 — which is on an interruptible rate — is less than $\$ 4.00$ per million Btu.

We do feel that the low gas costs cannot continue indefinitely, and have developed a biomass decision support tool to determine conditions at which biomass heating becomes economically feasible. This is discussed in Chapter 8.

This section presents some background information for this project, and summarizes a selection of previous studies performed for Fort Carson. 


\section{Table of Contents}

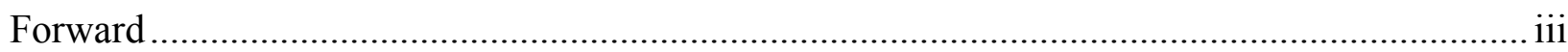

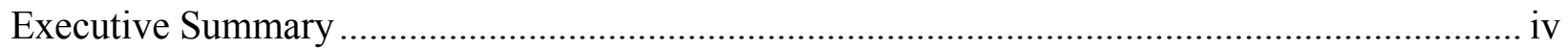

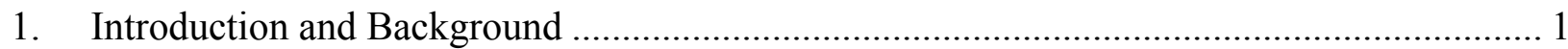

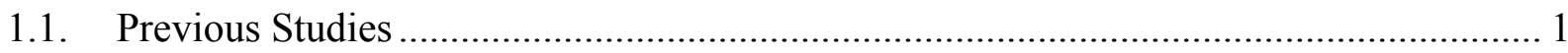

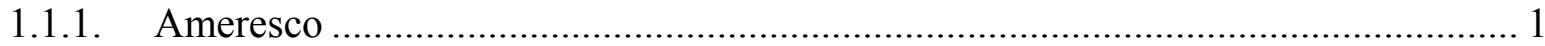

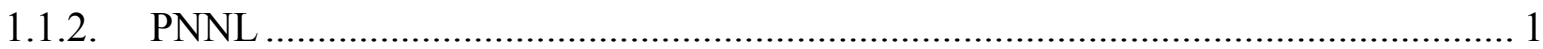

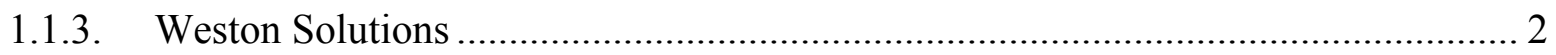

1.1.4. Malcolm Pirnie/NREL ................................................................................. 2

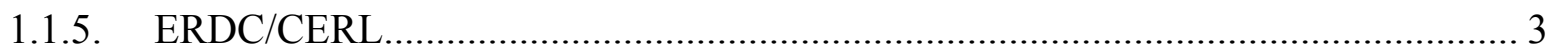

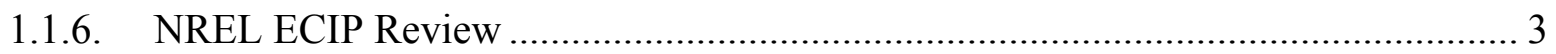

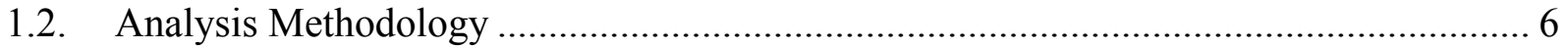

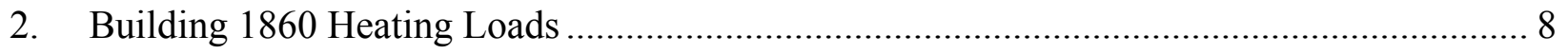

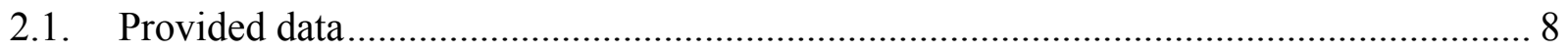

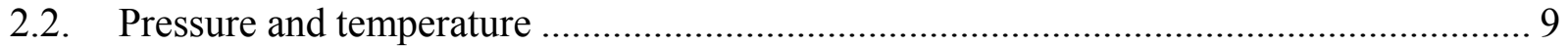

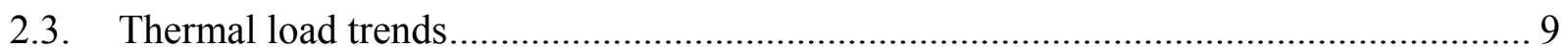

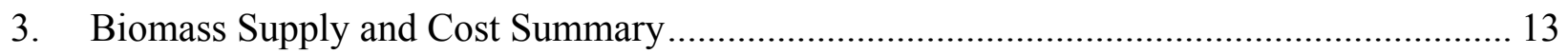

3.1. Biomass delivery and storage space ………………................................................ 14

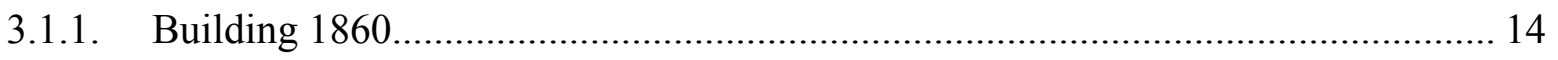

3.1.2. Combined Boiler-Chiller Facility (CBCF) ……………………………............ 14

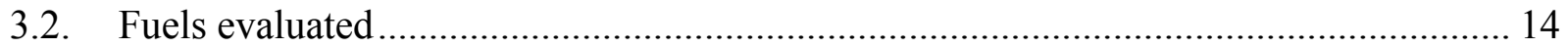

3.2.1. Wood physical and chemical characteristics ....................................................... 15

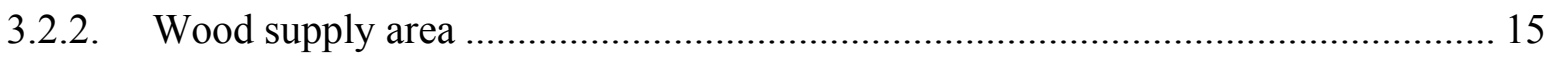

3.3. Summary of biomass generation - all sources …………………………………...... 17

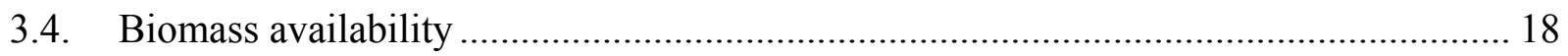

3.5. Antares report conclusions and recommendations ........................................................ 21

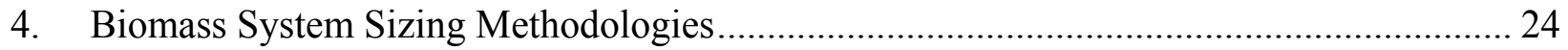

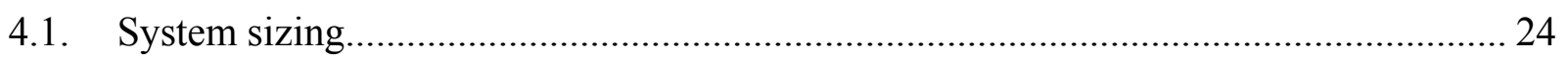

4.1.1. Sizing method 1 ............................................................................................... 24

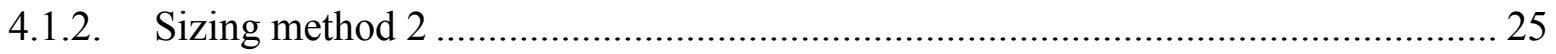




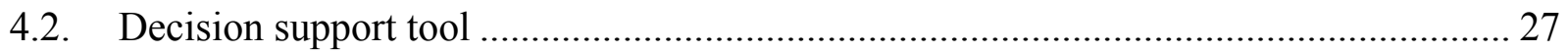

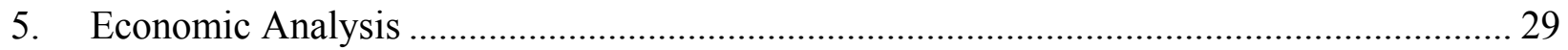

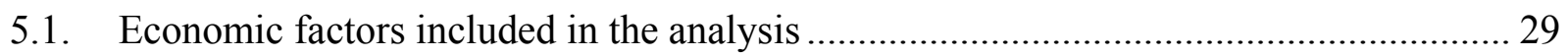

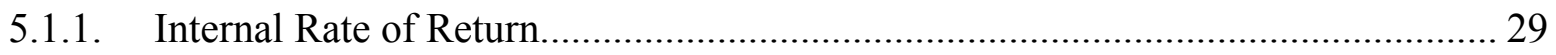

5.1.2. Savings-to-Investment Ratio.................................................................. 30

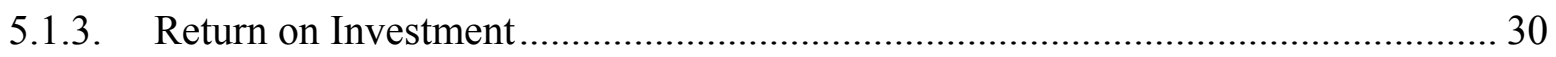

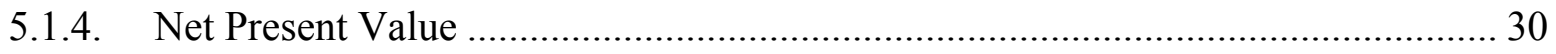

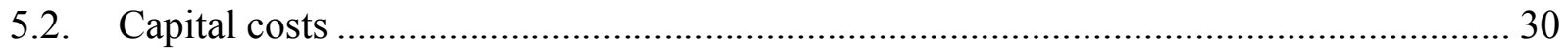

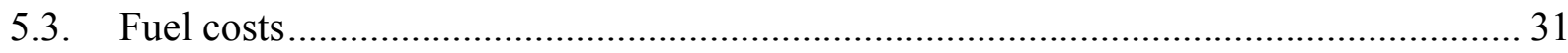

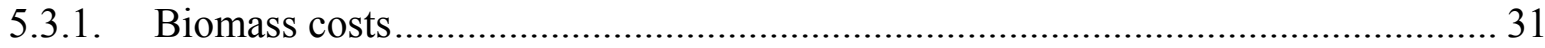

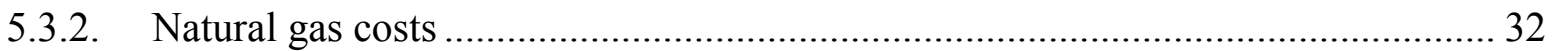

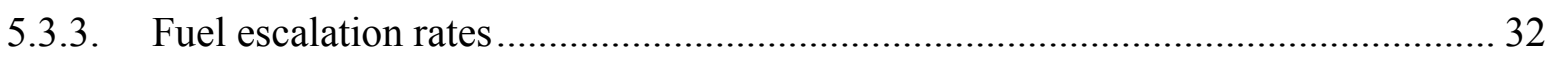

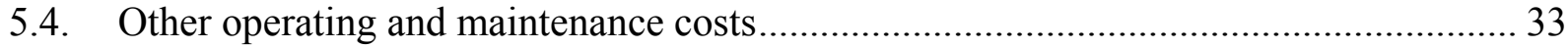

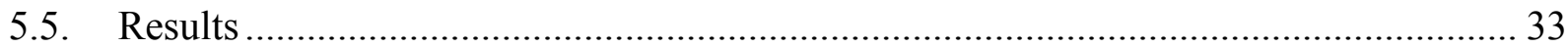

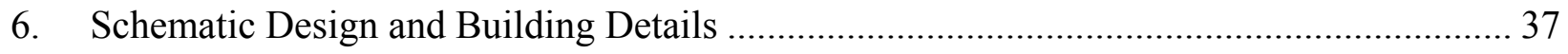

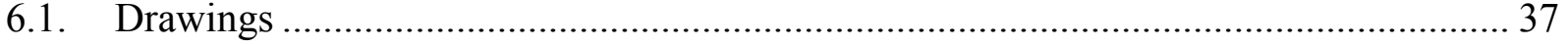

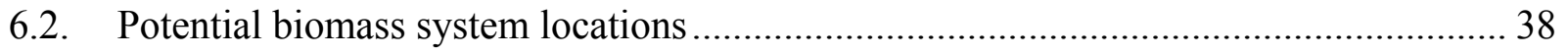

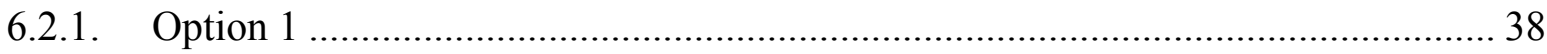

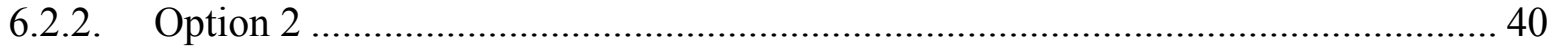

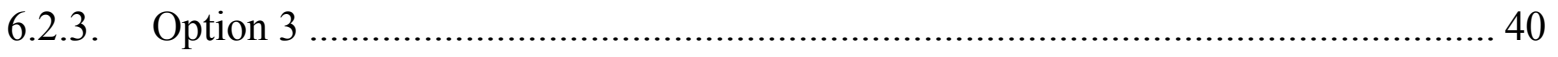

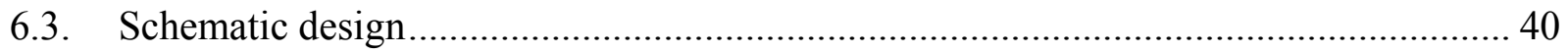

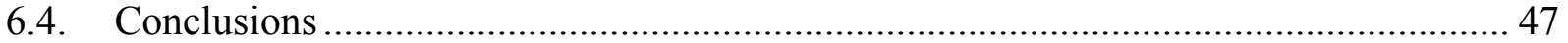

7. Fort Carson Environmental \& Regulatory Analysis .................................................. 48

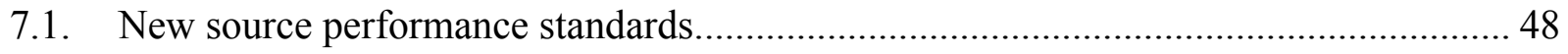

7.2. National emission standards for Hazardous Air Pollutants........................................ 49

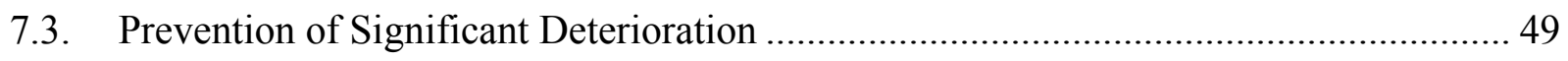

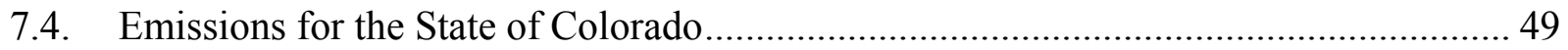

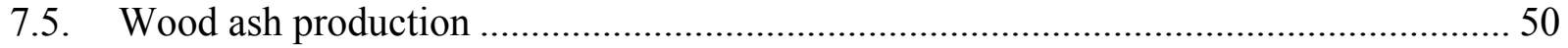

8. Development of a Biomass Decision Support Tool Model ............................................ 51

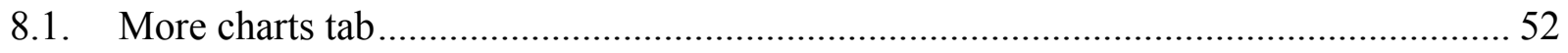

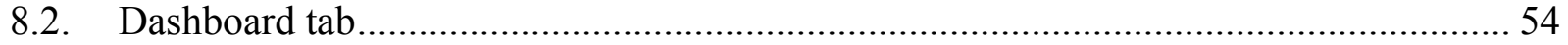


8.2.1. Parameters and advanced parameters …………................................................ 55

8.2.2. Outputs and linked values ................................................................................. 57

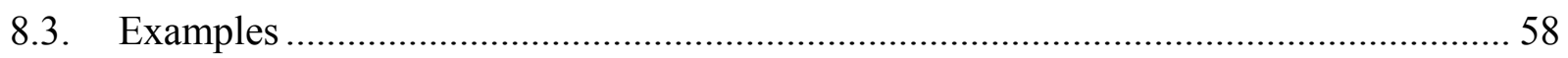

Appendix A Potential Wood Contaminants..................................................................................... 61

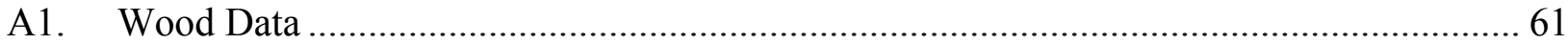

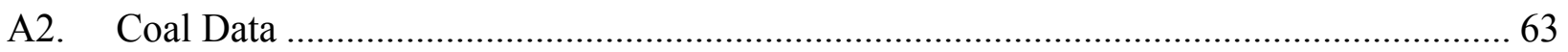

Appendix B System Size Vs. Load Served-Representative Examples ................................... 64

\section{Table of Figures}

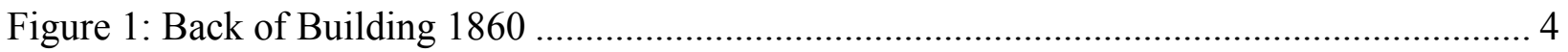

Figure 2: Aerial view of central heating plant and nearby area ................................................. 5

Figure 3: Central heating plant (Building 1860). Red outlines indicate potential locations for biomass heating plant and fuel storage ...................................................................... 6

Figure 4: Historical thermal load data for Building 1860 heating systems ……………............. 10

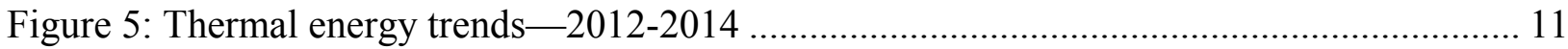

Figure 6: Thermal demand as a function of temperature (expressed as heating degree days-

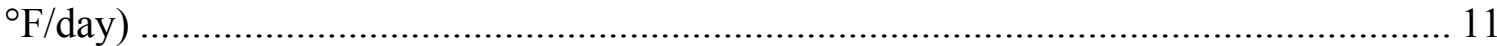

Figure 7: Thermal demand as a function of temperature (expressed as heating degree days-

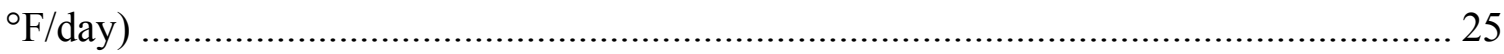

Figure 8: Building 1860 thermal load histogram ................................................................... 26

Figure 9: Biomass system size versus capacity factor and contribution factor …………............ 27

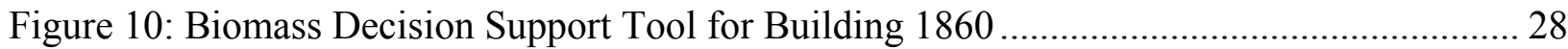

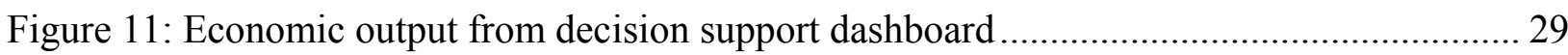

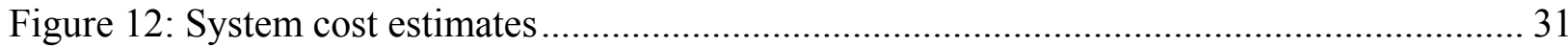

Figure 13: Fort Carson recent rate for interruptible gas service................................................ 32

Figure 14: Simple payback and SIR, from biomass decision support tool; natural gas at

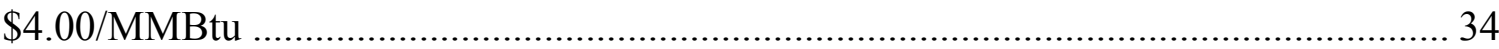

Figure 15: Projected natural gas and wood costs, with first year natural gas cost at

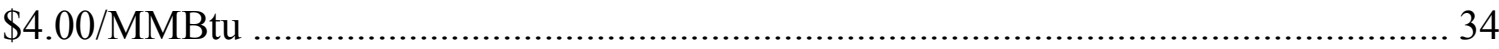

Figure 16: Simple payback and SIR; natural gas at \$4.70/MMBtu .............................................. 35

Figure 17: IRR, ROI and NPV for 1st year natural gas price of \$4.70/MMBtu............................ 35

Figure 18: Simple payback and SIR; natural gas at \$6.00/MMBtu............................................. 36

Figure 19: IRR, ROI and NPV for 1st year natural gas price of $\$ 6.00 / \mathrm{MMBtu}$............................ 36

Figure 20: Building 1860 location. Image provided by Fort Carson. ........................................ 37

Figure 21: Building 1860 plan view .................................................................................. 38 
Figure 22: Possible locations for a biomass facility (red, yellow and blue outlines).

Image provided by Fort Carson, modified by NREL. .................................................. 39

Figure 23: South corner of Building 1860. Photo by Randolph Hunsberger. ............................ 40

Figure 24: Simplified schematic of existing district heating system .................................... 41

Figure 25: Conceptual schematic showing primary biomass heating system added ................. 42

Figure 26: One potential system layout ........................................................................ 43

Figure 27: Conceptual layout of a biomass boiler (left) and chip (right) building .................... 44

Figure 28: Biomass system location Option 1, looking eastish .......................................... 44

Figure 29: Biomass system location Option1, looking north-northwest ................................ 45

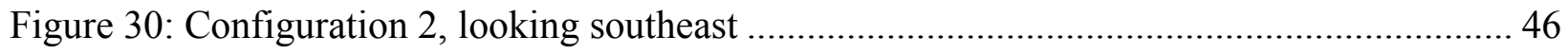

Figure 31: Configuration 2, looking northwest................................................................ 46

Figure 32: Biomass Decision Support Tool for Building 1860 .............................................. 51

Figure 33: Biomass contribution factor versus system size and load scale factor..................... 52

Figure 34: Biomass capacity factor versus system size and load scale factor .......................... 53

Figure 35: Sample chart of capacity factor and contribution factor as function of biomass system

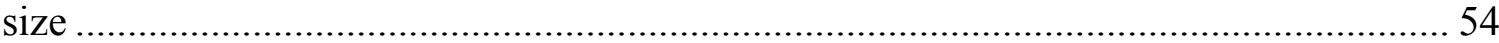

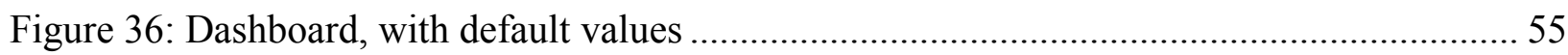

Figure 37: Payback and SIR with first year gas prices of \$5.00/MMBtu.................................. 58

Figure 38: IRR, ROI and NPV with first year gas prices of $\$ 5.00 / \mathrm{MMBtu}$.............................. 59

Figure 39: Thermal production from biomass and average wood cost as a function of biomass

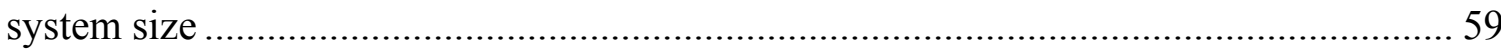

Figure 40: Projected gas and wood prices, at a first year gas price of \$5.00/MMBtu................ 60

Figure 41: Example of thermal demand (blue) and output (red) from a 12-MMBtu/hr system

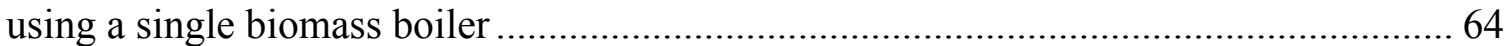

Figure 42: Example of thermal demand (blue) and output (red) for a 20-MMBtu/hr single

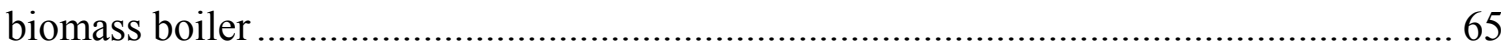

Figure 43: Example of thermal demand (blue) and output (red) for a 32-MMBtu/hr single biomass boiler

Figure 44: Thermal demand (blue) and output (red) — with daily variations — for a 32-MMBtu/hr

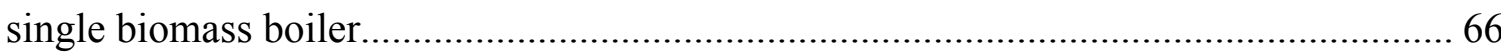




\section{Table of Tables}

Table 1: Escalation multipliers and natural gas price used for first 10-years of project operation 7

Table 2: Example boiler log data—section 1-from February 2014 (partial)............................... 8

Table 3: Example boiler log data — section 2-from February 2014 (partial)............................... 9

Table 4: Summary of Biomass Generation and Pricing for Fort Carson Area ............................... 31

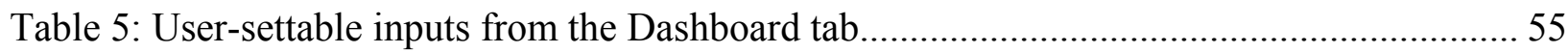

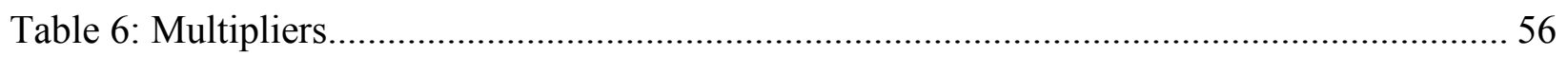

Table 7: Summary of Biomass Generation and Pricing for Fort Carson Area ………………...... 56

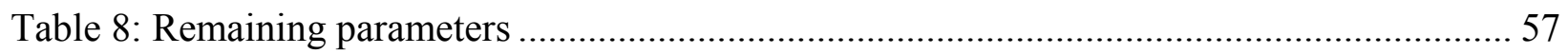

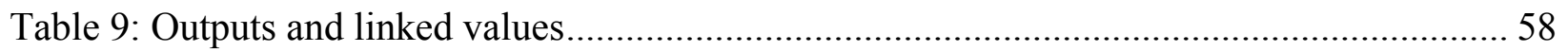

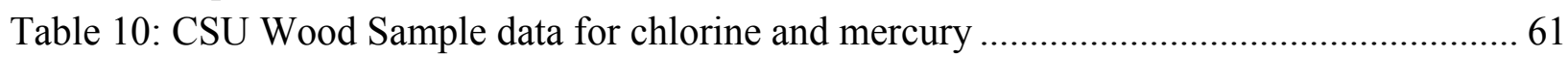

Table 11: Rocky Top Samples January 20, 2015 — chlorine measurements ...................................62 62

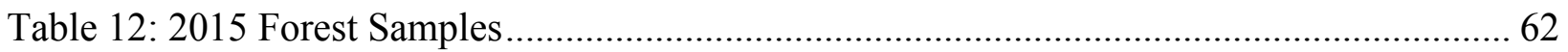

Table 13: Rocky Top Samples January 20, 2015-ultimate and proximate analysis ..................... 62

Table 14: Coal data, including HHV, ash, sulfur, mercury and chlorine .................................... 63 


\section{Introduction and Background}

NREL was hired by Fort Carson to perform an engineering analysis on the feasibility of heating a portion of the campus using woody biomass. We have been involved with several renewable energy studies for the base, including analysis of woody biomass, waste-to-energy, combined heat and power, and other renewable energy and energy efficiency studies, some of which are described below.

\subsection{Previous Studies}

Several previous studies have evaluated scenarios for renewable energy to serve Fort Carson. We present below a summary of a selection of prior work that is relevant to the current study, which includes analyses of biomass resource, biomass heating, and biomass heat and power.

\subsubsection{Ameresco}

Report date: 2008

Agency: Ameresco

Title: Unsolicited Proposal to Construct a Biomass Heating Plant at Fort Carson, CO

Salient details, findings or conclusions

Ameresco proposed to:

...finance, design, construct, possibly own, operate and maintain the new Biomass Boiler system and would additionally propose to operate the biomass boiler system and the existing central plant to provide the most economically attractive option for Fort Carson.

Ameresco hoped to sell thermal energy to Fort Carson from the natural gas and biomass plants at a rate of:

...between $\$ 15-\$ 20 \mathrm{MMBtu}$; this would include the operation and the maintenance of both the existing plant and the new plant.

This rate is considerably higher than Fort Carson would spend to own and operate the biomass plant discussed in the current report.

\subsubsection{PNNL}

Report date: December, 2008

Agency: Pacific Northwest National Lab (PNNL) 
Title: Renewable Energy Opportunities at Fort Carson, Colorado

Salient details, findings or conclusions

This report investigated several renewable energy technologies, including waste-to-energy

(WTE). With regard to WTE, the PNNL report offered the following observation:

The waste-to-energy projects evaluated at Fort Carson represent good theoretical potential. The key to these projects is the availability of waste from surrounding communities. Fort Carson waste alone cannot support an economically viable waste-toenergy plant, but the economics improve when community waste is used. There are three landfills in the Fort Carson region that may be able to supply this waste. It must be accompanied by an avoided tipping fee as a contribution to project costs.

\subsubsection{Weston Solutions}

Report date: January, 2009

Agency: Weston Solutions

Title: Fort Carson Biomass Cogeneration Facility

Salient details, findings or conclusions

This short paper evaluated "a direct combustion unit sized for $21 \mathrm{MW}$ total capacity, of which it would deliver 17.5 MW of thermal (60 MM Btu) (HTHW) and 3.1 MW of electrical power."

\subsubsection{Malcolm Pirnie/NREL}

Report date: September, 2010

Agencies: Malcolm Pirnie, Inc. and National Renewable Energy Laboratory (NREL)

Title: Feasibility Assessment for a Biomass Fueled Power Plant at Fort Carson, Colorado

Salient details, findings or conclusions

This study evaluated the feasibility of producing steam from biomass, which would then be used to produce electricity and to Chapter the heating and hot water demands of the base.

- "The district heating system serves a number of buildings at the Fort on a two loop configuration. Water enters the system at temperatures ranging from 275 to $365^{\circ}$ Fahrenheit $(\mathrm{F})$ and returns to the plant with a temperature in the range of 150 to $240^{\circ} \mathrm{F}$, or a $125^{\circ} \mathrm{F}$ differential. On the discharge side, the water has a pressure of 300 pounds per square inch (psi) and on the suction side 235 to 250 psi, or a differential of 45 psig." 
- The report assumed a natural gas sales price in year one of $\$ 13.00$ per MMBtusignificantly higher than current costs.

That report concluded that, "At this time, the economics associated with a $13 \mathrm{MW}$ power plant are not favorable and it is not recommended that the Fort actively pursue development of such a facility."

\subsubsection{ERDC/CERL}

Report date: August, 2012

Agency: Engineering Research and Development Center of the Construction Engineering Research Laboratory (ERDC/CERL)

Title: Energy Supply Alternatives for the Fort Carson, CO Combat Aviation Brigade

Salient details, findings or conclusions

In this study four alternatives for energy generation equipment were analyzed:

- Alternative 1: One Solar Saturn 20 gas turbine, with heat recovery, sized to meet critical electrical load of $1 \mathrm{MW}$ plus natural gas boiler(s) for peak heating loads.

- Alternative 2: Two gas internal combustion engines, with heat recovery, sized to meet the average annual heating loads plus natural gas boiler(s) for peak heating loads.

- Alternative 3: One woodchip boiler with a steam turbine sized to meet the peak electrical loads, with natural gas boiler(s) heating for redundancy.

- Alternative 4: One woodchip boiler that feeds a steam turbine sized to exceed the average annual electrical loads and pulling extraction steam to meet the peak heating loads plus a back-up bio-diesel generator, with heat recovery, sized to meet the critical electrical load of $1 \mathrm{MW}$ plus a natural gas boiler for heating redundancy.

\subsubsection{NREL ECIP Review}

Report date: 2013

Agency: National Renewable Energy Laboratory (NREL)

Title: Biomass Heating System Review for Fort Carson

Salient details, findings or conclusions

NREL conducted a brief review of an ECIP proposal that Fort Carson developed for an 8.5million Btu per hr biomass heating system, similar to the system investigated in the current study. 
That report stated that:

We found no factors that would clearly eliminate a biomass system from consideration. We performed an economic analysis that predicts that an $8.5-\mathrm{MMBtu} / \mathrm{hr}$ biomass system would produce a net present value of $\$ 6.7$ million over the first 20 -years of operation. We project that a larger system will have even better economic prospects, but as the size increases so does the sensitivity to wood supply costs and constraints.

The current report has been developed from the 2013 report, and the remainder of this document highlights significant components from that report.

- Building 1860 is on a corner lot, with Magrath Avenue fronting it to the northeast, and Prussman Boulevard paralleling it to the northwest. Parking adjacent to the facility consists of one row squeezed between the building and Prussman, and a second row along the back - though parking in the back competes with an overhead door, an entry door, and other obstacles (Figure 1).

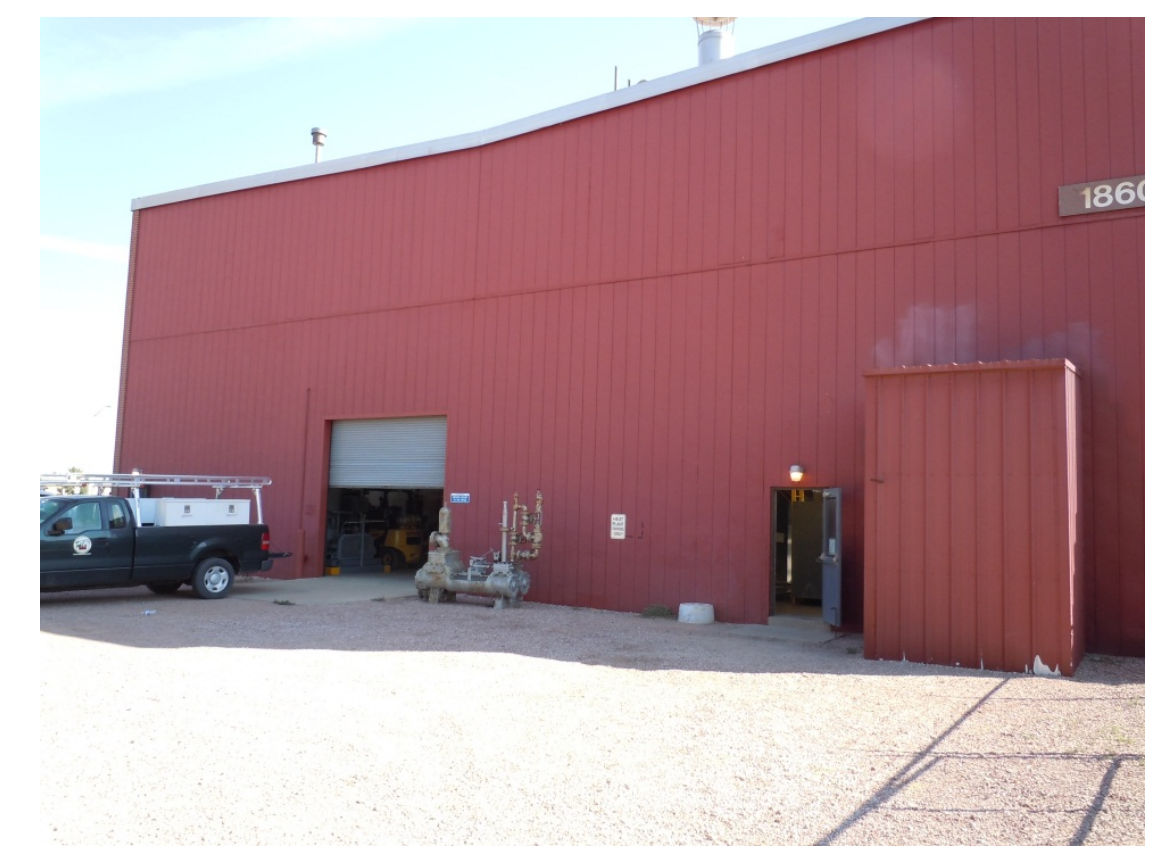

Figure 1: Back of Building 1860. Photo by Randolph Hunsberger, NREL.

- Beyond the dirt lot at the back of the building, behind a screen of trees, lie 10 propane tanks. Three cooling towers and a central chilling plant are on located to the southeast of the heating plant. This constrained arrangement presents challenges for location of a biomass heating system, which would require significantly more space than would a natural gas boiler of similar capacity - the combustor and boiler are larger and additional space is needed for fuel storage (both short- and long-term). An access route for fuel delivery trucks is critical. 
- Figure 2 provides an overview of the site and surrounding areas; the central heating plant is near the center of the image.

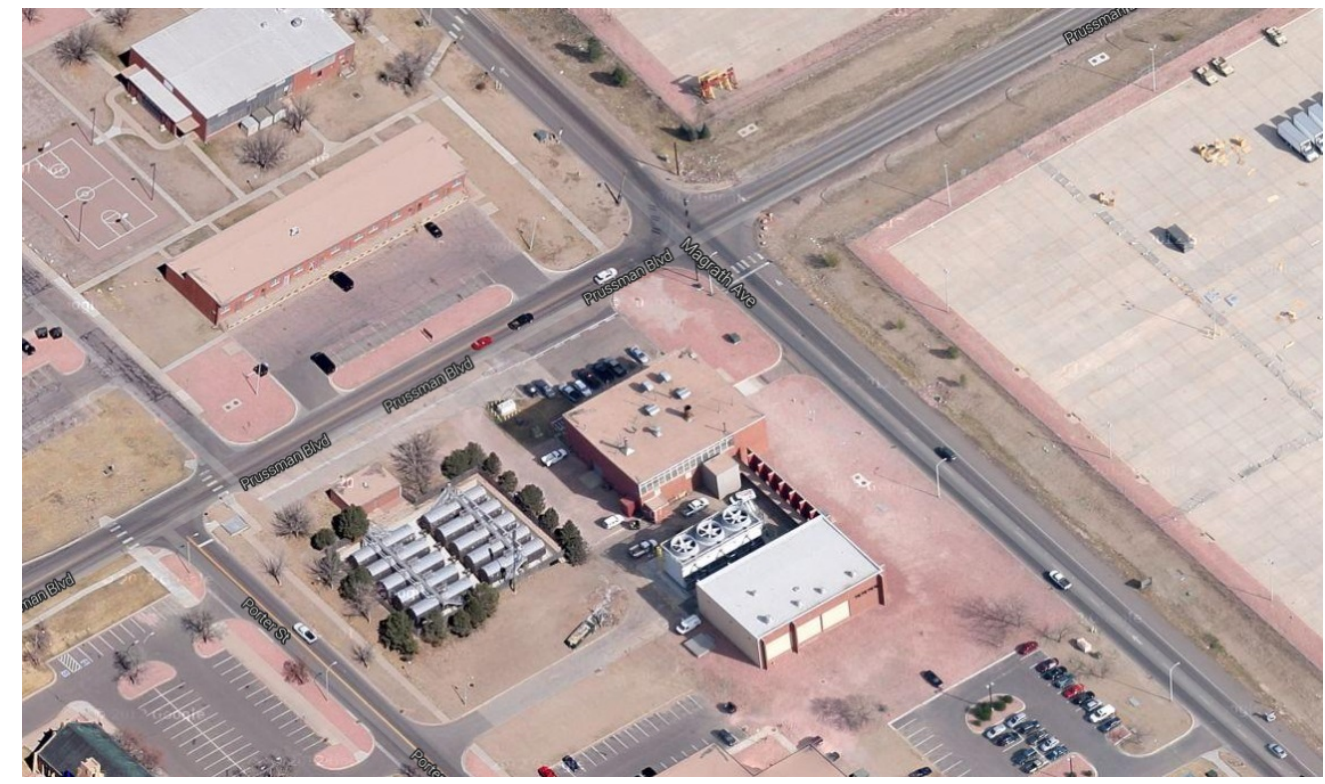

Figure 2: Aerial view of central heating plant and nearby area. Image provided by Fort Carson.

- In Figure 3 we've indicated, by red outlines, two possible locations for a heating plant and associated fuel storage. The viability of the first location, at the south corner of the building, depends on space available inside the building. A second potential location, across the parking lot and adjacent to the propane tanks, would require insulated overhead or underground lines to transport the hot water from the biomass system to Building 1860. 


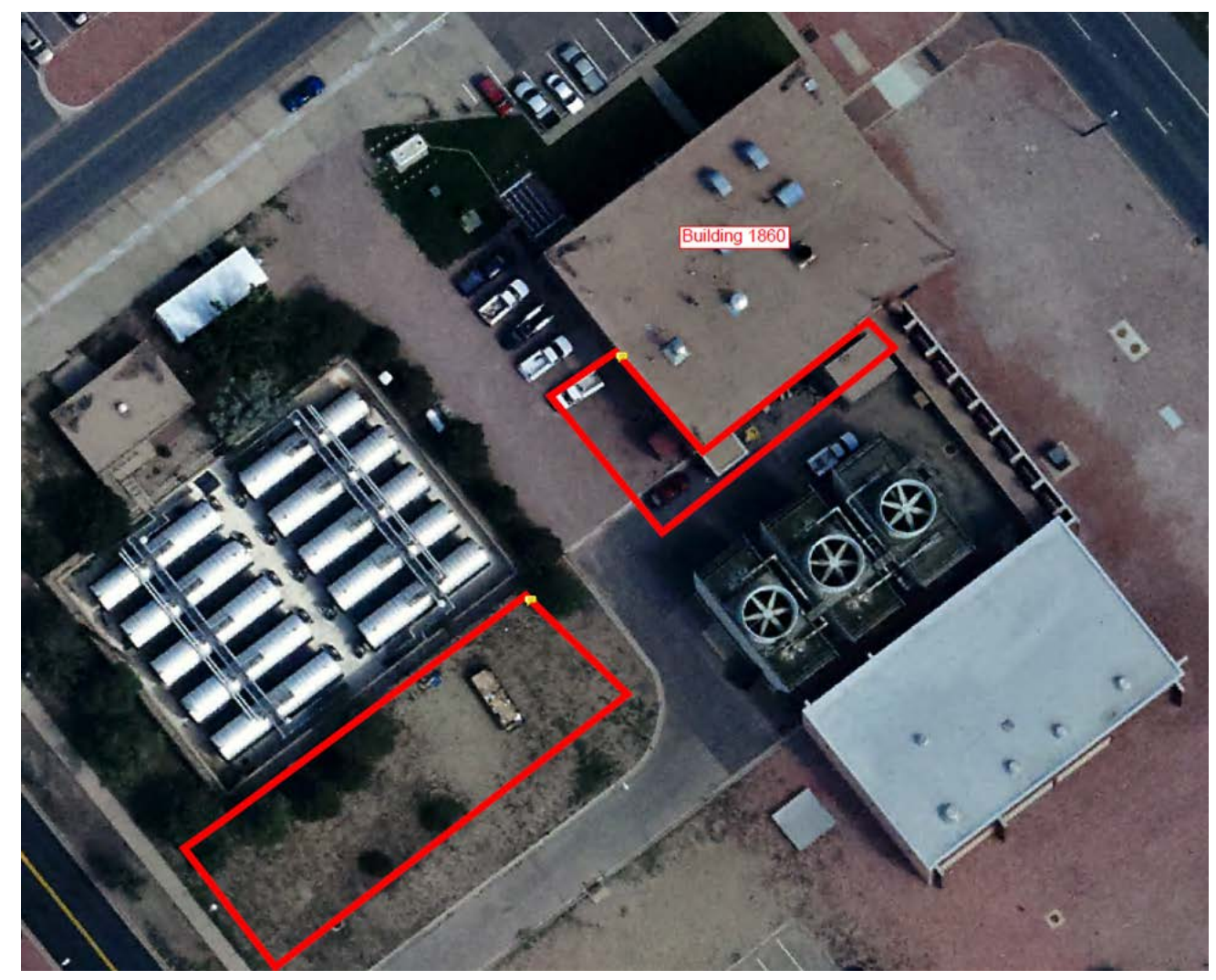

Figure 3: Central heating plant (Building 1860). Red outlines indicate potential locations for biomass heating plant and fuel storage. Image provided by Fort Carson, modified by NREL.

\subsection{Analysis Methodology}

We used the 2013 Chapter to NIST Handbook 135 to determine escalation factors for natural gas, diesel and heating oil. For biomass escalation, we used a factor equal to $60 \%$ of the diesel escalation - a method which has been demonstrated on past projects to be reasonable.

Table 1 shows the escalation multipliers and natural gas price used for the first 10-years of project operation ${ }^{2}$. These multipliers are used to estimate costs for each year based on 2013 costs.

\footnotetext{
${ }^{2}$ This analysis is based on a project under construction in 2014 and beginning operation in 2015. We calculated the NPV over 20-years, though, for legibility, only show the first 10 years in Table 2.
} 
Table 1: Escalation multipliers and natural gas price used for first 10-years of project operation

\begin{tabular}{|c|c|c|c|c|c|c|c|c|c|c|c|c|c|}
\hline Description & Year & 2014 & 2015 & 2016 & 2017 & 2018 & 2019 & 2020 & 2021 & 2022 & 2023 & 2024 & 2025 \\
\hline Natural gas multiplier & x 2013 cost & 1.04 & 1.05 & 1.13 & 1.20 & 1.27 & 1.33 & 1.35 & 1.39 & 1.43 & 1.47 & 1.48 & 1.47 \\
\hline Diesel multiplier & x 2013 cost & 0.90 & 0.88 & 0.89 & 0.91 & 0.93 & 0.95 & 0.97 & 0.98 & 1.01 & 1.02 & 1.04 & 1.05 \\
\hline Biomass multiplier & x 2013 cost & 0.94 & 0.93 & 0.93 & 0.95 & 0.96 & 0.97 & 0.98 & 0.99 & 1.01 & 1.01 & 1.02 & 1.03 \\
\hline Natural gas price & \$/MMBtu in & 6.64 & 6.71 & 7.22 & 7.66 & 8.11 & 8.49 & 8.62 & 8.88 & 9.13 & 9.39 & 9.45 & 9.39 \\
\hline
\end{tabular}

[These costs are significantly higher than current costs, for two reasons. One is that these were based on "firm" natural gas rates, but Building 1860 is on lower "interruptible" rates. Also, costs have been dropping since this study was complete. See Chapter 5-Economic analysis for a chart of recent natural gas prices.]

That report concluded with the following:

We recommend that the base perform a deeper analysis of biomass heating, which would provide an opportunity to answer some questions brought up in this report. A more detailed study should investigate biomass systems of greater capacity, and include the following tasks:

- Verify availability and cost of wood from Fort Carson

- Request wood-chip quotes from local vendors

- Review the feasibility of removing propane tanks and locating biomass equipment behind Building 1860

- Contact manufacturers and vendors to request quotes for biomass heating systems

- Contact manufacturers and vendors to determine space requirements for a biomass heating system

- Estimate the volume of fuel storage required based on desired number of days of biomass storage

- Acquire additional boiler logs to improve the estimate of annual biomass use and natural gas savings

The current report incorporates all of these tasks as components of the analysis. 


\section{Building 1860 Heating Loads}

In this section we present results on our analysis of the thermal loads served by Building 1860.

Fort Carson personnel provided NREL with Building 1860 boiler $^{3}$ logs covering March 2012 to September 2014 - a total of 30 months $^{4}$ of data.

\subsection{Provided data}

The operating logs are recorded daily, and include the data presented in Table 2 and Table 3 (showing 11 of the 28 days in the month).

Table 2: Example boiler log data—section 1—from February 2014 (partial)

\begin{tabular}{|c|c|c|c|c|c|c|c|c|c|c|c|}
\hline \multirow{2}{*}{\multicolumn{3}{|c|}{$\begin{array}{l}\text { Facilities Operating Log } \\
\text { Installation: Fort Carson }\end{array}$}} & & & & \multicolumn{4}{|c|}{ CDRL \# C.5.8.1.1.24 } & & \\
\hline & & & \multicolumn{2}{|c|}{ Plant: HTHW } & \multicolumn{3}{|c|}{ Bldg No.: 1860} & Feb & 2014 & & \\
\hline \multirow{2}{*}{ Date } & \multirow{2}{*}{$\begin{array}{c}\text { Expansion } \\
\text { tank } \\
\text { pressure }\end{array}$} & \multirow{2}{*}{$\begin{array}{c}\text { Generator } \\
\text { supply } \\
\text { pressure }\end{array}$} & \multirow{2}{*}{$\begin{array}{c}\text { Generator } \\
\text { outlet } \\
\text { temperature }\end{array}$} & \multirow{2}{*}{$\begin{array}{c}\text { Generator } \\
\text { return } \\
\text { temperature }\end{array}$} & \multirow{2}{*}{$\begin{array}{c}\text { Total flow } \\
\mathrm{m} / \mathrm{lbs} / \\
\mathrm{hr} .\end{array}$} & \multicolumn{3}{|c|}{$\begin{array}{c}\text { Generator Flue Gas \% } \\
\text { O2 } \\
\end{array}$} & \multicolumn{3}{|c|}{ Flue Gas Temp } \\
\hline & & & & & & 1 & 2 & 3 & 1 & 2 & 3 \\
\hline 1 & 239 & 277 & 350 & 268 & 397 & 4.3 & & & 268 & & \\
\hline 2 & 239 & 280 & 349 & 265 & 400 & 4.5 & & & 270 & & \\
\hline 3 & 241 & 280 & 351 & 268 & 395 & 4.3 & & & 270 & & \\
\hline 4 & 245 & $182 / 303$ & $351 / 345$ & $280 / 275$ & $425 / 275$ & 4.5 & & 5.3 & 269 & & 308 \\
\hline 5 & 241 & $280 / 300$ & $350 / 347$ & $282 / 282$ & $434 / 274$ & 4.4 & & 4.8 & 266 & & 305 \\
\hline 6 & 255 & $292 / 313$ & $340 / 345$ & $277 / 281$ & $436 / 276$ & 6.1 & & 4.2 & 265 & & 303 \\
\hline 7 & 247 & $286 / 256$ & $348 / 310$ & $275 / 290$ & $414 / 270$ & 4.2 & & 5 & 267 & & 306 \\
\hline 8 & 240 & 278 & 350 & 273 & 387 & 4.3 & & & 264 & & \\
\hline 9 & 238 & 277 & 348 & 264 & 394 & 3.6 & & & 266 & & \\
\hline 10 & 240 & 278 & 350 & 262 & 398 & 3.7 & & & 264 & & \\
\hline 11 & 239 & 276 & 351 & 272 & 393 & 4 & & & 266 & & \\
\hline
\end{tabular}

The first section of each monthly operating log, an example of which is shown in Table 2, is related to the operating conditions of the system, including the expansion tank pressure and boiler supply pressure, as well as the boiler outlet temperature and the boiler return temperature. It is not clear whether these pressures and temperatures vary significantly throughout the day, or if the values supplied are instantaneous or average values, but for the purposes of our analysis, these points are not particularly significant.

Table 3 shows a portion of the second section of the boiler log from February 2014. This data provides daily high and low outside temperatures values (which we used to calculate heating

\footnotetext{
${ }^{3}$ Technically, these aren't boilers, as they produce high-temperature hot water. The operating logs use the term "generator." We use "boiler" in this report, for convenience.

${ }^{4}$ Data from July 2012 was missing; we substituted data averaged from June 2012, for both oil (0 gal/day) and gas (149 Mft3/day) used during this period. As can be seen in Figure 4, this data appears consistent with expectations.
} 
degree days), as well as boiler energy daily heat output and natural gas input. It also provides the daily quantity of make-up water used, oil consumption ${ }^{5}$ and boiler (generator) efficiency.

Table 3: Example boiler log data—section 2-from February 2014 (partial)

\begin{tabular}{|c|c|c|c|c|c|c|c|c|c|c|}
\hline \multirow{3}{*}{ Date } & \multirow{3}{*}{$\begin{array}{c}\text { Outside } \\
\text { Temperatu } \\
\text { re High }\end{array}$} & \multirow{3}{*}{\begin{tabular}{|c|} 
Outside \\
Temperatur \\
e Low
\end{tabular}} & \multirow{3}{*}{$\begin{array}{c}\text { BTU's } \\
\text { Produced } \\
\text { (millions) }\end{array}$} & \multirow{3}{*}{$\begin{array}{c}\text { Gas Used M } \\
\text { Cu. Ft. }\end{array}$} & \multirow{3}{*}{$\begin{array}{c}\text { Make-up } \\
\text { water } \\
\text { (gallons) }\end{array}$} & \multirow{3}{*}{$\begin{array}{c}\text { Oil used } \\
\text { (gallons) }\end{array}$} & \multirow{3}{*}{$\begin{array}{c}\text { Generator } \\
\text { Efficiency } \\
\%\end{array}$} & Meter \# & $\# 1$ & \#2 \\
\hline & & & & & & & & Stop & 399452 & 595961 \\
\hline & & & & & & & & Start & 384668 & 581655 \\
\hline 1 & 34 & 16 & 798 & 1216 & 210 & 0 & 66 & & 14784 & 14306 \\
\hline 2 & 36 & 4 & 860 & 1302 & 370 & 0 & 67 & & & \\
\hline 3 & 46 & 13 & 807 & 1216 & 210 & 0 & 67 & & & \\
\hline 4 & 31 & 5 & 918 & 1383 & 540 & 0 & 67 & \multicolumn{2}{|c|}{ Total gas used M } & 29080 \\
\hline 5 & 9 & -6 & 952 & 1660 & 770 & 0 & 58 & & & \\
\hline 6 & 14 & -10 & 1181 & 1290 & 1130 & 0 & 75.9 & \multicolumn{2}{|c|}{ Total oil used gall } & 0 \\
\hline 7 & 44 & -1 & 934 & 1328 & 660 & 0 & 75 & & & \\
\hline 8 & 54 & 22 & 735 & 1054 & 540 & 0 & 70 & & & \\
\hline 9 & 33 & 20 & 828 & 1224 & 540 & 0 & 68 & \multicolumn{3}{|c|}{ Standard tons fuel used } \\
\hline 10 & 38 & 20 & 850 & 1249 & 520 & 0 & 69.0 & & & \\
\hline 11 & 48 & 19 & 772 & 1122 & 630 & 0 & 70 & & & \\
\hline
\end{tabular}

\section{2. $\quad$ Pressure and temperature}

The boilers are operated with an outlet pressure up to $300 \mathrm{psi}$, and temperature as high as $350^{\circ} \mathrm{F}$ in winter (lower in summer). Both of these values are higher than that at which typical biomass systems operate. For example, we contacted Messersmith and were told "we typically recommend a maximum temperature of $235^{\circ} \mathrm{F} @ 60$ psi."

For another project, we received a quote from Hurst Boiler for a $400 \mathrm{bhp}(13.4 \mathrm{MMBtu} / \mathrm{hr})$ biomass-fired boiler, rated at $150 \mathrm{psig}^{6}$ design pressure (135 psig max operating pressure), which would produce temperatures of approximately $360^{\circ} \mathrm{F}$.

\subsection{Thermal load trends}

Building 1860 serves year-round thermal loads in a district heating system. As expected, loads are highest in winter, but continue in summer at 80 to 130 MMBtu per day ${ }^{7}$. Figure 4 shows thermal load data from March 2012 to September 2014.

\footnotetext{
${ }^{5}$ The boilers can operate on oil or natural gas, though the quantity of oil used is typically very small-a total of less than 7,000 gallons used over the period of data available to us, and more than half of that use (3831 gallons) occurring during the period of March $1^{\text {st }}$ and $2^{\text {nd }}, 2014$.

${ }^{6}$ Note a minor potential for confusion of units: $p$ sig = pounds per square inch, gauge; psia = pounds per square inch, absolute; psia = psig + atmospheric pressure. At standard conditions, sea level atmospheric pressure is 14.7 psia, or zero psig; atmospheric pressure typically decreases with altitude; psia can never be less than zero. If a unit is written as psi, it usually, but not always, refers to gauge pressure. If you measure the air pressure in your bicycle tires, the unit is psig. How do you know? Because you measure it with an air pressure gauge.
} 


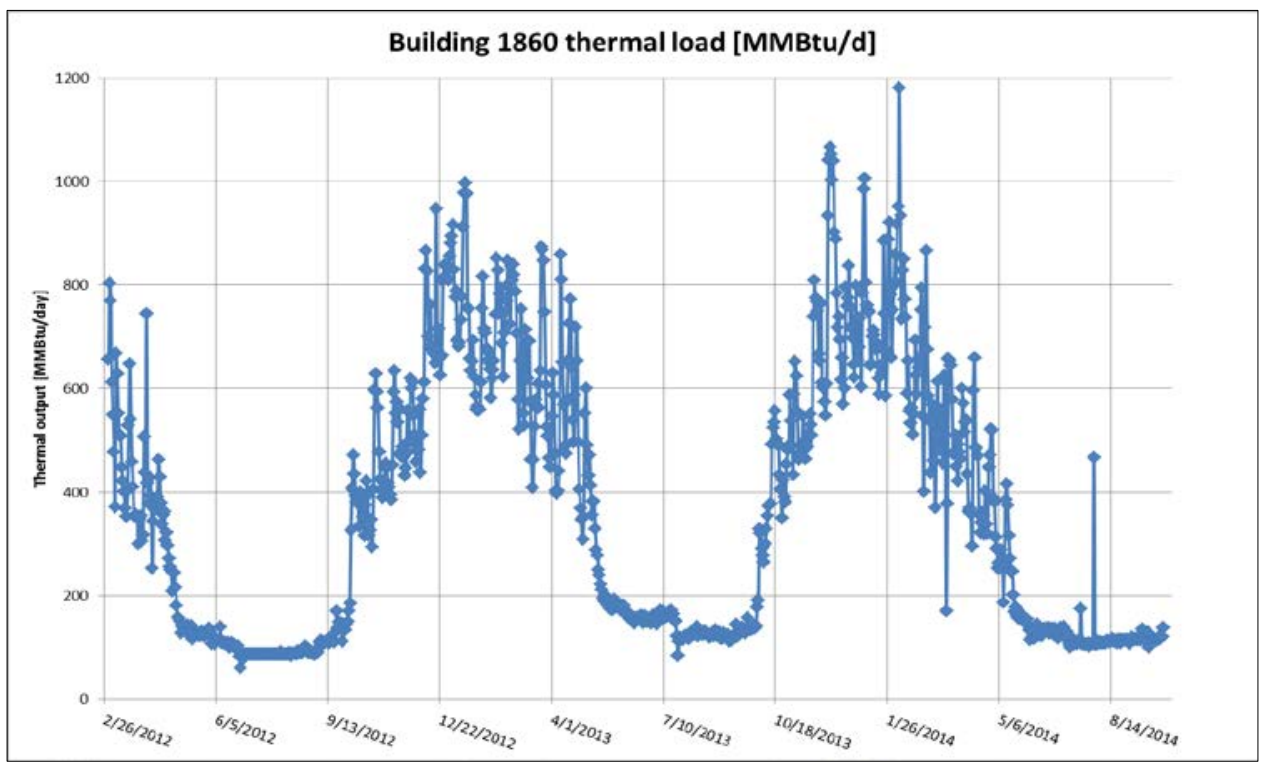

Figure 4: Historical thermal load data for Building 1860 heating systems

Compared to summer loads, winter loads are highly variable. This is due to a combination of the effects of weather (temperature, sun, snow, wind, etc.) and building occupancy, which makes it difficult to determine a simple mathematical relationship between temperature (heating degree days) and thermal energy use.

As shown in Figure 5, over the period for which data was provided, the period beginning March 1, 2012 had the lowest total annualized thermal energy use for the loads served by Building 1860. These loads increased in 2013, then dropped again through 2014. Note that each point represents thermal energy use for one year, divided by 365 to get annualized daily average thermal load in million Btu per day. This chart shows trends in energy use, which could correlate to changes in building use, or to variations in climatic conditions over the time shown.

\footnotetext{
7 "Loads" refers to boiler output, not to fuel input. This value will be the same whether supplied by oil, gas or wood chips, but-due to differences in operating efficiencies-input energy will very.
} 


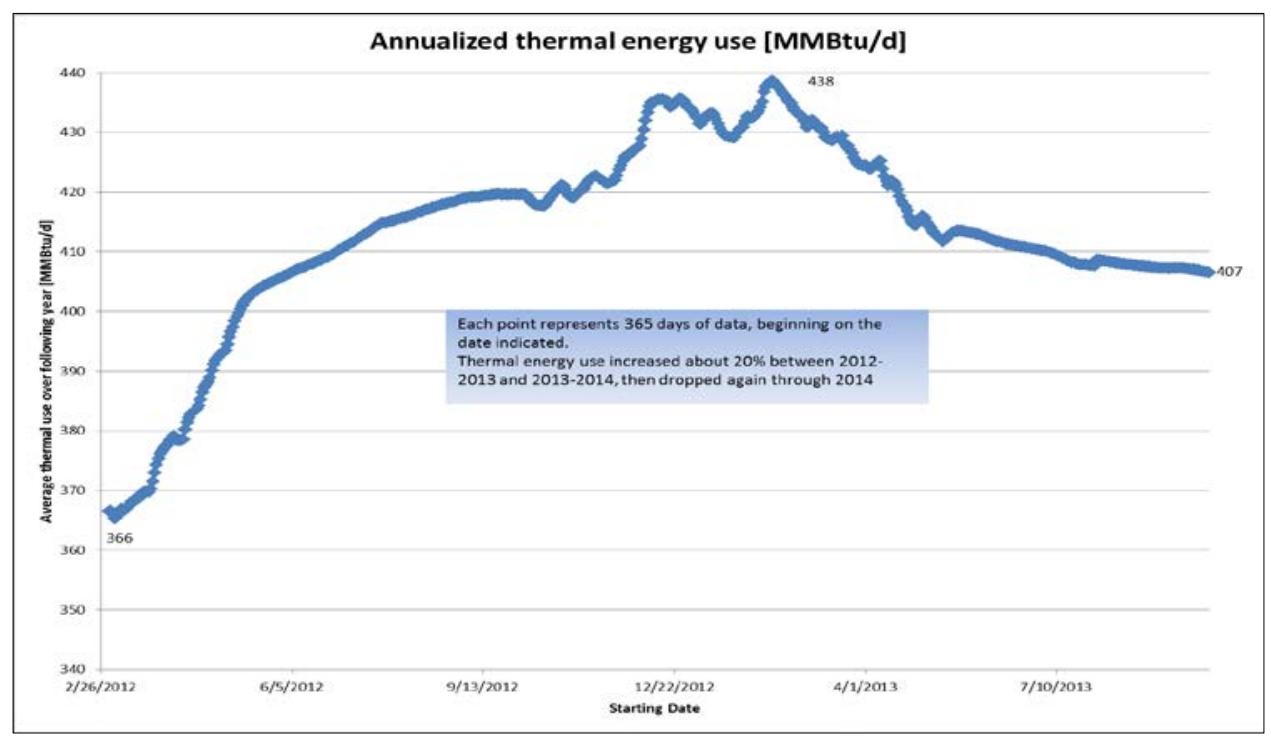

Figure 5: Thermal energy trends-2012-2014

Figure 6 shows the relationship between temperature and thermal loads for the period March 2012 to September 2014. This shows that the data exhibits a somewhat linear relationship; however, using the equation shown in the chart to estimate future heating demand will tend to predict, on average, loads that are too high on the coldest days, and - due to the large variance in values during the milder days - attempts to estimate the percentage of annual load served by any specific boiler size will result in significant errors.

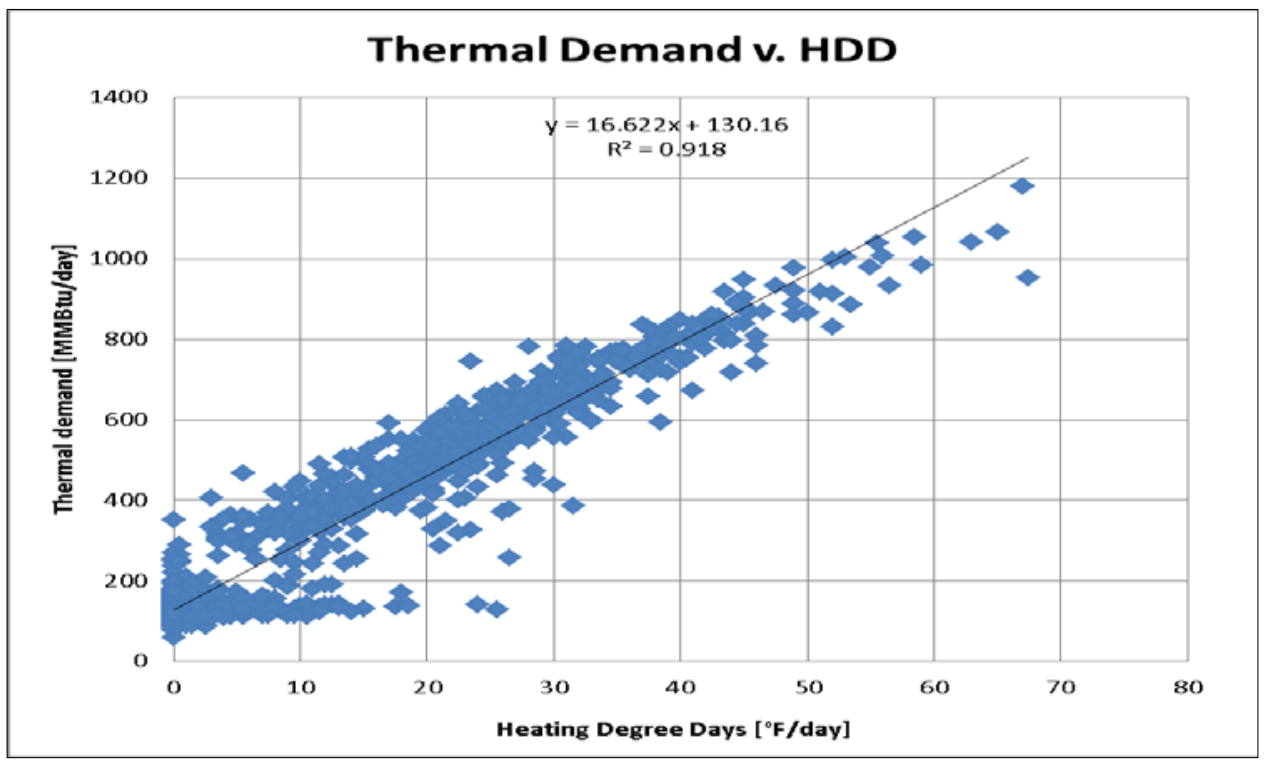

Figure 6: Thermal demand as a function of temperature (expressed as heating degree days${ }^{\circ} \mathrm{F} /$ day) 
See Chapter 4-Biomass System Sizing Methodologies, for an explanation of how this data was used to determine the relationship between the system size and the estimated annual heat production. Chapter 5-Economic Analysis discusses how the data is used to develop economic parameters. 


\section{Biomass Supply and Cost Summary}

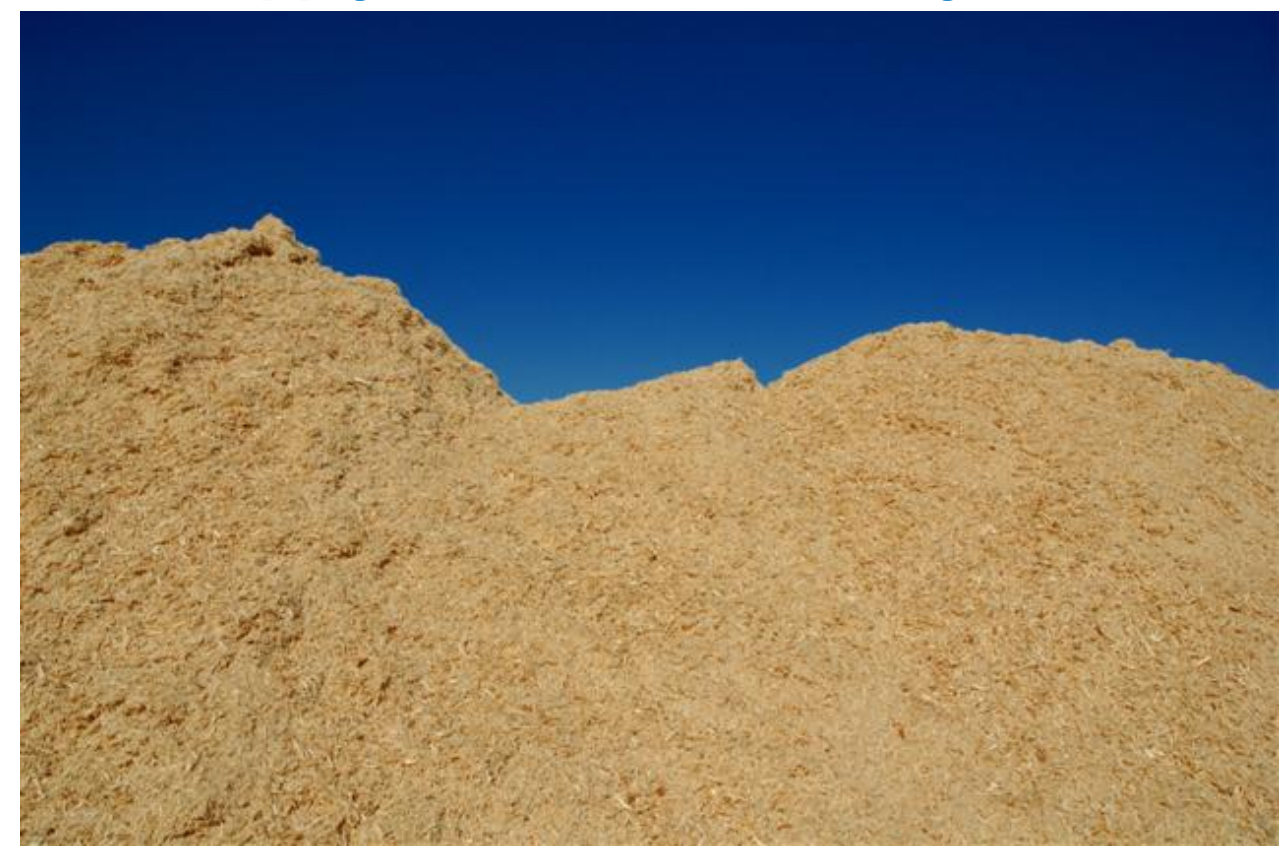

Figure 7: Photo by Randolph Hunsberger, NREL

In this chapter we provide a summary of the biomass supply and cost assessment performed by Antares Group in support of this study. The full Antares report is available as an unpublished supplement. A summary of biomass analysis supplied by Colorado Springs Utilities (CSU) is included as an appendix.

The cost, availability and quality of feedstock - in this case, woody biomass - are critical to the success of any biomass project. Smaller systems are particularly sensitive to the composition, moisture content and form factor of the feedstock.

High ash content can lead to fouling of boiler surfaces; high moisture content can reduce operating efficiency, or even prevent the system from operating; high levels of contaminants can cause corrosion issues or unacceptable air emissions; wood particles that are too large or too small can interfere with proper feeding and handling and can obstruct combustion air; and inclusion of dirt, rocks or other debris can damage fuel handling equipment, boiler surfaces, or ash augers.

NREL subcontracted with Tim Rooney of Antares Group to provide an analysis of the availability and cost of biomass for this project. The resulting 30-page report-Biomass Resource Assessment for Fort Carson - was completed in February 2015, and is summarized below. 
Relevant highlights from the Antares report are provided as bullet points below. The full report contains additional details ${ }^{8}$.

\subsection{Biomass delivery and storage space}

This study is focused on a biomass heating system for Building 1860. Antares also looked at the possibility of supplying fuel for a biomass system located at the combined boiler-chiller facility.

\subsubsection{Building 1860}

- The site is somewhat constrained to the southwest due to the presence of parking and a propane tank farm. Additional room is located to the northeast of the building, although this would be more visible to traffic along Magrath Avenue. Siting the system in the rear of the building may require some relocation and/or reorganization of existing parking and other equipment behind this building.

- Biomass fuel deliveries would need to come in via Gate 3. Passing through security could be expedited if the delivery company pays for a "Rapid Gate" pass.

\subsubsection{Combined Boiler-Chiller Facility (CBCF)}

- There is no shortage of room for a biomass system at this facility. The CBCF includes a new boiler building that houses six 2-MMBtu/hour natural gas condensing boilers that currently serve a hangar and several other buildings. Biomass deliveries would need to drive approximately 10 miles from Gate 3 to the CAB complex unless it is determined that they could be received at the gate of the facility near that area.

\subsection{Fuels evaluated}

- This study includes the following types of biomass

- Forest biomass (typically from forest fuels reduction on public and private land, utility right-of-way maintenance and burned forest area rehabilitation from the Black Forest and Waldo Canyon fires);

○ Coproducts from wood manufacturing (bark, sawdust, chips and slabs/trim ends);

- Urban biomass (tree trimmings, recycled pallets, construction debris, dunnage including material from Fort Carson); and

\footnotetext{
${ }^{8}$ [NREL] In this Supplement, NREL comments are in Times New Roman font, and Antares text is in Calibri. Missing text is denoted by ellipses [...]
} 
○ Pellet fuels (premium pellets from Confluence Energy's Kremmling or Walden mills).

- Typically, urban wood biomass has lower moisture content than other unprocessed wood fuels. However, it often also has a higher percentage of fines and inorganic materials that result in higher ash production. Forest biomass may consist of chipped or ground logs, whole trees, tops and branches or a combination thereof. Forest biomass often has a higher moisture content than urban wood but usually has a low (1.5\% or below) ash content. If tops and branches are chipped along with stems, the ash content may increase and the wood fuel may have higher nitrogen and silica content because of the presence of foliage (leaves and pine needles). Use of stumps is not typically recommended due to high ash content due to soil contamination. Pellet fuels are a premium, consistent, processed wood fuel with moisture content below $15 \%$ and low ( $1.5 \%$ or below) ash content.

\subsubsection{Wood physical and chemical characteristics}

- Fuel heating values were calculated based on assumed moisture content of the asreceived fuels and a dry ( $0 \%$ moisture) wood fuel heat content of $8,500 \mathrm{Btu} / \mathrm{lb}$, or 17 MMBtu/dry ton.

- There is some variability in the dry heat content between tree species, but moisture content is a primary driver in wood fuel heat content.

- Where available, moisture content assumptions are taken from values reported by suppliers. If not available, typical moisture content values are used (45\% for chips and bark, $20 \%$ for sawdust or trim ends/scraps).

- All wood fuel costs are based on delivery of 2-inch minus diameter chipped or ground wood to a boiler plant at Fort Carson. The boiler design will dictate the actual fuel size specification.

- Pellet fuels and other engineered wood fuels such as torrefied wood pellets have lower moisture, higher density, and higher energy density than forest or urban biomass. Because of their higher energy density, there may be some potential capital cost savings for a pellet boiler, as the size of the boiler vessel and storage facilities required are somewhat smaller than those required for a typical wood chip boiler. The tradeoff is that pellets and torrefied wood fuel are significantly more expensive.

\subsubsection{Wood supply area}

- The biomass fuel supply shed for Fort Carson includes locations within an approximate 60-minute one-way drive time of Fort Carson. 
- Key assumptions used to derive this drive-time limit include an average annual natural gas cost of $\$ 4.80 / \mathrm{MMBtu}$ at Fort Carson, average road speed of 50 miles per hour, an hourly truck operating cost of $\$ 120$ per hour, and a truck capacity of 23 tons.

- The assumed FOB (freight on board - roadside prior to delivery) price was $\$ 45$ per asreceived ton.

- Exhibit 1 shows the estimated supply shed boundary. Depending on the actual truck road speeds, the maximum haul distance ranges from about 40 miles (one-way) for locations to the southwest of Fort Carson such as Florence and Cañon City to about 70 miles to the north for locations on the I-25N corridor such as Castle Point.

\section{Exhibit 1. 60 Minute One-Way Drive Time Boundaries around Fort Carson. Map by Antares.}

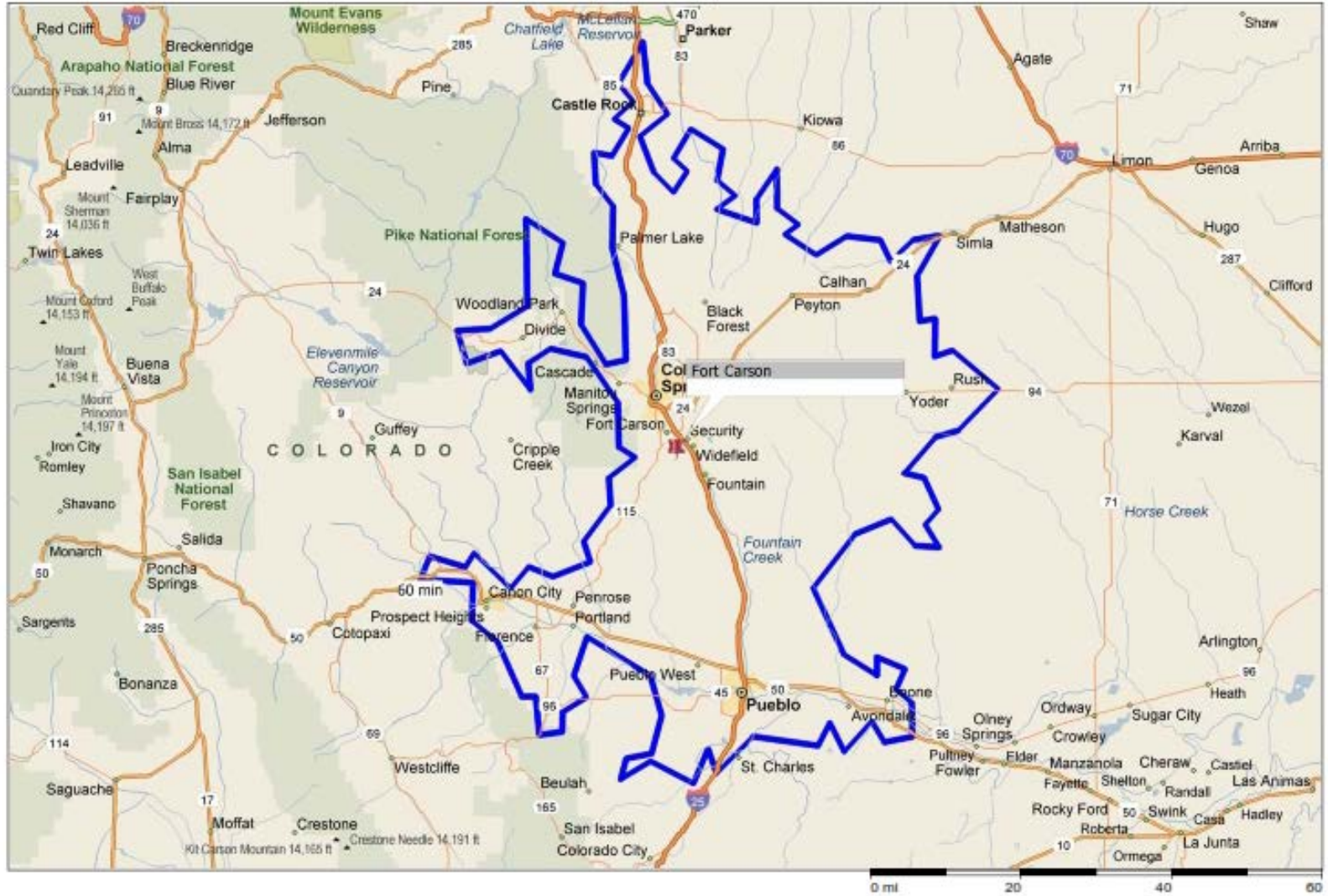

- Some biomass fuels are available from locations outside the boundary shown in Exhibit 1. This study highlights several of those that can be part of a cost-effective fuel supply for Fort Carson if most of the fuel for a project is sourced from within this supply shed. This includes biomass from the Pikes Peak Ranger District in Pike National Forest and the few operating sawmills in the area. 
- The annual average delivered cost of biomass needs to be approximately $\$ 53$ per ton to be on par with natural gas costs of $\$ 4.80 / \mathrm{MMBtu}^{9}$.

- The delivered cost of biomass from other regional wood fuel suppliers located in Denver, Fort Morgan, Fort Collins, Walden and Kremmling [...] is significantly higher than the current cost of natural gas at Fort Carson. [They ...] could be backup suppliers in the event of a shortfall from more local suppliers.

- Supplier $4[\ldots]$ produces approximately 30 truckloads of logs and 10 loads of chips per day at peak production [...] The estimated cost of this material would be between $\$ 50$ and $\$ 60$ per ton of chips delivered to Fort Carson. Most of this wood is fairly green, so assuming a moisture content of 45 percent, the heat energy cost for this material would range from $\$ 5.35$ to $\$ 6.42$ per MMBtu.

\subsection{Summary of biomass generation - all sources}

Exhibit 2. Summary of Biomass Generation and Pricing for Fort Carson Area

\begin{tabular}{|c|c|c|c|c|c|c|}
\hline Company & Type of material & $\begin{array}{l}\text { Quantity } \\
\text { (tons/ } \\
\text { year) }\end{array}$ & $\begin{array}{l}\text { Energy Value } \\
\text { (MMIBtu/ } \\
\text { year) }\end{array}$ & $\begin{array}{l}\text { Delivered } \\
\text { Cost } \\
\text { (\$/ton) }\end{array}$ & MC\% & $\begin{array}{l}\text { Delivered Cost } \\
\text { (\$/MMBtu) }\end{array}$ \\
\hline Supplier $1^{10}$ & Trim ends & 72 & 979 & $\$ 1.11$ & 20 & $\$ 0.08$ \\
\hline & $\operatorname{Tr}$ & 36 & 490 & $\$ 51.0$ & 20 & $\$ 3.75$ \\
\hline Sup & Grot & 10,000 & 122,400 & $\$ 47.50$ & 28 & $\$ 3.88$ \\
\hline Supp & Ground & 14,100 & 151,725 & $\$ 61.63$ & 37 & $\$ 5.73$ \\
\hline Supp & Bark, chips & 7,200 & 72,420 & $\$ 59.04$ & 41 & $\$ 5.87$ \\
\hline & Chips & 1,500 & 14,025 & $\$ 72.83$ & 45 & $\$ 7.79$ \\
\hline Supplier 7 & Sawdust, chips, bark & 2,000 & 18,700 & $\$ 74.06$ & 45 & $\$ 7.92$ \\
\hline \multicolumn{2}{|c|}{ Total/weighted average } & 34,908 & 380,739 & $\$ 58.11$ & 36 & $\$ 5.33$ \\
\hline
\end{tabular}

- Additional wood fuel, potentially up to 52,000 tons per year, may be recovered by ramping up recovery of wood from construction debris and wood from MSW. This would require wood fuel prices that justify investment in expanded material recovery facilities at transfer stations or landfills or diversion of wood from landfills prior to acceptance.

- Wood fuel prices pegged to be competitive with natural gas costs at Fort Carson do not provide a sufficient incentive for wood waste recyclers to engage in a new, large scale wood waste recovery. The potential boost in revenue from sales of wood fuel over

\footnotetext{
${ }^{9}$ [NREL] Actual natural gas prices are below \$4 per million Btu, as of March 2015. See Supplement 5-Economic analysis for recent historical prices.

${ }^{10}$ [NREL] In this report, names of potential suppliers have been replaced with generic identifiers. See the unpublished Antares report for names.
} 
current tipping fees also does not justify investment in a new material recovery operation by a waste management company at a landfill or transfer station.

\subsection{Biomass availability}

- All mill byproducts and recovered urban wood biomass are currently used for valueadded products. Utilization of this material for wood fuel by Fort Carson would require diversion of this material from other markets.

- A significant quantity of wood fuel is available from fuels reduction efforts on National Forest System land. Approximately half of that material is not utilized and instead is decked in log form, piled as slash on site, or is ground and left on site. There are small quantities of wood recovered from fuels reduction on public and private land.

- Besides the Fort Carson heating project, the other major prospective wood fuel user in the area is the CSU Drake Power Plant. The CSU Drake Power Plant cofiring project is currently inactive. CSU is in the process of determining the future status of that power station. $^{11}$

- Exhibit 3 presents a supply/price curve for the Fort Carson supply shed showing the heating value of biomass available (MMBtu/year) vs. the weighted average current delivered price of that fuel $(\$ / M M B t u)$. The supply curve reflects the pricing of different types of mill and forest residues. Pricing information was provided by suppliers via telephone survey and, in the case of Supplier 3 and Supplier 7, indicative bids. Approximately 276,000 MMBtu, or 27,000 tons per year (based on an average moisture content of $41 \%$ ) are available to Fort Carson at a price equal to or less than the current price of natural gas at Fort Carson ${ }^{12}$. The weighted average price of wood fuel at the quantity required by Fort Carson (assuming use of 10,000 tons of fuel per year ${ }^{13}$ and no other new sources of wood fuel demand) would be $\$ 3.85 /$ MMBtu if Fort Carson is able to use construction debris for a portion of its fuel.

\footnotetext{
${ }^{11}$ [NREL] Fort Carson personnel met with Colorado Springs Utilities, who indicated that they have concerns about high levels of chlorine in biomass samples that they had analyzed, so they may not resume co-firing. They plan to have additional samples of forest biomass tested as part of their analysis. They indicated that the coal they have been using has very low chlorine levels-approximately 10 to 20 parts per million.

${ }^{12}$ [NREL] Note that this statement is based on a natural gas price of $\$ 4.80 / \mathrm{MMBtu}$; it is currently less than this.

${ }^{13}$ [NREL] Actual use could be 6,000 to 12,000 green tons per year, depending on system size selected.
} 
Exhibit 3. Current Supply/Price Curve for Biomass (\$/MMBtu vs. MMBtu/year)

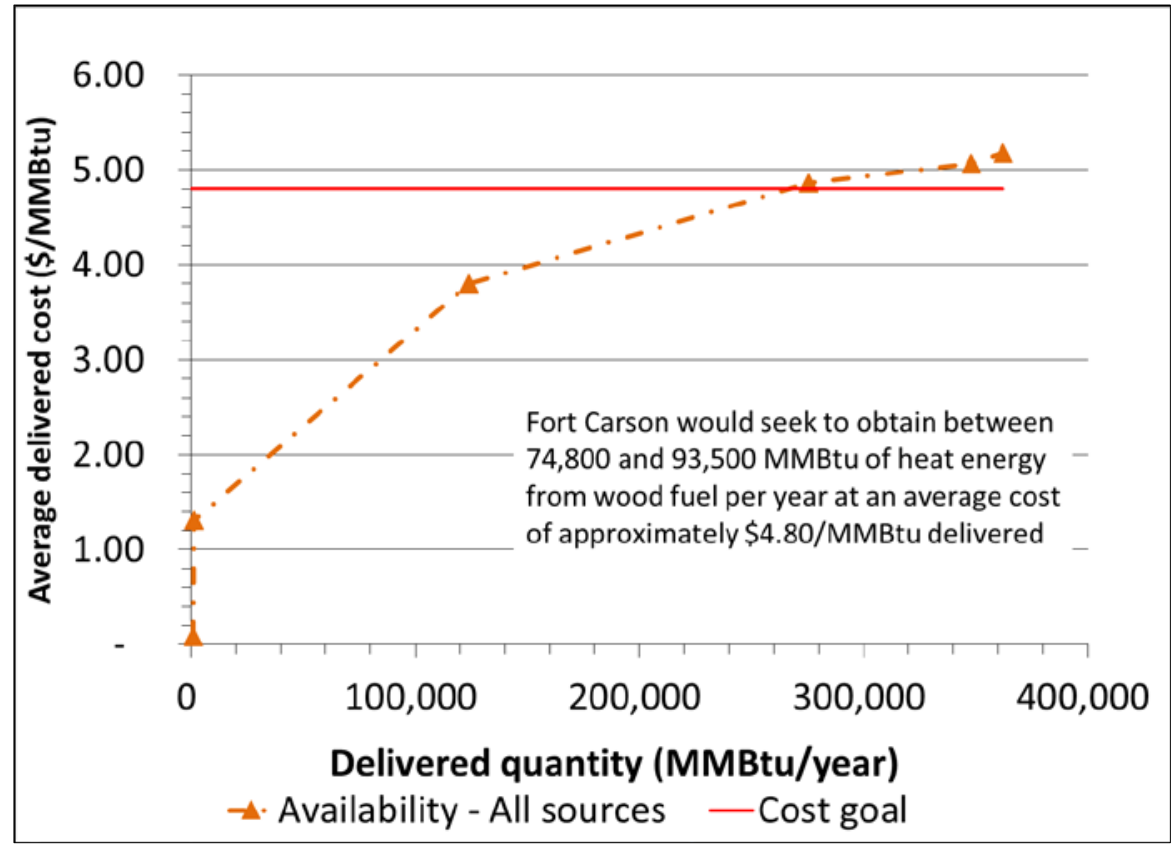

- The lowest cost supplier (with the exception of a very small quantity from a local mill work company) is Supplier 3. The reported price for wood fuel from Supplier 3 is based on additional recovery of wood construction debris, a portion of which would contain glues and adhesives. As mentioned earlier, if Fort Carson requires fuel that does not include any glues or adhesives, the cost of wood fuel is likely to match or exceed current natural gas prices due to the additional cost to segregate glued wood from non-glued material.

- Note that the prices described previously for wood fuel are in current (2015) dollars. Historically, wood fuel prices in many areas where biomass fuel is an established commodity, such as the U.S. Southeast, are less volatile than natural gas prices. In addition, the escalation rate for wood fuel [...] is commonly lower than that for natural gas. However, for the Fort Carson project, there are very few suppliers that are likely to supply wood for a biomass heating project. Therefore, the escalation rate will be determined by the terms of the purchase agreement with the supplier. This is really a matter of negotiation. There is no published commodity futures index applicable to this case that Fort Carson can rely on to peg future wood costs. That said, many biomass supply agreements contain a fuel escalation clause that is tied to diesel prices. Diesel prices are one driver for wood fuel costs, especially for forest biomass. Suppliers may seek an annual or quarterly diesel fuel adjustment clause and may or may not ask for an additional increase based on the Consumer Price Index (CPI) applied to the non-fuel portion of the costs of biomass. Exhibit 4 provides an example calculation of the impacts 
of rising diesel costs, labor rates and consumer prices on delivered wood fuel costs to Fort Carson. ${ }^{14}$

Exhibit 4. Example Biomass Price Escalation vs. Industrial Natural Gas

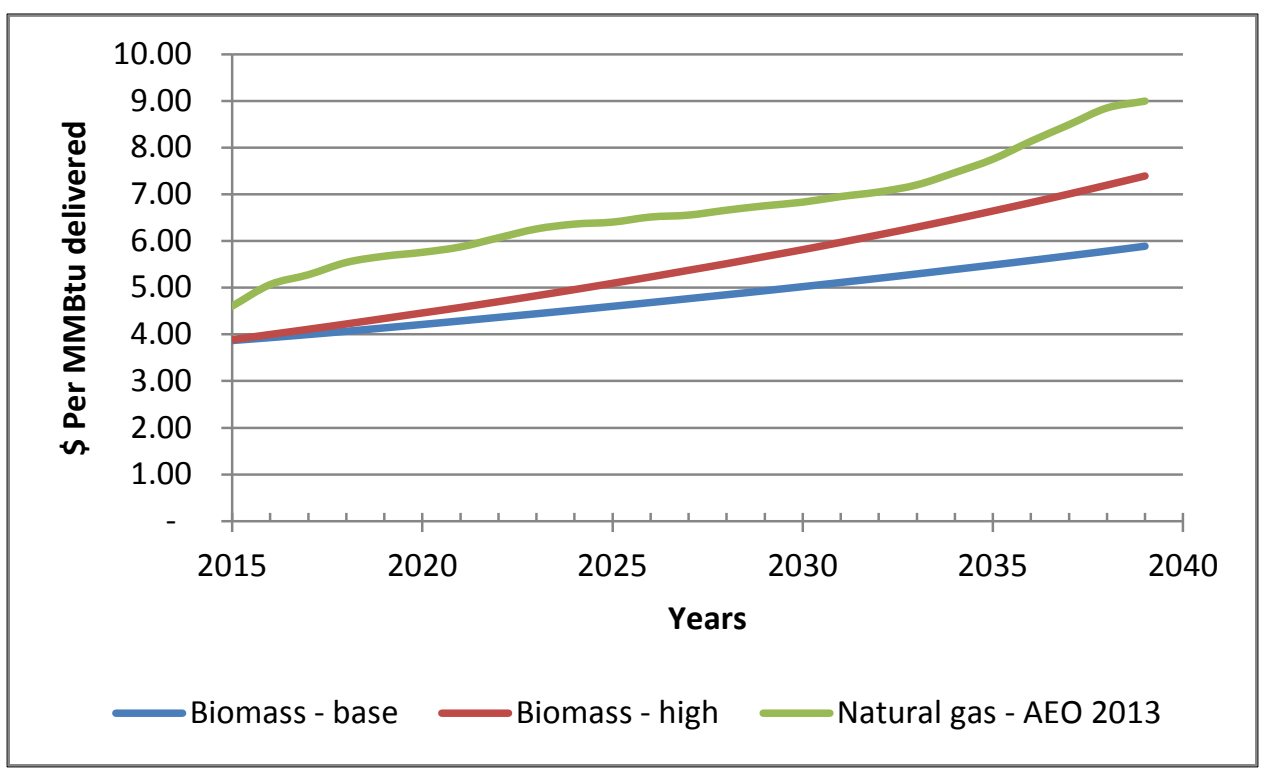

Note: Diesel price and industrial natural gas projections based on EIA AEO 2013 data. This analysis assumes a delivered biomass cost of $\$ 47.50$ per ton and an average round-trip delivery distance of 25 miles. For the base biomass case, the CPI is assumed to increase at an annual rate of $2 \%$ and labor is assumed to increase by $0.66 \%$. For the high biomass case, CPI increases at $2.5 \%$ per year and labor increases by $4 \%$ per year.

- For the period from 2015 - 2039, the projected rise in diesel prices results in an annual wood fuel increase of $0.06 \%$ to $0.08 \%$ (compound annual growth rate). The combined impacts of rising diesel, consumer prices and labor rates on wood fuel ranges between $1.8 \%$ and $2.7 \%$ per year. This is lower than the $2.8 \%$ compound annual growth rate of industrial natural gas based on EIA's 2013 Annual Energy Outlook projections for the same period.

- Exhibit 5 shows the supply and demand ratios for low and high wood supply and demand cases for the Fort Carson supply shed. The mid-range case assumes that CSU resumes cofiring at a moderate level (10\% of heat input for Unit 5) and results in a small supply shortfall for all users in the region. This overall shortfall is small and could be made up by other regional wood fiber users using more local wood resources. The high demand/low supply scenario illustrates how important the CSU cofiring program is for

\footnotetext{
14 [NREL] For our analysis, we used the escalation rates supplied by the 2014 Annual Supplement to the NIST 135 Handbook, as described in Supplement 5-Economic analysis.
} 
fuel supply reliability for Fort Carson and other wood fiber users in the region. If wood biomass generation does not remain at current levels and CSU attempts to ramp up its cofiring program to $25 \%$ of fuel use by Unit 5 , there will be a significant regional wood fiber shortfall.

\section{Exhibit 5. Annual wood supply and demand case for the Fort Carson supply shed}

\begin{tabular}{|c|c|c|c|}
\hline Supply and demand values & $\begin{array}{l}\text { Low supply/ } \\
\text { high demand } \\
\text { (tons) }\end{array}$ & $\begin{array}{l}\text { Mid-range } \\
\text { (tons) }\end{array}$ & $\begin{array}{l}\text { High supply/ low } \\
\text { demand (tons) }\end{array}$ \\
\hline Current biomass generation & & & \\
\hline Mill byproducts & 9,308 & 9,308 & 9,308 \\
\hline Forest biomass & 3,000 & 7,800 & 15,600 \\
\hline Total current supply & 12,308 & 17,108 & 24,908 \\
\hline Resources: not currently generated & & & \\
\hline Construction debris diversion and landfill wood & 5,000 & 10,000 & 52,334 \\
\hline Total additional recoverable supply & 5,000 & 10,000 & 52,334 \\
\hline Summary of supply & & & \\
\hline Currently recovered biomass & 12,308 & 17,108 & 24,908 \\
\hline Additional recoverable biomass & 5,000 & 10,000 & 52,334 \\
\hline Total supply & 17,308 & 27,108 & 77,242 \\
\hline Demand & & & \\
\hline Current & 12,308 & 13,208 & 17,108 \\
\hline Proposed future & 30,000 & 18,000 & 8,000 \\
\hline Total demand & 42,308 & 31,208 & 25,108 \\
\hline Net availability - with additional recoverable biomass & $(25,000)$ & $(4,100)$ & 52,134 \\
\hline (including additional recoverable biomass) & 0.6 & 1.5 & 9.7 \\
\hline $\begin{array}{l}\text { Ratio of supply/demand - All demand } \\
\text { (including additional recoverable biomass) }\end{array}$ & 0.4 & 0.9 & 3.1 \\
\hline
\end{tabular}

\subsection{Antares report conclusions and recommendations}

- There is a sufficient quantity of wood biomass generated to support a biomass heating facility at Fort Carson if it is the only major new user of wood fiber in its wood supply shed to enter the market in the lifetime of the project $[\ldots]$ This area is bounded roughly by Castle Rock in the north, Pueblo to the south, Florence to the west and the small towns of Yoder and Rush to the east.

- Overall, suppliers contacted for this study indicated that they could provide approximately three times the required quantity of wood fuel for a proposed biomass boiler project at Fort Carson that would utilize between 8,000 and 10,000 tons of wood fuel per year. 
- Currently, nearly all of the wood fiber generated in the region is sold for other uses (primarily landscaping materials, bedding and soil amendments).

- The market value for landscaping products is several times that for fuel wood. Mills and wood recyclers may divert some lower quality fiber from these markets to Fort Carson, but much of the wood fuel for Fort Carson is likely to come from increased recovery of wood construction debris in order to meet increased demand. There is sufficient wood waste generated from construction and remodeling to support this. It would require existing wood recyclers to market more aggressively to homebuilders in the area. It is not likely that wood fuel prices provide a sufficient incentive for waste management companies to forgo or drop tipping fees and segregate wood waste for sale to Fort Carson.

- The largest and most economical wood fuel supplier in the region, Supplier 3, is located in Colorado Springs. Supplier 3 is a wood recycling and organic materials company that accepts wood primarily in the form of pallets, logs, and tree trimmings, grinds it in tub grinders and sells it for mulch, fuel, bedding and feedstock for compost operations.

- Supplier 3 indicated that it is capable of providing Fort Carson with its entire fuel requirement - between 8,000 and 10,000 tons of wood fuel per year-for $\$ 47.50$ per ton delivered, or $\$ 3.88 / \mathrm{MMBtu}$. This is contingent on a five-year minimum contract, fuel specifications for the project and other supply obligations.

- Increasing their wood resource, as discussed previously, requires increasing acceptance of roll-offs from homebuilders. A portion of that material may include wood containing glues and adhesives (i.e., veneer, plywood, OSB). Segregating glued wood would significantly increase the cost of wood fuel, to levels on par or greater than the current cost of natural gas at Fort Carson.

- Several other companies in the area are capable of providing quantities of clean wood (without glues or adhesives) sufficient to meet Fort Carson's wood fuel demand, albeit at a cost that would exceed that of natural gas at Fort Carson. One other waste recycler, Colorado Industrial Recycling, and a small sawmill, McComb Lumber, did not provide quantity or pricing information in support of this study.

- The only other identified major potential new wood fuel user in the area is CSU's Drake Power Plant. In 2014, CSU operated a biomass cofiring demonstration at Unit 5 of the 46 MWe capacity pulverized coal power station. That demonstration was halted due to a May 2014 fire at the Drake Power Plant (unrelated to the biomass project).

- The cofiring program's future is currently uncertain. ... If the cofiring project were to resume at Unit 5 at a $25 \%$ level (as indicated in conceptual plans for the program), the Drake Power Plant would require approximately 20,000 tons of wood [per year], or 57\% of the total quantity potentially available based on the results of this study.

- Unit 7 is also a possible candidate for cofiring. Supplier 3 was under contract to supply CSU with wood fuel during the demonstration project. Supplier 3 indicated it would be 
difficult to meet the demand for both Drake Power Plant and a biomass boiler system at Fort Carson.

- Exhibit 6 summarizes the most significant wood fuel supply opportunities and concerns for a biomass heating project at Fort Carson. As long as CSU does not resume cofiring at the Drake Power Plant, fuel quantity is not likely to be a concern.

\section{Exhibit 6. Fort Carson Wood Fuel Supply Key Opportunities and Risks}

\begin{tabular}{|c|c|}
\hline Opportunities & Risks \\
\hline $\begin{array}{l}\text { - Sufficient wood fuel available from a } \\
\text { reputable supplier with a track record } \\
\text { of successfully meeting wood } \\
\text { biomass fuel requirements } \\
\text { - } \text { Preliminary bids that show wood fuel } \\
\text { prices below current natural gas costs } \\
\text { at Fort Carson }{ }^{15} \\
\text { - Potential additional supplies from } \\
\text { stewardship contracting on National } \\
\text { Forest system land }\end{array}$ & $\begin{array}{l}\text { - Strong existing market for wood fiber } \\
\text { Potential impacts of demand from CSU } \\
\text { cofiring on supply availability and } \\
\text { price } \\
\text { - } \quad \text { Favorable contract pricing only if wood } \\
\text { with glues/adhesives can be used } \\
\text { - Small number of potential suppliers } \\
\text { (i.e., lack of backup supplies at } \\
\text { acceptable prices) with one economic } \\
\text { supplier } \\
\text { - Stewardship contract slated to end in } \\
\text { 2021 with no renewal guarantee }\end{array}$ \\
\hline
\end{tabular}

- Based on these results, ANTARES recommends the following actions:

- Coordinate with CSU on its decision-making process during spring 2015;

- If the cofiring project will not resume, determine whether obtaining an EPA classification of construction debris as a non-waste fuel at Fort Carson is feasible;

- Assess other potential federal rules or regulations related to combustion of wood containing glues or adhesives at federal facilities that may impact project feasibility;

- If it is not possible to use wood containing glues or adhesives for fuel, consider the impacts of fuel costs that exceed current gas prices on project lifecycle costs; and

- If a project is approved, continue to work with Supplier 3 and other potential suppliers to give them adequate lead time ( 6 months to a year) to conduct marketing and outreach to procure additional wood biomass as needed.

\footnotetext{
${ }^{15}$ This statement is based on a natural gas price of $\$ 4.80 / \mathrm{MMBtu}$. The price has recently dropped below $\$ 4 / \mathrm{MMBtu}$, making this more of a risk than an opportunity.
} 


\section{Biomass System Sizing Methodologies}

This section documents the process used to develop sizing curves for the biomass heating system to be incorporated in the district heating system in Building 1860. The sizing curves estimate the biomass heating system capacity factor and contribution to total thermal load, as a function of biomass system size. We used the sizing curves as part of a decision support dashboard, which will be discussed in more detail in Chapter 8-Development of a Biomass Decision Support Tool Model.

There are several common methods used for sizing biomass heating systems, which — depending on factors such as the availability of back-up and thermal storage systems - can be designed to meet any portion of a site's annual heating load. In the present case, the entire load can be met with the existing natural gas generators, which means that the biomass system can be feasibly sized anywhere up to the peak load.

In this document, we discuss some of the methods we used to evaluate biomass heating systems, with capacity factor and contribution factor estimates serving as our two primary metrics for comparing effects of changing system size.

\section{1. $\quad$ System sizing}

As previously mentioned, Fort Carson personnel provided NREL with daily boiler logs extending from March of 2012 to September of 2014 - missing only July 2012. In Chapter 3 we analyzed this data in a number of ways, including attempts to derive a relationship between temperature (heating degree days) and thermal load.

A general rule of thumb is that a biomass system sized at 50 to 70 percent of a system's peak load can be expected to provide $90 \%$ of the annual heating demand for that load, with the remainder made up by the fossil fuel system. Over the period of data provided for Building 1860, the peak load was about 50-MMBtu/hr. Based on this rule of thumb, we would expect a single biomass system sized at 25- to 33-MMBtu/hr to be ideal, but further analysis, presented below, shows that a system in this size range will be significantly too large for this particular application - even if natural gas prices increase significantly.

\subsubsection{Sizing method 1}

In Chapter 2 we presented the relationship between thermal demand and heating degree days, as shown in Figure 8, below. 


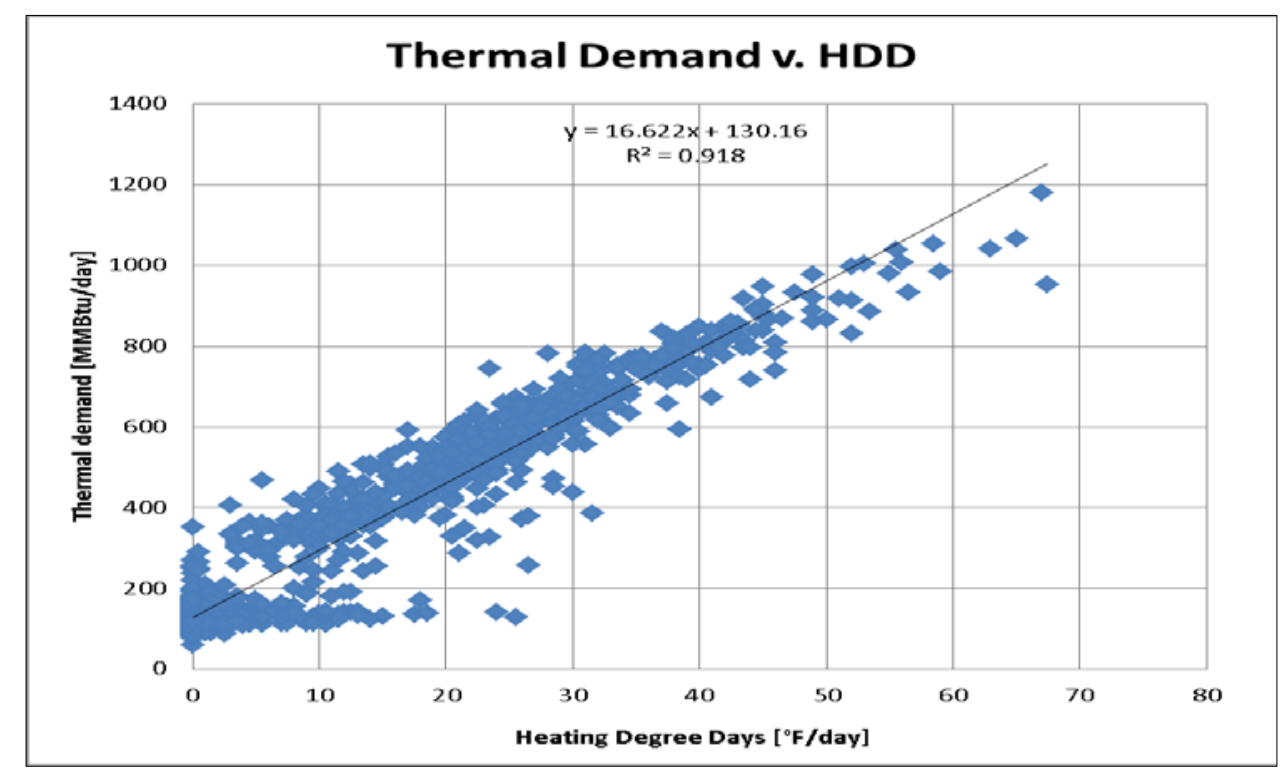

Figure 8: Thermal demand as a function of temperature (expressed as heating degree days${ }^{\circ} \mathrm{F} /$ day)

In our first attempt at sizing the biomass system, we used this relationship, along with typical meteorological year (TMY) data, to estimate, for a given boiler size, the amount of energy that would be supplied by biomass. If the biomass system is too small, then it will produce a limited amount of heat in the winter. On the other hand-since a biomass system operates best close to peak output, with decreasing efficiency as the relative load decreases - a system sized for peak winter loads won't operate efficiently in the summer, and will probably be turned off during extended periods of low load ${ }^{16}$. We developed a spreadsheet model using these constraints that estimates the percentage of load that could be served by biomass systems of various sizes, but felt that it wasn't sufficiently accurate for our purposes.

\subsection{2. $\quad$ Sizing method 2}

As discussed in Chapter 2, due to variability in load served by Building 1860 the correlation between heating degree days and thermal energy use is not precise, resulting in uncertainty in predicted output at a given temperature, so we developed an alternate method for modeling the system. We created a histogram to summarize the system daily output, and used that as the basis of the model.

We used 24 months of consecutive data-October 2012 to September 2014 - to have an equal representation of all seasons. The resulting histogram chart is shown in Figure 9, which displays

\footnotetext{
${ }^{16}$ For more detail, see Appendix A.
} 
the frequency of occurrence within each load bin in blue (which uses the left-hand vertical axis), and the cumulative frequency in red (which uses the right-hand vertical axis).

Note that this data is bimodal, meaning that there are two significant peaks, with loads between 100 and 120 million Btu per day having the highest frequency of occurrence. The second peak is less defined, and covers a range between 500 and 700 million Btu per day. It's this duality that makes picking a single biomass boiler difficult - the left-hand peak would be best served by an 8-MMBtu/hr system, while the right-hand peak would require a much larger system.

We used this histogram data - along with typical values for biomass system turn down capacity (4:1) - to model the daily thermal load and to determine, for a range of plant sizes, the plant's capacity factor and the contribution factor (i.e. what percentage of the load could be met with biomass).

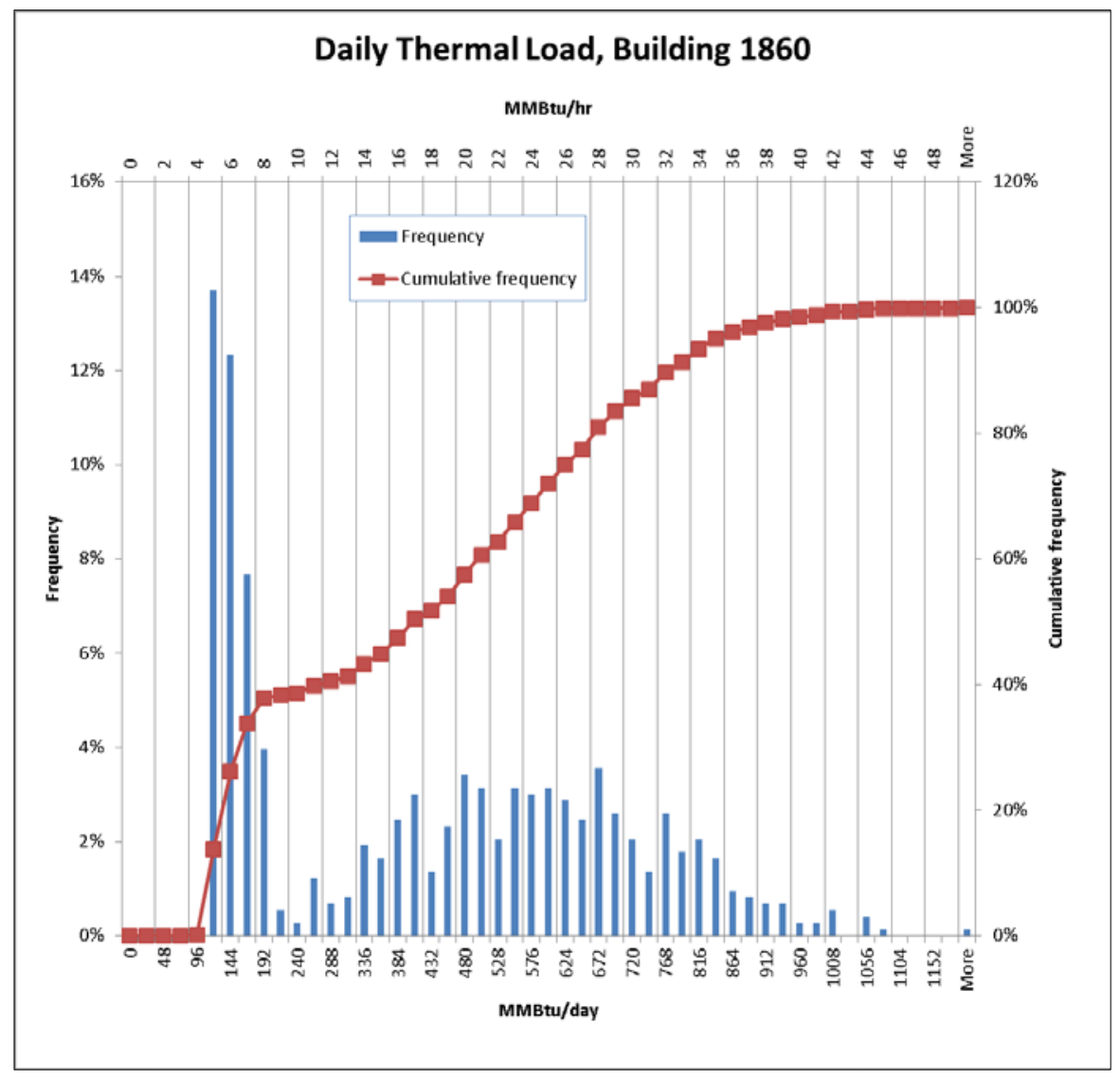

Figure 9: Building 1860 thermal load histogram

We used the above information to develop charts and equations relating the system size to the contribution factor and capacity factor, as shown in Figure 9. 


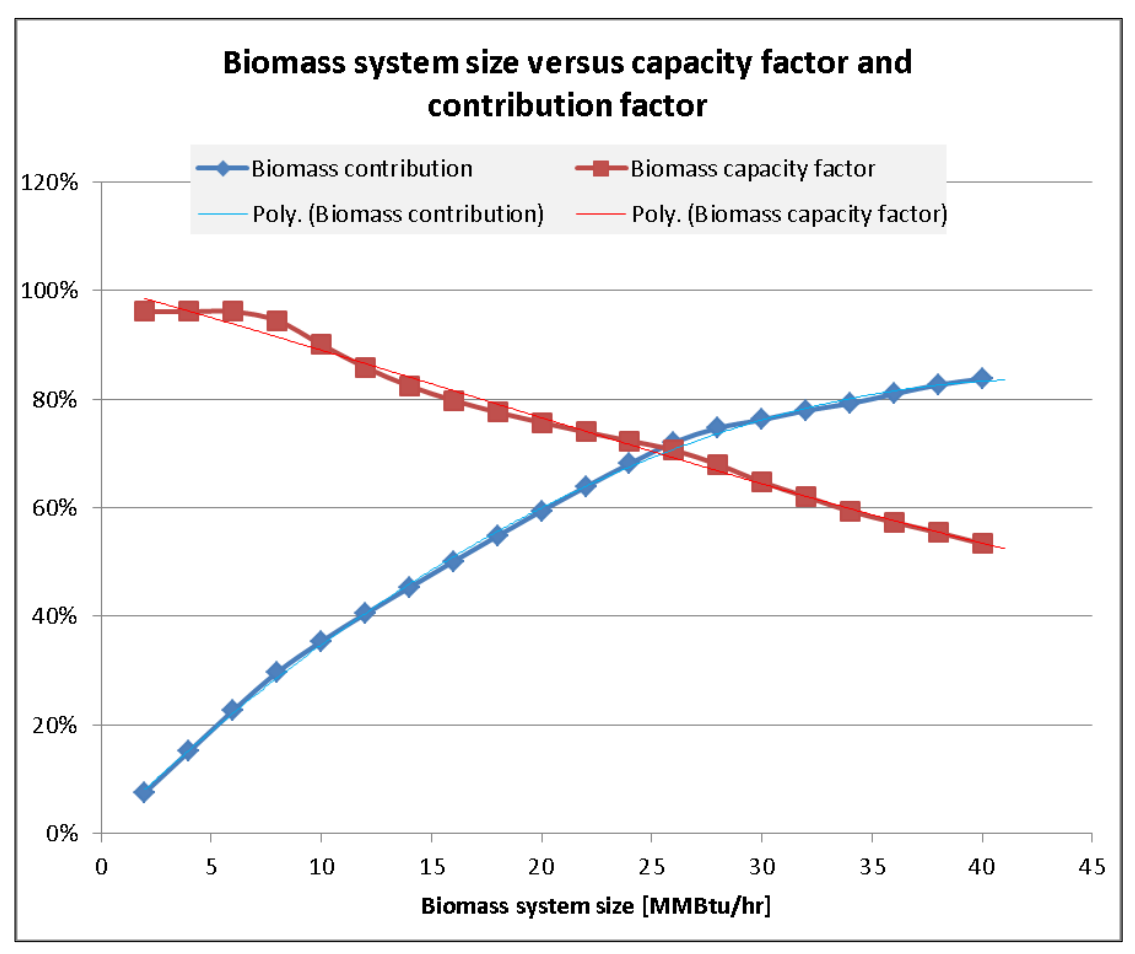

Figure 10: Biomass system size versus capacity factor and contribution factor

Notice that - no matter how large the biomass system is - a single biomass system can't provide $100 \%$ of the annual thermal demand. This is due to limitations resulting from the boiler's turndown capacity ${ }^{17}$. When the load gets too low the biomass system has to be shut down and the natural gas system has to take over ${ }^{18}$. In addition, the system will need to be down for about two weeks each year for annual maintenance, which further reduces its annual capacity factor and contribution to the load.

\subsection{Decision support tool}

We integrated the data presented above, along with economic data discussed in Chapter 5, into a decision support model that allows users to alter various parameters and produce tabular and graphical outputs to support decisions for adding a biomass system to the Building 1860 district heating loop.

A screenshot of the decision support tool is shown in Figure 11. Operating instructions for the dashboard are provided in Chapter 8-Development of a Biomass Decision Support Tool Model.

\footnotetext{
${ }^{17}$ We have used a biomass system turndown capability of 4-to-1 (i.e. it can only operate at $25 \%$ capacity or above); actual turndown ratio will be specified by the chosen system manufacturer.

${ }^{18}$ For more detail, see Appendix A.
} 


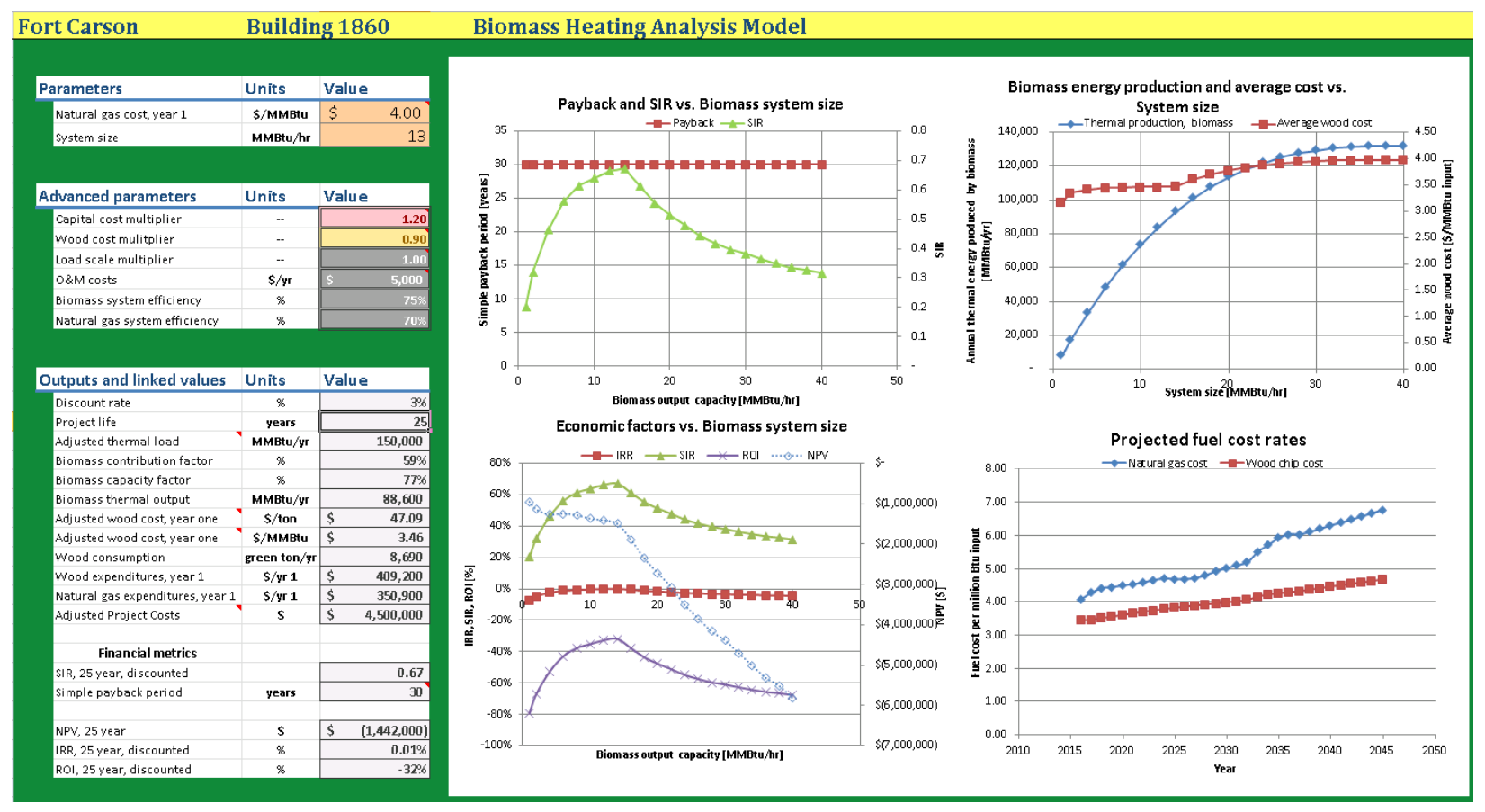

Figure 11: Biomass Decision Support Tool for Building 1860 


\section{Economic Analysis}

In this chapter we discuss the economic factors that we used to evaluate a biomass heating facility for Fort Carson.

\subsection{Economic factors included in the analysis}

We've designed the biomass decision support tool (described in more detail in Chapter 8) to provide output in terms of five economic factors - simple payback period (SPP), internal rate of return (IRR), savings-investment ratio (SIR), return on investment (ROI), and net present value (NPV). All of these are calculated in the output values, and all except simple payback period are included in the chart shown in Figure 12 and described below.

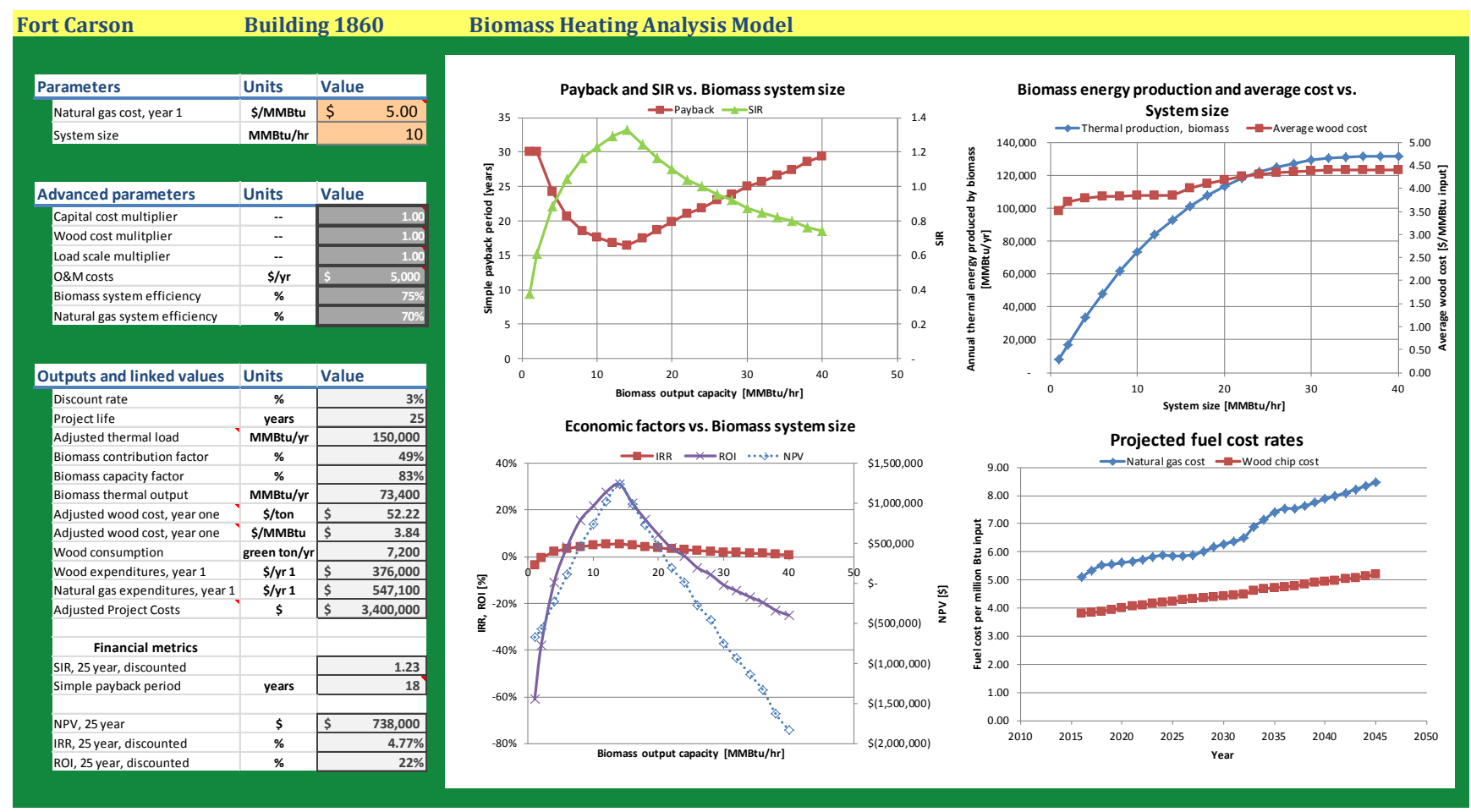

Figure 12: Economic output from decision support dashboard

\subsubsection{Internal Rate of Return}

The internal rate of return (IRR), which we calculate using the Microsoft Excel IRR function, is the discount rate at which NPV for all cash flows is equal to zero. 


\subsubsection{Savings-to-Investment Ratio}

The savings-to-investment ratio (also called benefit-to-cost ratio), is a dimensionless number, calculated by dividing all dollar savings by the sum of capital costs.

For the decision support dashboard, we've calculated the SIR based on discounted dollars, over the 25-year period of analysis. See Section 5.1.4 for details on the discount rate selected.

\subsubsection{Return on Investment}

Return on investment (ROI) is calculated as shown in Equation 1.

$$
\begin{gathered}
\text { Equation 1: Calculation of ROI } \\
\text { ROI }=\frac{\text { (Gain from Investment }- \text { Cost of Investment) }}{\text { Cost of Investment }}
\end{gathered}
$$

For our analysis, we've discounted all monies using the discount rate discussed in Section 5.1.4.

\subsubsection{Net Present Value}

Excel has a built-in function for calculating NPV, which discounts all expenses and income to current-year dollars, using a user-selectable discount rate ${ }^{19}$-and sums these discounted amounts over the analysis period. For increased flexibility we don't use the Excel function, but calculate NPV over a 25-year analysis period directly in the Economic analysis tab of the decision support dashboard ${ }^{20}$.

\subsection{Capital costs}

We've developed capital cost equations based on two quotes that we've recently received from a large boiler manufacturer for two biomass systems - one 13.4-MMBtu/hr (400 bhp) and one $100-\mathrm{MMBtu} / \mathrm{hr}$ (3,000 bhp). The larger system consisted of two 1,500 bhp units. Items in the quotes include:

- major components like burner and boiler, fuel storage and handling

- shipping, installation, startup, training

- electrical and piping work

To this we added, for each system, costs for additional engineering, project management, paint and landscaping, and a new building.

\footnotetext{
${ }^{19}$ The discount rate used in our model-3.0\%-is from the latest Annual Supplement to NIST handbook 135 and NBS Special Publication 709: http://energy.gov/sites/prod/files/2015/03/f20/ashb14.pdf.

${ }^{20}$ This is one of the hidden tabs.
} 
We used these quotes to develop scaling factors to estimate costs for a range of system sizes. These costs (Figure 13) are used for calculating the economic results. We feel that these equations should produce costs within $+/-35 \%$ for a typical installation (in 2015 dollars).

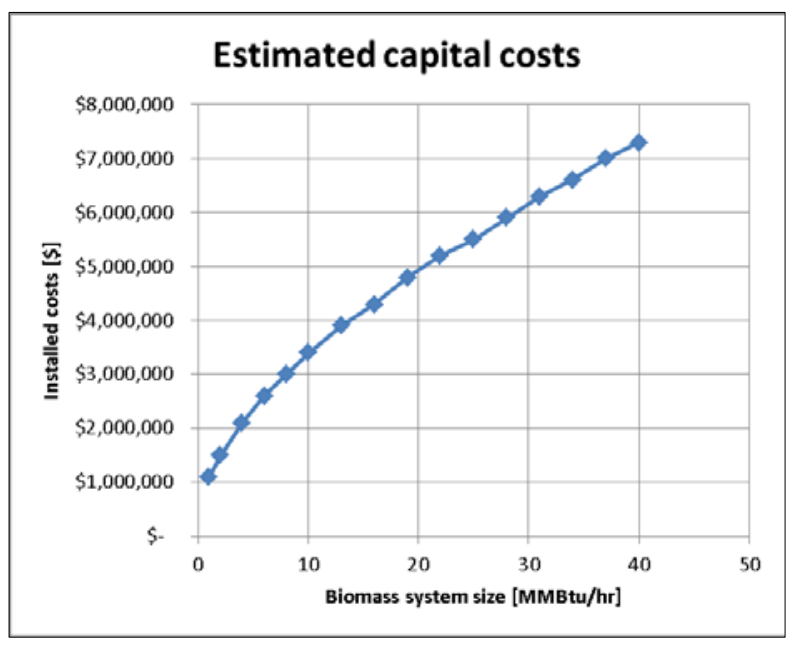

Figure 13: System cost estimates

\subsection{Fuel costs}

Economic performance of a biomass system will be highly dependent on costs for wood chips and for natural gas. Current natural gas prices are too low — and wood chip prices too high - to support a biomass heating system on economic factors alone.

\subsubsection{Biomass costs}

Biomass costs are presented in Chapter 3 and summarized in Table 4, below, which is sorted based on delivered cost per million Btu.

Table 4: Summary of Biomass Generation and Pricing for Fort Carson Area

\begin{tabular}{|l|l|r|r|r|r|r|}
\hline Company & \multicolumn{1}{|c|}{$\begin{array}{c}\text { Type of material } \\
\text { Quantity } \\
\text { (tons/ } \\
\text { year) }\end{array}$} & $\begin{array}{c}\text { Energy Value } \\
\text { (MMBtu/ } \\
\text { year) }\end{array}$ & $\begin{array}{c}\text { Delivered } \\
\text { Cost } \\
(\$ / \text { ton) }\end{array}$ & $\begin{array}{c}\text { Moisture } \\
\text { Content (\%) }\end{array}$ & $\begin{array}{l}\text { Delivered Cost } \\
\text { (\$/MMBtu) }\end{array}$ \\
\hline Supplier 1 & Trim ends & 72 & 979 & $\$ 1.11$ & 20 & $\$ 0.08$ \\
Supplier 2 & Trim ends & 36 & 490 & $\$ 51.03$ & 20 & $\$ 3.75$ \\
Supplier 3 & Ground wood & 10,000 & 122,400 & $\$ 47.50$ & 28 & $\$ 3.88$ \\
Supplier 4 & Ground wood & 14,100 & 151,725 & $\$ 61.63$ & 37 & $\$ 5.73$ \\
Supplier 5 & Bark, chips & 7,200 & 72,420 & $\$ 59.04$ & 41 & $\$ 5.87$ \\
\hline
\end{tabular}

\footnotetext{
${ }^{21}$ [NREL] In this report, names of potential suppliers have been replaced with generic identifiers. See the unpublished Antares report for names.
} 


\begin{tabular}{|l|l|r|r|r|r|r|}
\hline Company & \multicolumn{1}{|c|}{ Type of material } & $\begin{array}{c}\text { Quantity } \\
\text { (tons/ } \\
\text { year) }\end{array}$ & $\begin{array}{c}\text { Energy Value } \\
\text { (MMBtu/ } \\
\text { year) }\end{array}$ & $\begin{array}{c}\text { Delivered } \\
\text { Cost } \\
(\$ / t o n)\end{array}$ & $\begin{array}{c}\text { Moisture } \\
\text { Content }(\%)\end{array}$ & $\begin{array}{c}\text { Delivered Cost } \\
\text { (\$/MMBtu) }\end{array}$ \\
\hline Supplier 6 & Chips & 1,500 & 14,025 & $\$ 72.83$ & 45 & $\$ 7.79$ \\
Supplier 7 & Sawdust, chips, bark & 2,000 & 18,700 & $\$ 74.06$ & 45 & $\$ 7.92$ \\
\hline \multicolumn{2}{|c|}{ Total/weighted average } & $\mathbf{3 4 , 9 0 8}$ & $\mathbf{3 8 0 , 7 3 9}$ & $\mathbf{\$ 5 8 . 1 1}$ & $\mathbf{3 6}$ & $\mathbf{\$ 5 . 3 3}$ \\
\hline
\end{tabular}

There is a negligible amount of material available for less than $\$ 3.75$ per million Btu. If Fort Carson prioritizes purchases based on energy cost, the majority of the wood will be in the range of $\$ 3.88$ per MMBtu. If the biomass system is larger than 14-MMBtu/hr, more expensive wood will need to be purchased.

\subsubsection{Natural gas costs}

Fort Carson pays two different rates for natural gas, depending on whether the gas is firm or interruptible. Building 1860 is on the interruptible rate, and the central boiler-chiller facility $(\mathrm{CBCF})$ is on the firm rate.

Figure 14 shows the interruptible rate paid by Fort Carson from October 2012 to March 2015. The most recent rate is below $\$ 4$ per million Btu.

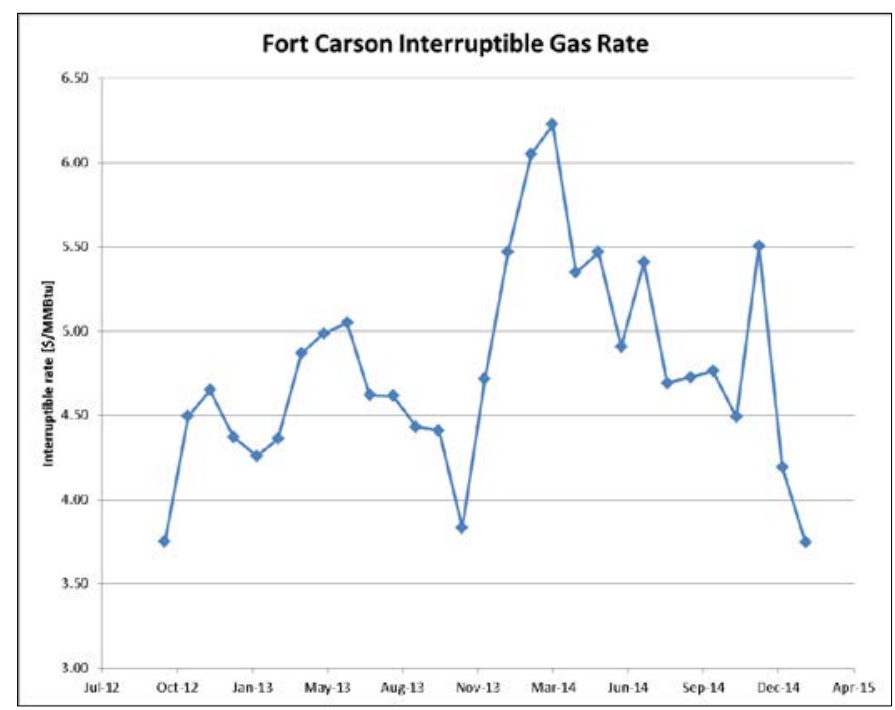

Figure 14: Fort Carson recent rate for interruptible gas service

\subsubsection{Fuel escalation rates}

The NIST Handbook 135 and annual Supplements provide escalation rates for natural gas, diesel fuel and electricity, but not for wood chips. 
As discussed in Chapter 3, wood prices have historically been much more stable than have oil or natural gas prices. Approximately $60 \%$ of the cost of wood is related to fuel costs for harvesting, collecting and transporting the chips. The equipment used depends primarily on diesel fuel. A method for estimating wood chip price escalation - recommended by Dr. William Strauss of FutureMetrics - is to set wood chip escalation rates at $60 \%$ of diesel fuel escalation rates.

We have used NIST escalation rates for natural gas, and $60 \%$ of NIST diesel escalation rates for estimating future costs of wood chips.

\subsection{Other operating and maintenance costs}

A biomass heating system installed in Building 1860 would be operated by the existing staff, which would significantly decrease the O\&M costs compared to hiring additional staff to run that system. It typically requires a few hours per week for someone to inspect the system and order chips, etc. We've included a few thousand dollars per year for annual maintenance and replacement of wear items.

If a system were to be installed in the Central Boiler Chiller Facility (CBCF), additional staff would be required, as that site is currently not manned.

\subsection{Results}

Fort Carson's energy manager, Scott Clark, indicated that "ECIP projects are focused on simple payback and SIR. ECIP requires renewable projects have an SIR above 1.0 and a simple payback of 20 years or less for renewable." 22

Both SIR and simple payback period are plotted on the chart shown in Figure 15, which is calculated based on a first year natural gas cost of $\$ 4.00$ per million Btu, and wood chips at their default costs (discussed in Chapter 3). Note that the best SIR is about 0.55 , for a $14-\mathrm{MMBtu} / \mathrm{hr}$ biomass system, and simple payback period is greater than 30 years for all sizes ${ }^{23}$.

\footnotetext{
${ }^{22}$ Email from Scott Clark, 2015-04-01.

${ }^{23}$ Since the maximum acceptable simple payback period is 20 years, the program is set to display a maximum simple payback period of 30 years, and a minimum of zero, to prevent the chart axes from getting loo large or showing negative numbers.
} 


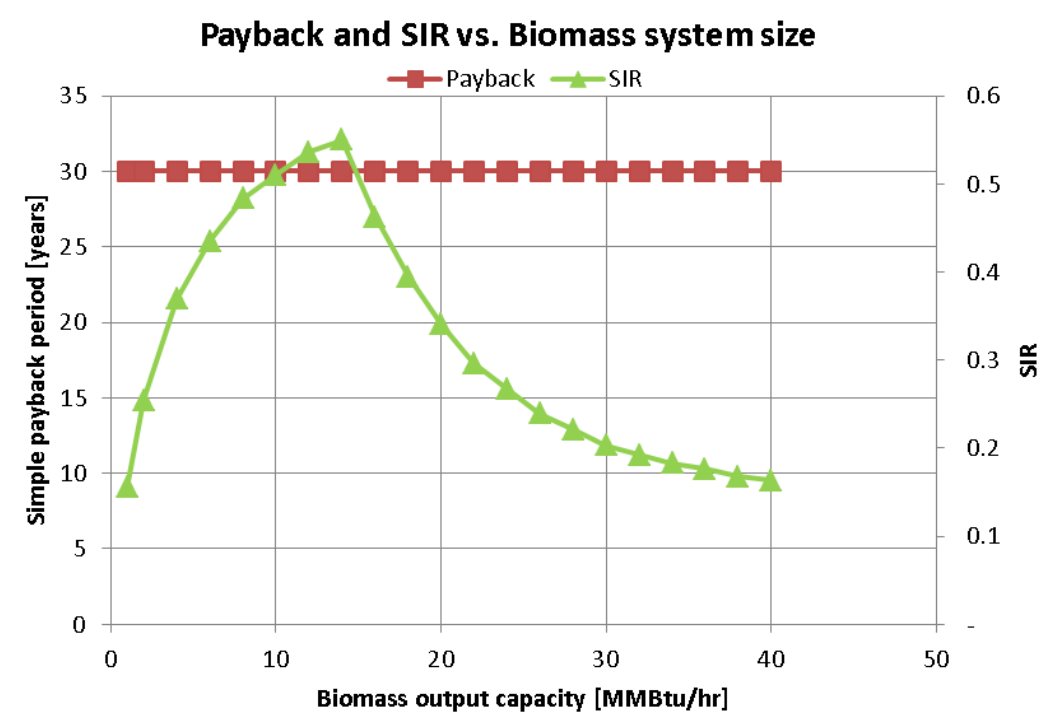

Figure 15: Simple payback and SIR, from biomass decision support tool; natural gas at $\$ 4.00 / M M B t u$

Evidence for the cause of the weak economic performance can be seen in Figure 16, which shows the escalation rates for both fuels over 30 years. The cost of gas is barely more than the cost of wood for at least the first 18 years.

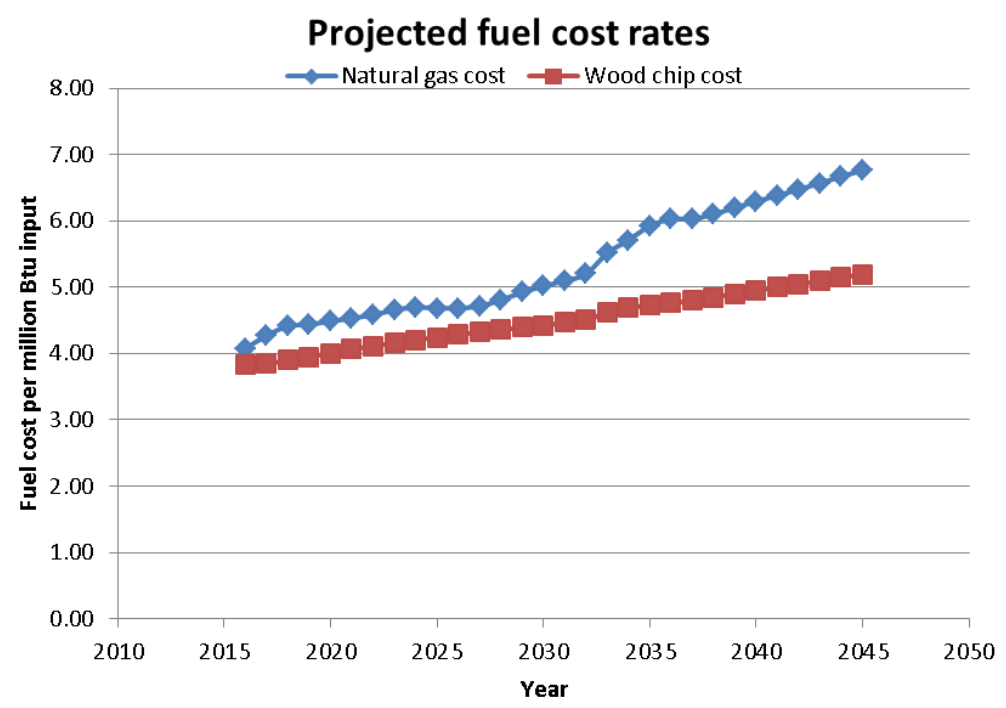

Figure 16: Projected natural gas and wood costs, with first year natural gas cost at \$4.00/MMBtu The desired ECIP conditions are not reached until the first year natural gas price reaches $\$ 4.70$ per million Btu, as shown in Figure 17. 
At this cost, NPV is positive for systems between about 10- and 16-MMBtu/hr, but the economic results are still pretty weak. This can be seen in Figure 18.

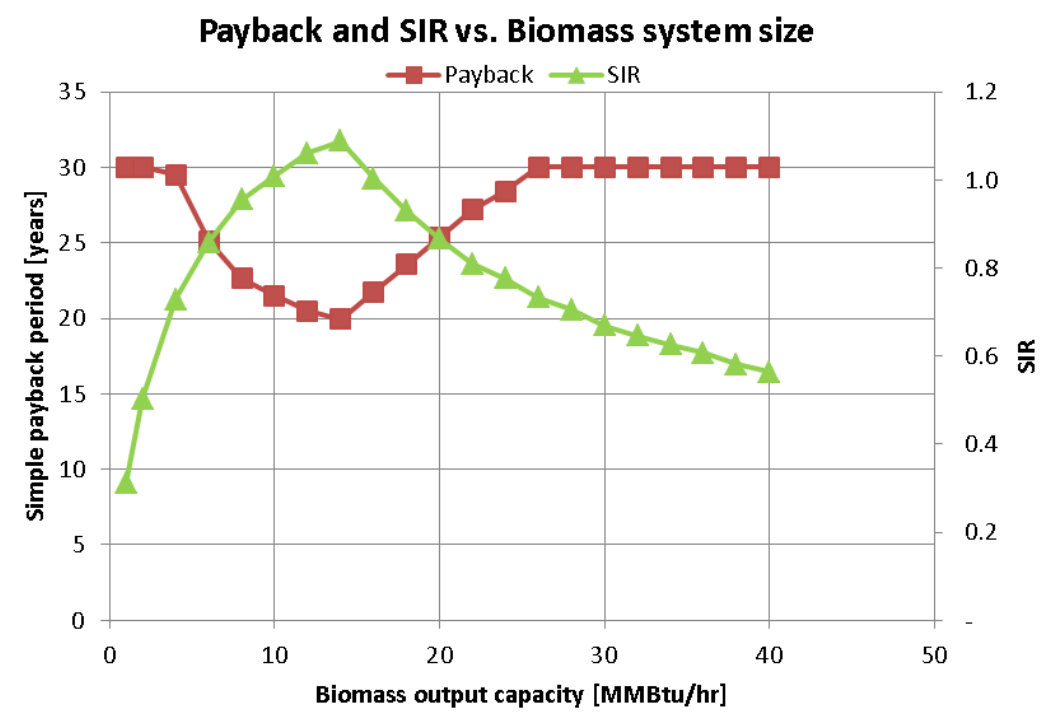

Figure 17: Simple payback and SIR; natural gas at \$4.70/MMBtu

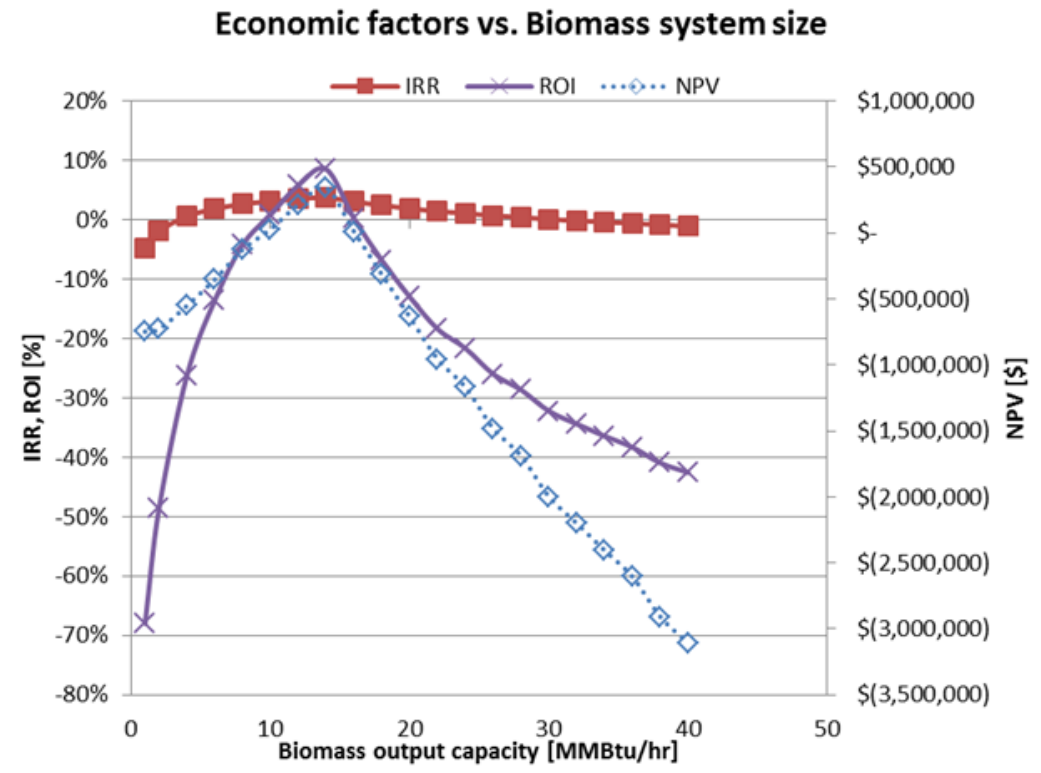

Figure 18: IRR, ROI and NPV for 1st year natural gas price of \$4.70/MMBtu

We provide one last example, with a first year natural gas price of $\$ 6.00$ per MMBtu. At this price, economics look much better, with a simple payback period of less than 20 years for 
biomass systems between about 4- and 35-MMBtu/hr, and SIR above 1.0 for any system larger than 2-MMBtu/hr, as shown in Figure 19.

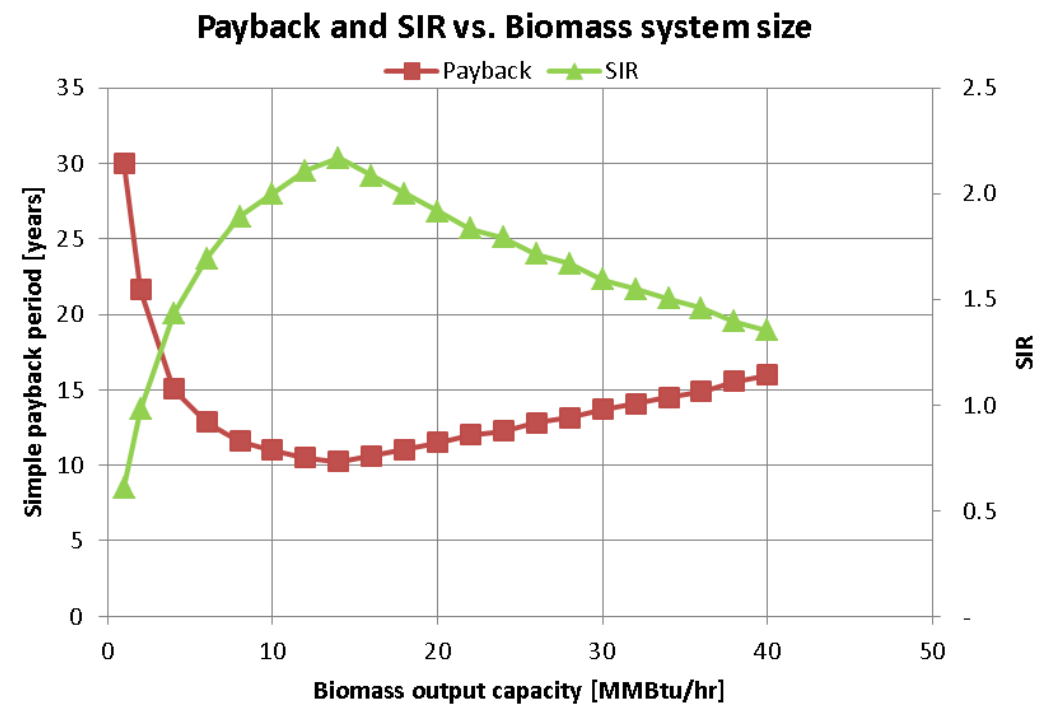

Figure 19: Simple payback and SIR; natural gas at \$6.00/MMBtu

Similarly, Figure 20 shows that systems in this range have positive NPV_reaching above $\$ 4,000,000$ for mid-sized systems_ - and high IRR and ROI.

The "optimum" system size in this range appears to be about 14-MMBtu/hr.

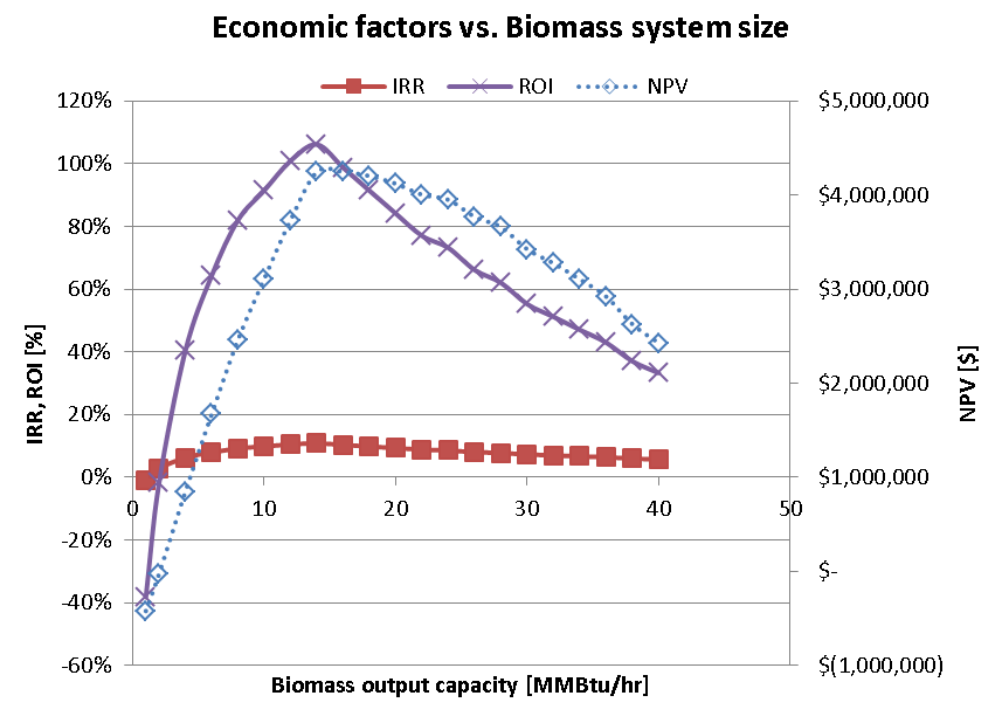

Figure 20: IRR, ROI and NPV for 1 st year natural gas price of $\$ 6.00 / M M B t u$ 


\section{Schematic Design and Building Details}

In this chapter we present possible locations and configurations for a biomass system integrated with the existing district heating system in Building 1860.

Building 1860 is located on a corner lot, adjacent to Prussman Boulevard, between Magrath Avenue and Porter Street, as shown in Figure 21.

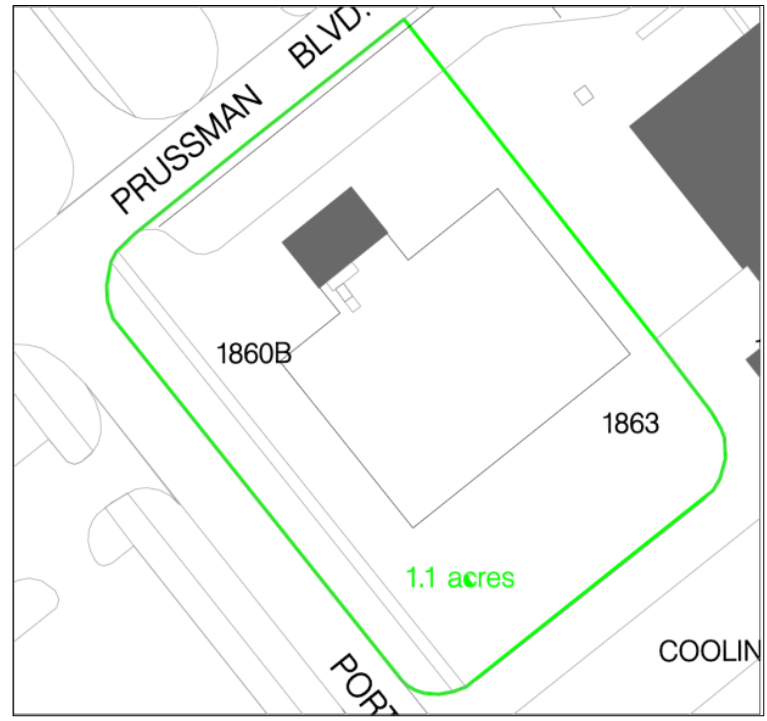

Figure 21: Building 1860 location. Image provided by Fort Carson.

\subsection{Drawings}

Fort Carson provided us with a compact disk containing numerous drawings of Building 1860, as well as the nearby chiller building. Figure 22 is a combustion air plan drawing ${ }^{24}$, and we've included it here because it provides the essential layout of the existing boilers and other major components within the building. It's obvious from this drawing that there is not a lot of free space available within this building to place a biomass boiler, along with the required ash handling equipment. Based on the scale indicated on the drawing, we estimate that this room is approximately 80 feet by 100 feet.

\footnotetext{
${ }^{24}$ Part of the drawing is covered by the general notes.
} 


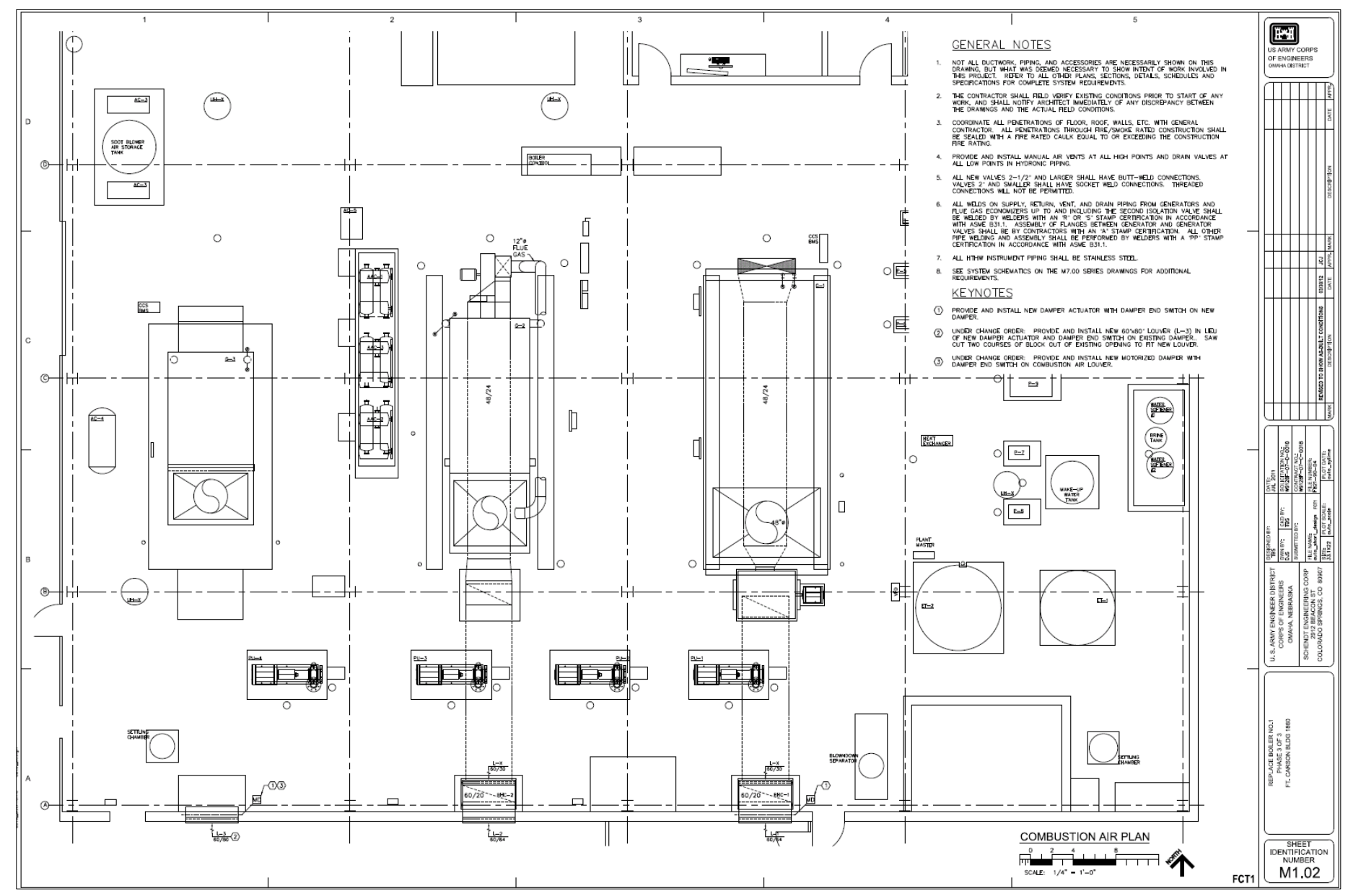

Figure 22: Building 1860 plan view

\subsection{Potential biomass system locations}

Three NREL engineers visited the site with Fort Carson personnel in September 2014 and identified potential locations for a biomass heating plant. These are indicated by red, yellow and blue outlines in Figure 23.

The primary siting criteria includes easy access for chip delivery, sufficient space, minimal installation costs, and location close to the existing building to reduce piping losses. We present a brief overview of the site options below, then present some drawings of possible biomass and chip building configurations.

\subsubsection{Option 1}

We designated the area at the back (south) corner of the building as Option 1, approximately indicated by the blue L-shaped outline in Figure 23. This location would have the advantage of "hiding" the biomass system, but space in this area is limited and access for fuel deliveries is 
constrained. In addition, this area is used for employee parking, which would need to be relocated.

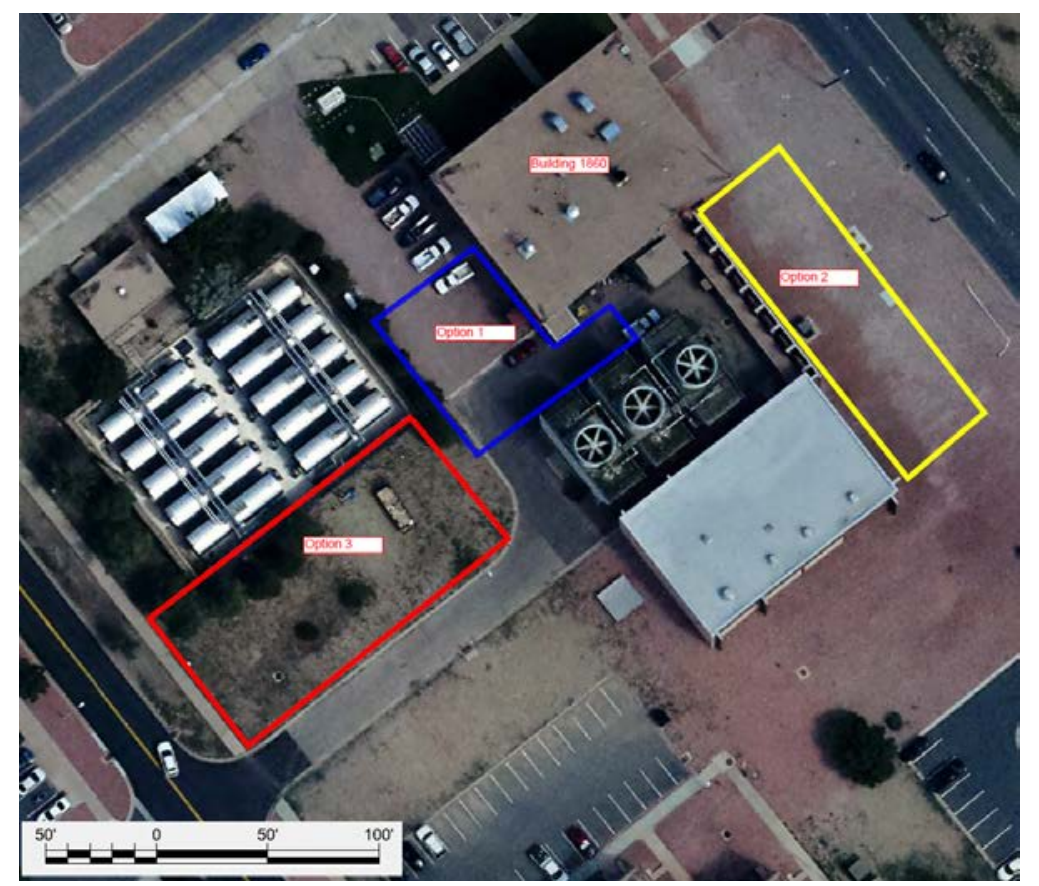

Figure 23: Possible locations for a biomass facility (red, yellow and blue outlines). Image provided by Fort Carson, modified by NREL.

Figure 24 is a shot of the south corner of Building 1860 - the area designated as Option 1—with the cooling towers behind the photographer. Note that the building includes a projection of about 10 -feet into this area, which would need to be removed or accommodated for by a biomass facility. 


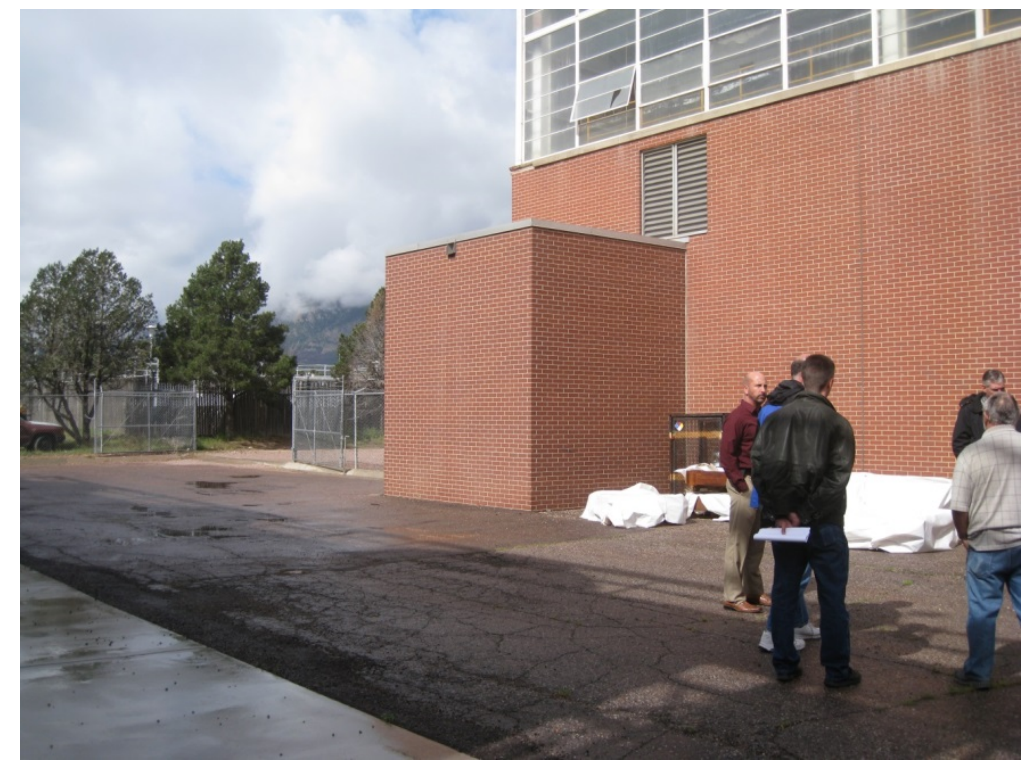

Figure 24: South corner of Building 1860. Photo by Randolph Hunsberger.

\subsubsection{Option 2}

The yellow outline at the front of the building in Figure 23-between the screen wall and Magrath Avenue - designates the approximate location of Option 2. This area has more space and easier access than Option 1. Magrath Avenue is a one way street, so delivery trucks would head northwest on Magrath and pull off on the left side of the road.

The type and location of underground utilities would need to be determined before construction, as the chip bunker would extend significantly below ground.

\subsubsection{Option 3}

A third option is to put the boiler building and chip building farther south - in the area indicated by the red rectangle in Figure 23-or remove some of the propane tanks and put the buildings there. These options would require insulated pipes - either elevated or underground - to connect the biomass system to the existing distribution system.

\subsection{Schematic design}

We've created a simplified schematic of the existing district heating system served by Building 1860 (Figure 25), using Taco's Hydronic Systems Solution (HS2) software ${ }^{25}$. The intent of this drawing is not to document the exact equipment, but to provide an overview of the general district heating layout and flow loops, so pump details, and some other parameters don't describe

\footnotetext{
${ }^{25}$ https://www.taco-hvac.com/products/design_tools/hydronic_system_solution/index.html
} 
actual equipment. Also, ancillary equipment, like expansion tanks and make-up water, are not shown.

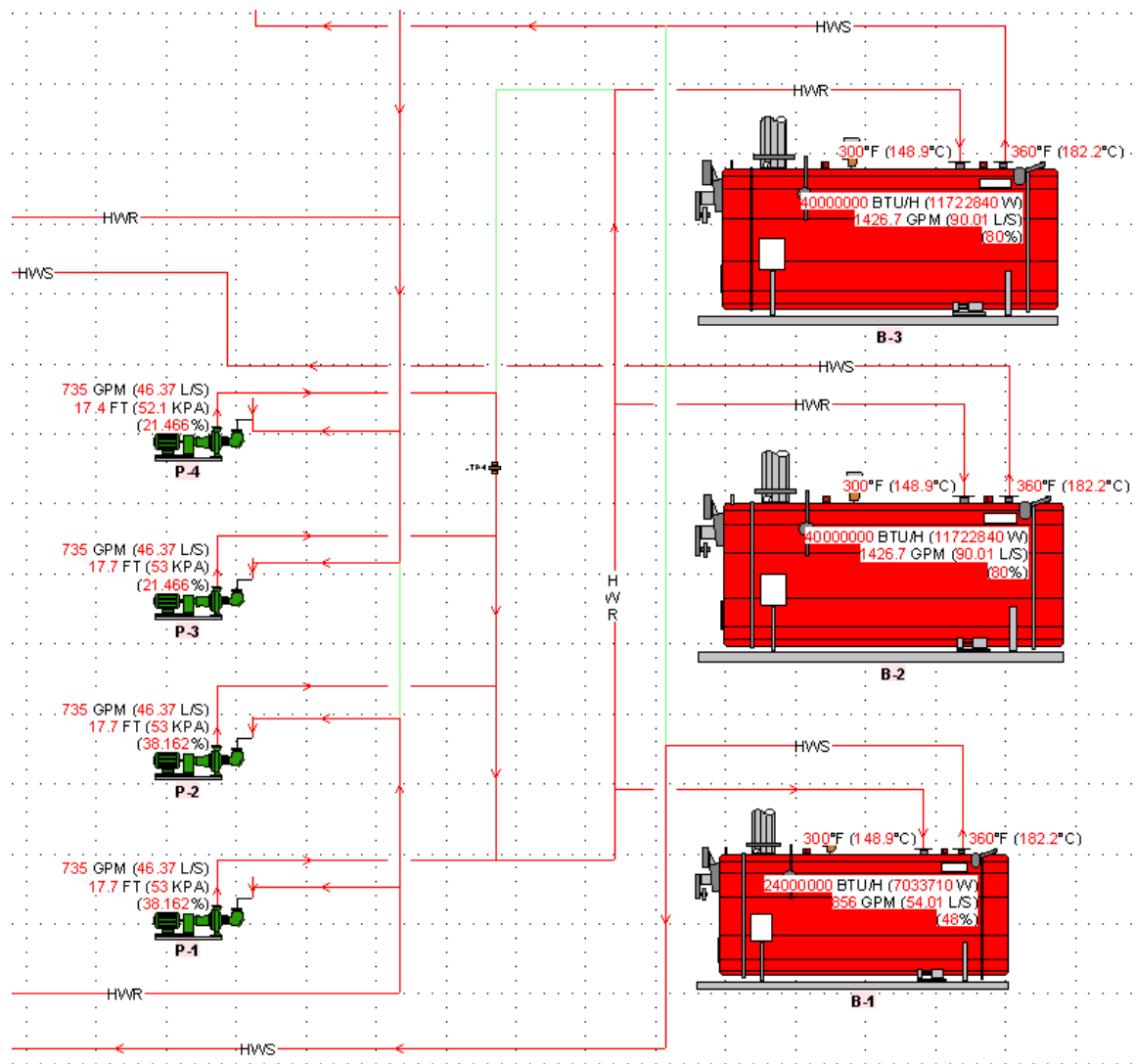

Figure 25: Simplified schematic of existing district heating system

There are three sets of supply and return pipes - two sets of 12" lines and one set of 10" lines. The pumps (and expansion tanks) are on the return side, raising the pressure of the water before it enters the boilers.

The biomass system could tie-in to any of the hot water supply (HWS) and hot water return (HWR) headers, matching the existing pipe sizes.

We've created a conceptual drawing (Figure 26) in which we've added a biomass system to the existing district heating loop. The system is set up such that all the boilers can serve all of the loads, so water can flow in either direction depending on which boiler is operating - and multiple boilers can operate simultaneously.

The biomass system shown is $10 \mathrm{MMBtu} / \mathrm{hr}$. The actual size is not yet determined, but can be selected with the help of the decision support dashboard.

Controls would need to be added to coordinate all boilers. 


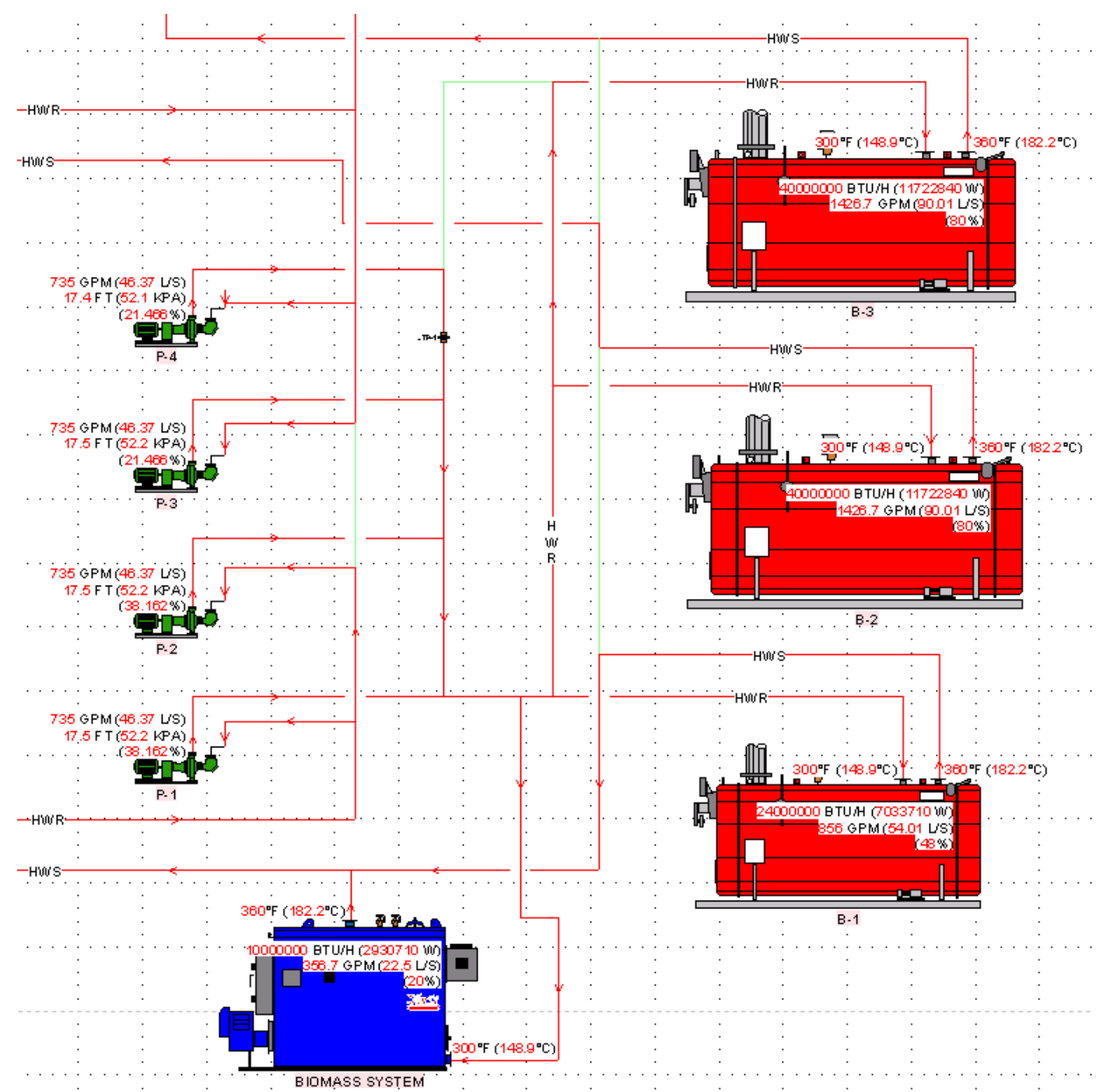

Figure 26: Conceptual schematic showing primary biomass heating system added

Figure 27 shows a representative layout of a biomass boiler system, in this case a $400 \mathrm{bhp}$ ( 13.4-MMBtu/hr) biomass boiler. This plan view provides a relative scale of typical biomass components, and the space required to house them. In this case, the over-all layout is about 70 feet by 40 feet. This layout includes a 10x12 foot control room, but the existing control room in Building 1860 may be sufficient to house the required components. 


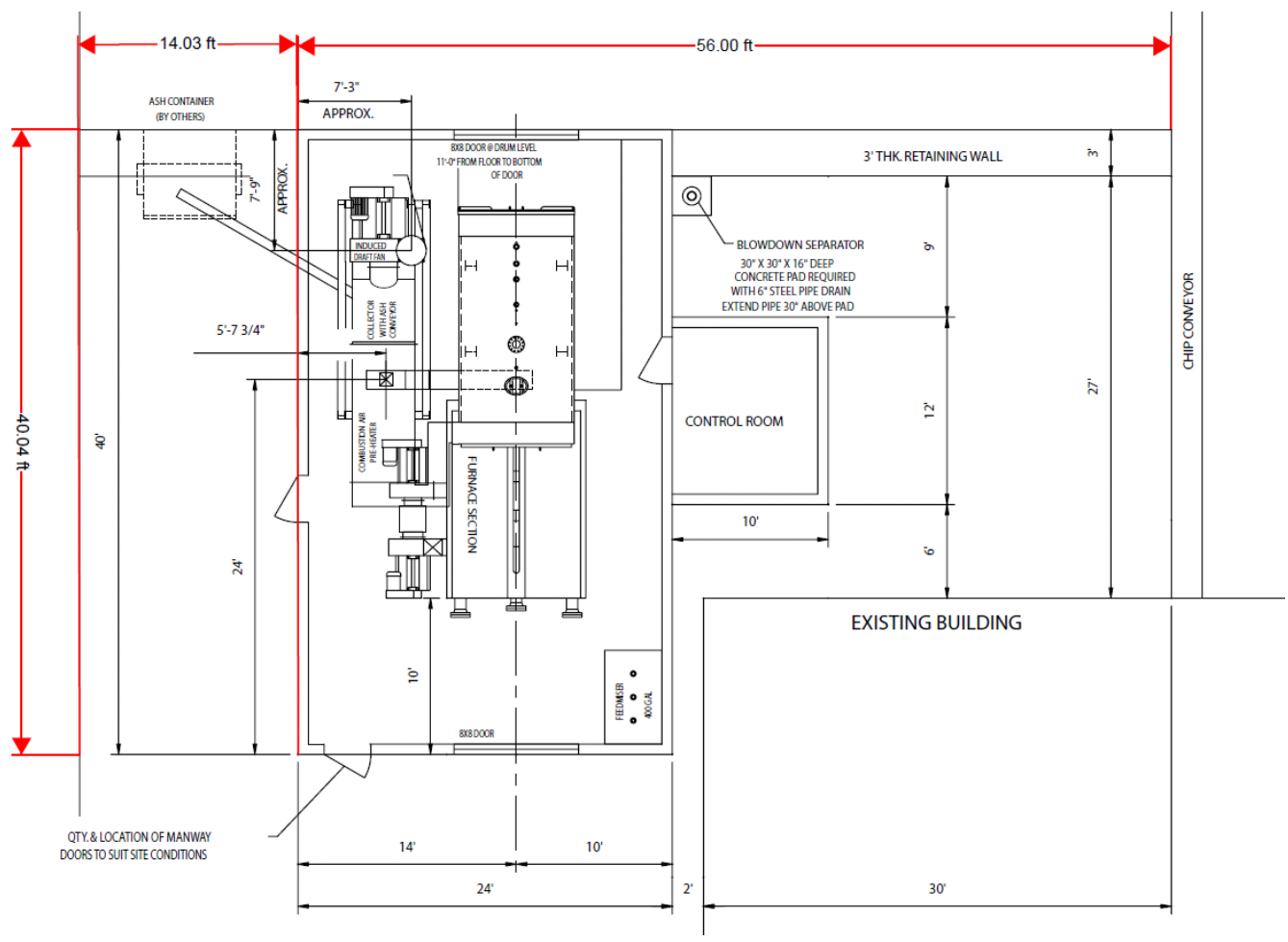

Figure 27: One potential system layout

For the preliminary design, we've split the building into two functional units, one for the boiler and related equipment, and one for the storage of wood chips and housing the control room. We did this to make the layout more flexible, but —once a site is selected - there's no reason that the chip and boiler buildings couldn't be combined.

Figure 28 shows a conceptual layout of a biomass boiler building and a separate building with chip storage below ground and a control room on the ground floor. The relationship between the two buildings is flexible. Roofs have been removed for clarity. 


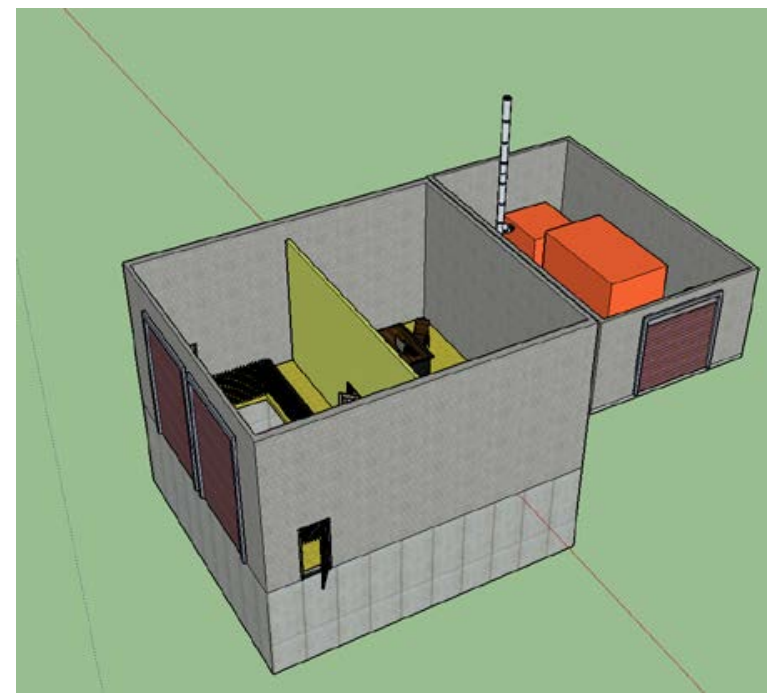

Figure 28: Conceptual layout of a biomass boiler (left) and chip (right) building

Figure 29 shows the buildings from Figure 28, but with some separation between them. We have located the boiler building between Building 1860 and the cooling towers, and placed the chip building between Building 1860 and the propane tanks. Note that space is very tight, and access for the chip van is limited.

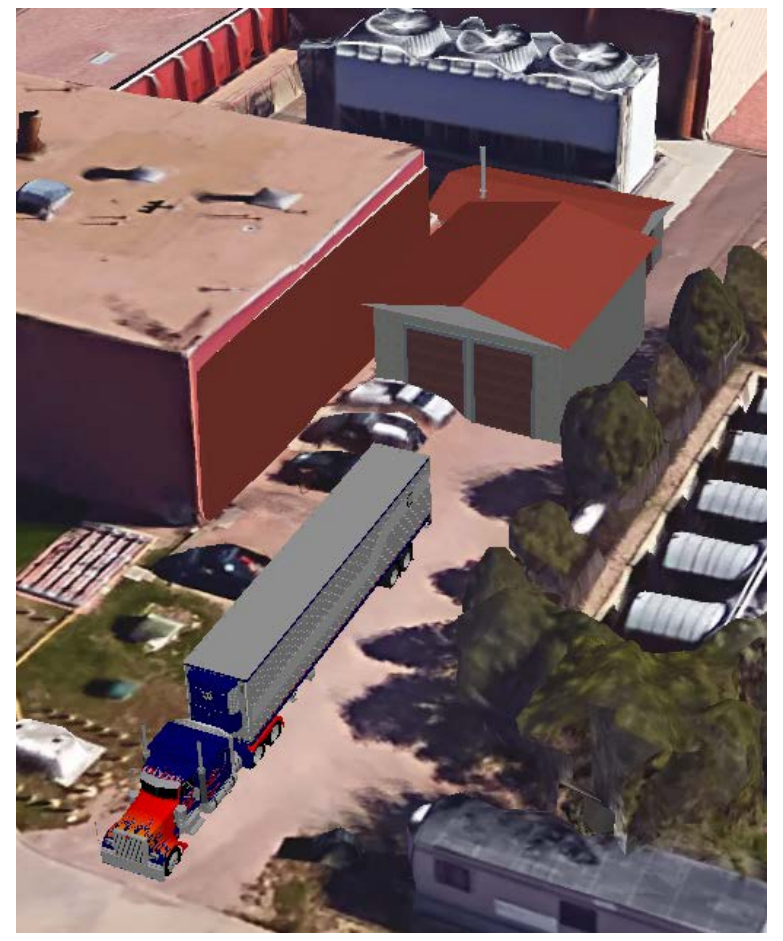

Figure 29: Biomass system location Option 1, looking eastish

Figure 30 provides an aerial view of Option 1 looking north-northwest. 


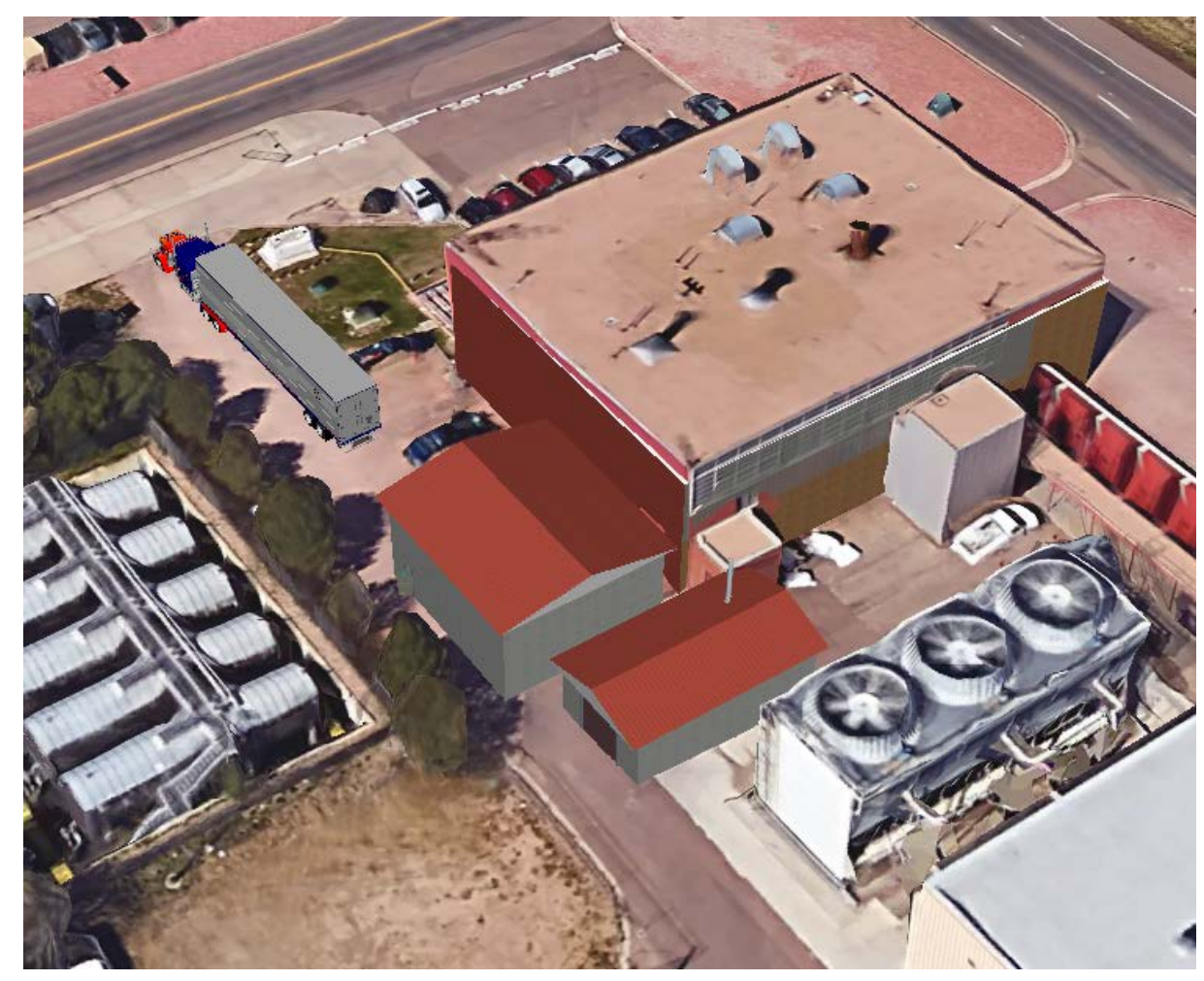

Figure 30: Biomass system location Option1, looking north-northwest

Figure 31 shows the location for Option 2, with the biomass systems located between Building 1860 and Magrath Avenue. In this configuration, fuel trucks would exit Magrath onto a ramp (not shown), passing the plant, then backing up to the fuel pit doors. Careful planning will be required to ensure that there is sufficient room for the delivery van to maneuver and align with the doors.

After making a delivery, trucks should pull back onto Magrath and not into the MagrathPrussman intersection. The farther the plant is moved to the southeast, the easier it will be to get trucks on to and off of Magrath. Insulated pipes will need to be run from the wood system to the other boilers - either above or under ground.

Utilities will need to be surveyed, as the chip pit will be below grade. Obstructions like the electrical box will probably need to be relocated, and most of the gravel area will need to be paved for truck access. 


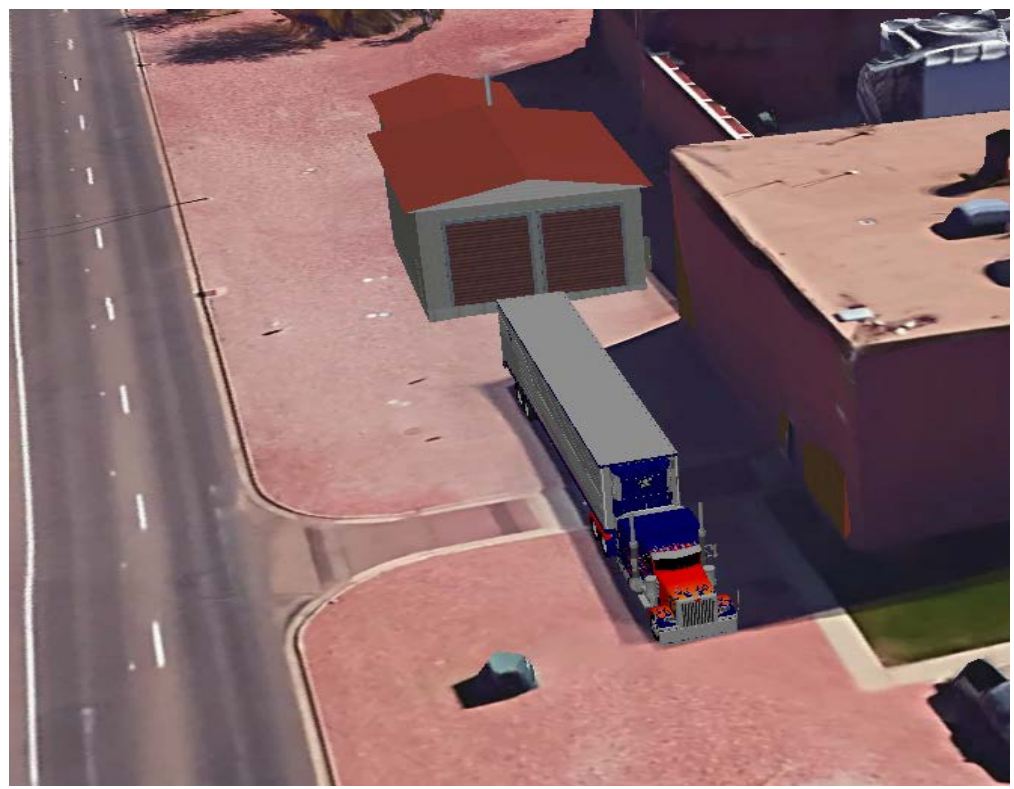

Figure 31: Configuration 2, looking southeast

Figure 32 shows another view of Option 2. Note that a roll-up door has been included with the boiler building for ease of equipment access.

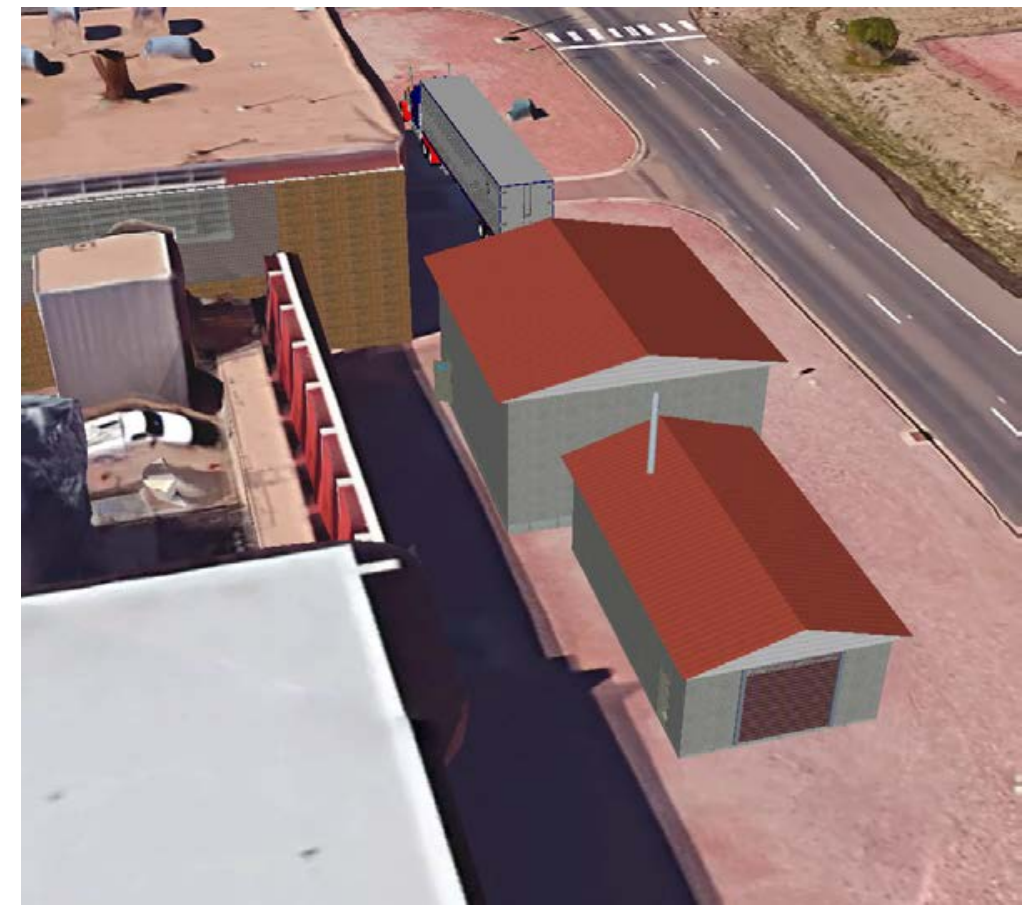

Figure 32: Configuration 2, looking northwest 


\subsection{Conclusions}

We've looked at three different location options for a biomass heating system, and have used a two-part building design for evaluating these options. We would preliminarily recommend locating the biomass system between the screen wall and Magrath Avenue, assuming that existing utilities located in that area won't eliminate that opportunity.

The burner/boiler equipment, and chip storage can be in separate buildings or combined. If space permits, the biomass control room can be integrated into the existing Building 1860 control room, or the biomass building can incorporate a new control room. Some of these choices will ultimately depend on the system size and configuration chosen. 


\section{Fort Carson Environmental \& Regulatory Analysis}

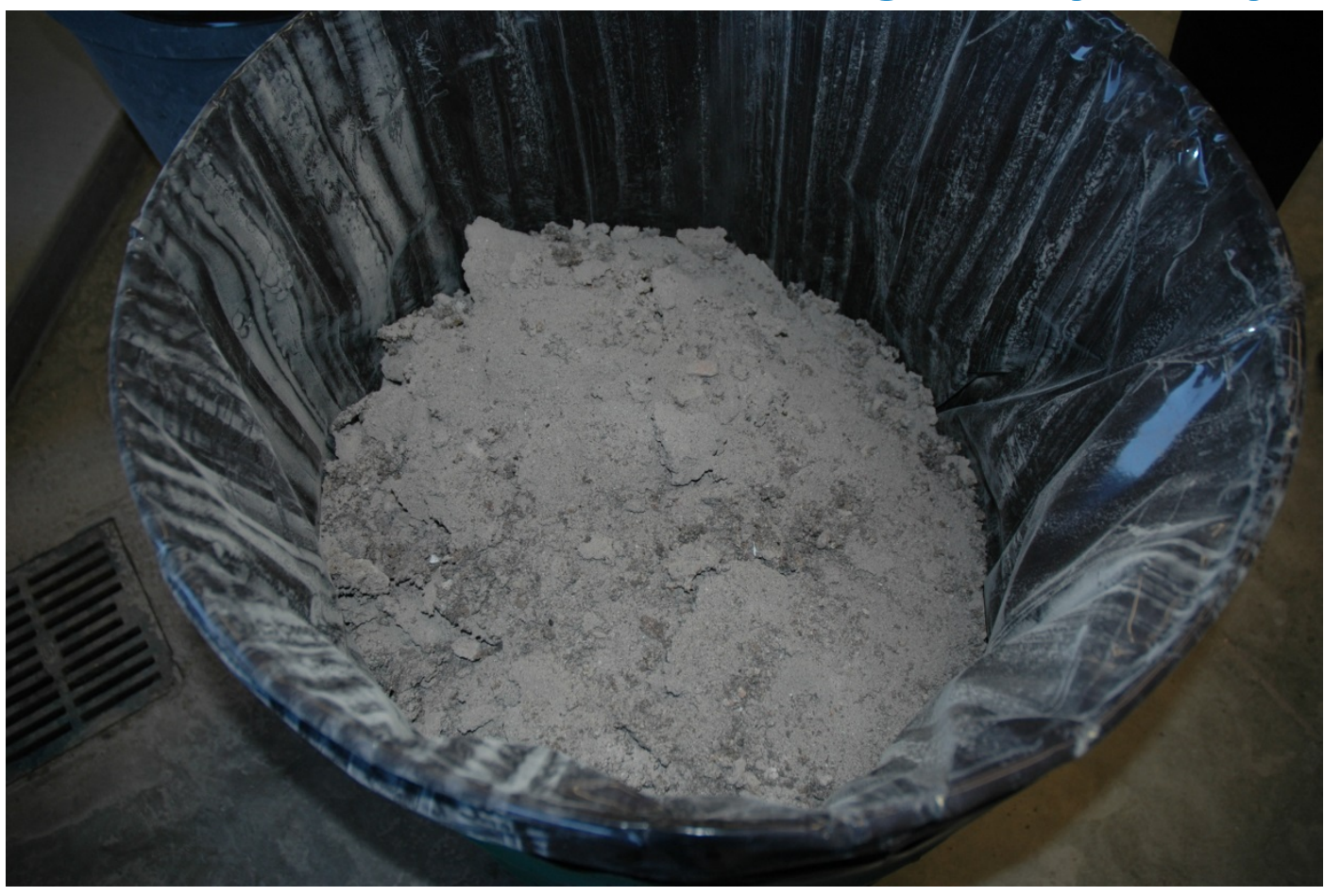

Figure 33: Photo by Randolph Hunsberger, NREL

This chapter provides details about regulatory requirements for a biomass system at Fort Carson, as well as an estimate of air emissions.

Gaining an understanding of the emissions and permitting implications of any new project is an important aspect of environmental and regulatory analysis. Emissions can be estimated for a new facility using either EPA's AP-42 emissions factors or emissions data from vendors. Air emissions at large installations are typically assessed on a cumulative basis. The expected emissions from a biomass facility need to be considered along with the emissions of existing equipment and equipment potentially retired due to the biomass implementation.

In order to understand the cumulative emissions ramifications, it is prudent to discuss the biomass predicted emissions with the base's environmental consultant. A summary of potential regulatory implications is presented in the following sections.

\subsection{New source performance standards}

Any size of biomass boiler will be subject to EPA new source performance standards (i.e., specific emission limitations and monitoring requirements). NSPS will have emission limits, 
monitoring requirements, performance testing requirements, and time constraints for the required notifications and reports.

\subsection{National emission standards for Hazardous Air Pollutants} Because the base is likely a minor source of hazardous air pollutants (HAPs), most "maximum achievable control technology" standards will not apply. However, the EPA promulgated minor source (area source) standards for boilers that will require energy assessments and routine tuning, both longer-term considerations.

\subsection{Prevention of Significant Deterioration}

The EPA emissions factor for carbon monoxide $(\mathrm{CO})$ for wood residue combustion boilers is 0.6 lb/MMBtu of heat input. For 20 MMBtu of heat input, $\mathrm{CO}$ emissions are projected to be 12 pounds per hour. For a full year of operation (potential to emit) the system would emit approximately 53 tons per year of $\mathrm{CO}$. Since $\mathrm{CO}$ emissions under this scenario will increase by less than the significant emission level of 100 tons/year, the boiler will not be subject to EPA prevention of significant deterioration (PSD) review. As a result, the permit application will not have to be prepared under PSD rules. This will allow the avoidance of "best available control technology" analyses for pollutants emitted from the new unit and extensive dispersion modeling (national ambient air quality standards, increment analyses, and visibility analyses).

\subsection{Emissions for the State of Colorado}

Emissions limits in Colorado are governed by the Colorado Department of Health and Environment. The key emissions related to biomass combustion are particulate matter (PM) and carbon monoxide (CO). Carbon monoxide is controlled with good combustion and is a function of the combustion technology employed. Particulate matter is captured by air pollution control equipment that consists typically of multiclones, baghouses or electrostatic precipitators (ESPs). The governing Colorado regulation is "Regulation NO. 1 Emission Control for Particulate Matter, Smoke, Carbon Monoxide, and Sulfur Oxides. 5 CCR 1001-3 ${ }^{26 \%}$.

For particulate matter emissions in this system size range, Section III.A.1.b. is applicable and says:

For fuel burning equipment with designed heat inputs greater than $1 \times 10^{\wedge} 6$ Btu per hour, but less than or equal to $500 \times 10^{\wedge} 6$ Btu per hour, the following equation will be used to determine the allowable particulate emission limitation.

\footnotetext{
${ }^{26}$ http://www.sos.state.co.us/CCR/GenerateRulePdf.do?ruleVersionld=1870\&fileName=5\%20CCR\%201001-3
} 
$\mathrm{PE}=0.5(\mathrm{FI})^{-0.26}$

Where: $\mathrm{PE}=$ Particulate Emission in pounds per million Btu heat input.

FI = Fuel Input in Million BTU per hour.

Given a likely boiler output rating of 14 million Btu per hour ${ }^{27}$, the equation yields an allowable PM emission rate of:

$=0.5(20)^{-0.26}$

$=0.23 \mathrm{lbs}$ per MMBtu

As a representative example of a system is this size range, one equipment manufacturer estimates that their system will produce PM emissions of $0.35 \mathrm{lb}$ per MMBtu or less at the outlet of the multiclones. Therefore, further control is required, which is deemed herein to be an ESP. The costs associated with the ESP and ash removal systems have been included in the analysis. In order to realize the savings for eliminating the ESP, the fuel input would need to be about 13 MMBtu/hr. For a boiler efficiency of $70 \%$, this would relate to a heat output of $9.1 \mathrm{MMBtu} / \mathrm{hr}$.

\subsection{Wood ash production}

Clean wood chips burned in a properly-operating combustor or gasifier typically produce between $0.5 \%$ and $2.0 \%$ ash - the white wood having lower ash content, and needles and bark having higher-meaning for every ton of wood burned, 10 to 40 pounds of ash will be produced. A 400-BHP (13.4-MMBtu/hr) boiler connected to the district heating system in Building 1860 is expected to consume about 11,000 green tons of wood chips per year; if the primary fuel is clean, debarked wood, 50 to 100 tons of ash will result. This ash can be used on the base as a beneficial soil amendment—at appropriate levels—or disposed of in a landfill.

\footnotetext{
${ }^{27} 20-\mathrm{MMBtu} / \mathrm{hr}$ input, at $70 \%$ efficiency
} 


\section{Development of a Biomass Decision Support Tool Model}

NREL developed a decision support tool to help Fort Carson personnel assess the feasibility of adding a biomass heating system to an existing district heating system in Building 1860. This chapter documents the structure and operation of that tool, which is largely based on the sizing curves presented in Chapter 4 and the cost curves discussed in Chapter 5.

The decision support tool is intended to be self-explanatory and simple to use, but this document should answer any questions that arise.

We integrated the system sizing data presented in Chapter 4, along with economic data discussed in Chapter 5, and the biomass supply data from Chapter 3, into a decision support model that allows users to alter various parameters and produce tabular and graphical outputs to support decisions for adding a biomass system to the Building 1860 district heating loop.

A screenshot of the Dashboard tab of the decision support tool is shown in Figure $34 .$.

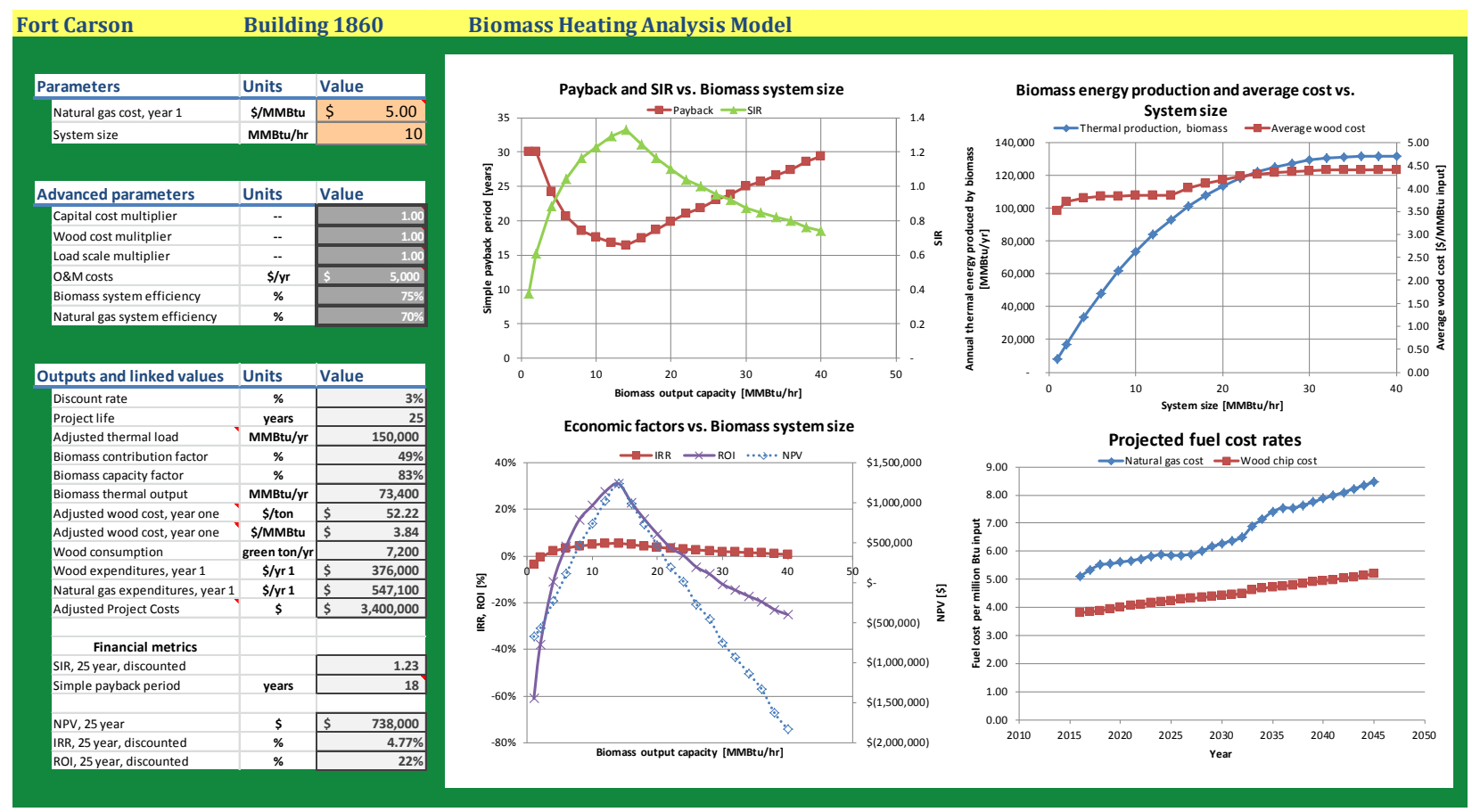

Figure 34: Biomass Decision Support Tool for Building 1860 


\section{1. $\quad$ More charts tab}

The data depicted in the "More charts" tab supports or underlies many of the calculations in the "Dashboard" tab, and contains a number of useful charts, most of which have been shown in other report Chapters and so aren't discussed in this report.

Two charts that have not been previously presented are shown below as Figure 35 and Figure 36.

Biomass contribution is the percentage of the annual load that is satisfied by biomass. We have presented it as a surface plot, with system size on the horizontal axis and load scale multiplier factor (discussed in Section 8.2.1.1, below) on the vertical axis.

The biomass contribution factor for a given combination of system size and load scale factor is represented by a region denoted by a particular color, with each color representing the range depicted in the key above the chart.

Within the range of system sizes and load scale factors used, the lowest contribution factor$7.5 \%$ - occurs in the upper-left corner (i.e. highest load and smallest system size), and the highest $-86 \%$ to $87 \%$ — occurs near the lower-right corner (i.e. lowest load and largest system).

If a motivation for installing a biomass system is to offset natural gas and oil consumption, a high contribution factor is desirable.

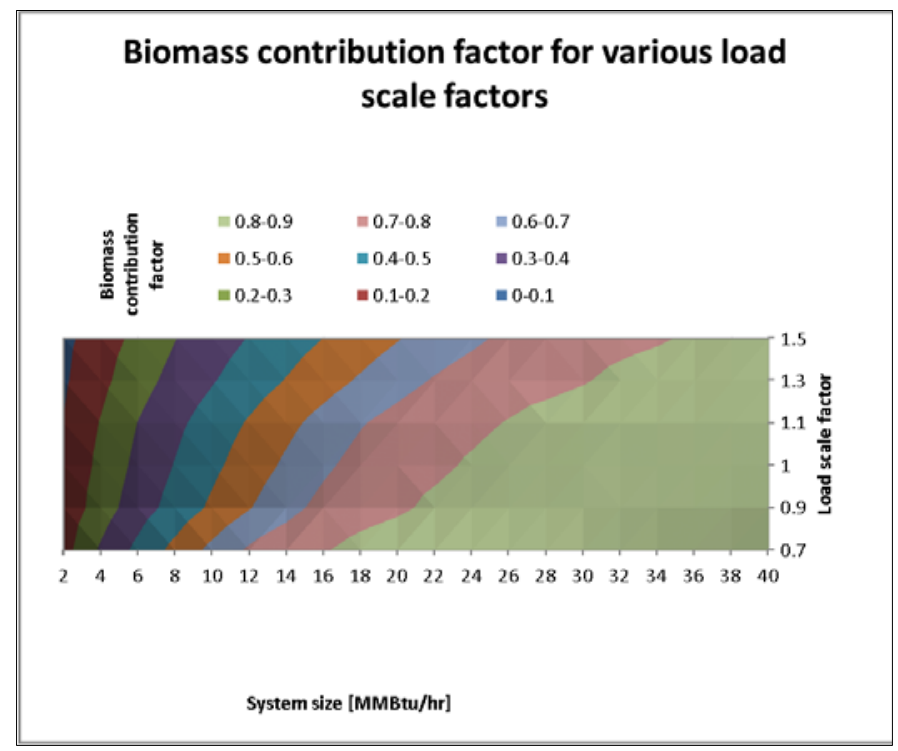

Figure 35: Biomass contribution factor versus system size and load scale factor

The biomass capacity factor chart is very similar to the biomass contribution chart. It is a measure of the expected annual output of the biomass system, as a fraction of the total annual potential output (i.e. if the system were to operate at full rated capacity, 24 hours per day, 365 days per year). As with contribution factor, a high capacity factor is generally desirable. 
As expected, the minimum value- $0.25(25 \%)$ - is in the lower-right corner of the chart (i.e. the largest system at the lowest load), and the maximum value - $0.96(96 \%)$ - is in the upper-left corner (i.e. the smallest systems at the largest load).

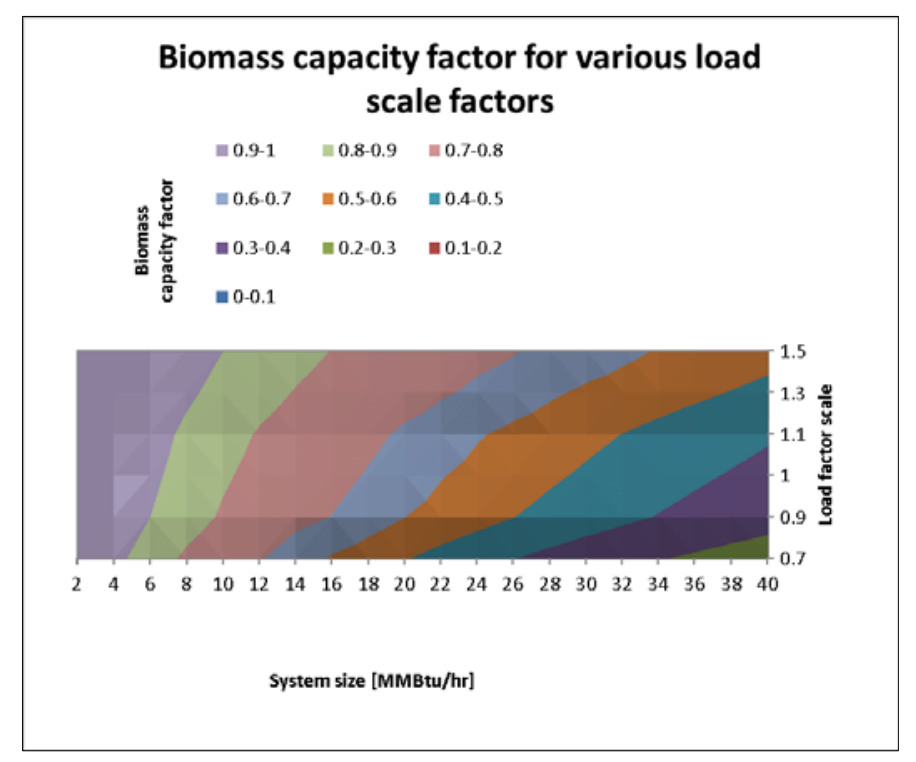

Figure 36: Biomass capacity factor versus system size and load scale factor

Figure 37 is a chart of capacity factor and contribution factor, as functions of biomass system size and with the load scale multiplier set to 1.0. Note that capacity factor and contribution factor are conflicting measures; in the figures above, the highest capacity factor occurs diametrically opposite the highest contribution factor. These two measures, in combination with the financial metrics discussed in Chapter 5, are important components used to determine an "optimal" system size. 


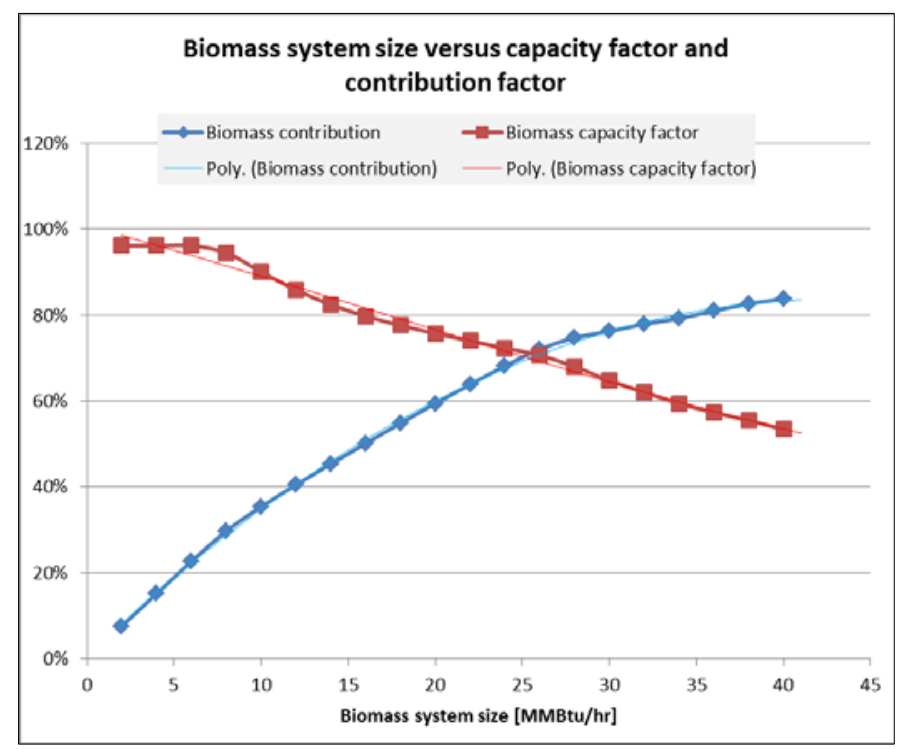

Figure 37: Sample chart of capacity factor and contribution factor as function of biomass system size

\subsection{Dashboard tab}

Figure 38 shows the Dashboard tab with default values. Column E, on the left, contains user inputs, as well as outputs and linked values, with descriptive names in Column $\mathrm{C}$ and units in Column D. Some of the names and values include comments that will be displayed when the cursor is placed in or above the cell.

Four output graphs are displayed on the right side of the dashboard, and include financial metrics and other values of interest. These graphs, as well as the financial metrics, are discussed in Chapter 5. All of the inputs and outputs are discussed below. 


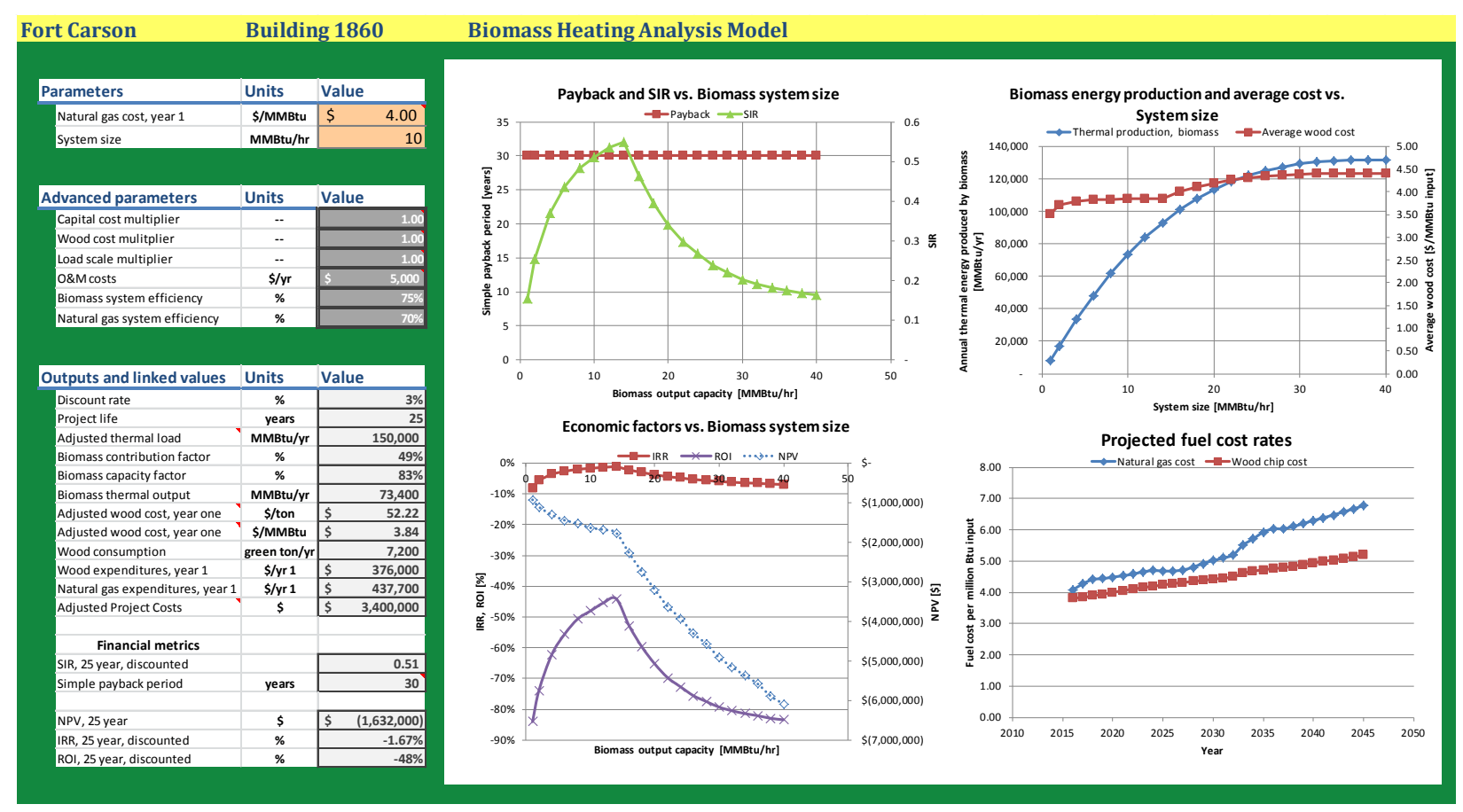

Figure 38: Dashboard, with default values

\subsubsection{Parameters and advanced parameters}

The primary variables of user interest will probably be the two listed in the Parameters section: year one natural gas cost, and system size, which are the top two entries in Table 5.

The advanced parameters include multipliers for capital costs, wood cost and load scale, as well as entries for annual operation and maintenance (O\&M) costs, biomass system efficiency and natural gas system efficiency.

Table 5: User-settable inputs from the Dashboard tab

\begin{tabular}{|c|c|c|}
\hline Parameters & Units & Value \\
\hline Natural gas cost, year 1 & \$/MMBtu & 4.00 \\
\hline System size & MMBtu/hr & 10 \\
\hline Advanced parameters & Units & Value \\
\hline Capital cost multiplier & -- & 1.00 \\
\hline Wood cost mulitplier & -- & 1.00 \\
\hline Load scale multiplier & -- & 1.0 \\
\hline O\&M costs & $\$ / y r$ & 5,000 \\
\hline Biomass system efficiency & $\%$ & $75 \%$ \\
\hline Natural gas system efficiency & $\%$ & $70 \%$ \\
\hline
\end{tabular}




\subsubsection{Multipliers}

The three multipliers are used to adjust factors that are based on complex calculations. For example, base capital costs are calculated, as explained in Chapter 5, by exponential scaling of recent system quotes. Rather than discard these data points, the user can enter scale values between 0.7 and 1.5 to decrease or increase the base calculations for applications with higher or lower typical installation costs. Conditional formatting has been applied to provide a visual indication of scaling factors that have been changed from the default value of 1.00, as shown in Table 6: cells with values below 1.00 are colored in yellow, and values above 1.00 are colored in pink.

\section{Table 6: Multipliers}

\begin{tabular}{|l|c||r|}
\hline Advanced parameters & Units & Value \\
\hline Capital cost multiplier & -- & 0.70 \\
\hline Wood cost mulitplier & -- & 1.50 \\
\hline Load scale multiplier & -- & 1.00 \\
\hline
\end{tabular}

Wood costs are based on supplier quotes, as discussed in Chapter 3 and summarized in Table 4 . The wood cost multiplier is used to scale the costs in this entire table.

Table 7: Summary of Biomass Generation and Pricing for Fort Carson Area

\begin{tabular}{|l|l|r|r|r|r|r|}
\hline \multicolumn{1}{|c|}{ Company } & \multicolumn{1}{|c|}{$\begin{array}{r}\text { Type of material } \\
\text { (tons/ } \\
\text { year) }\end{array}$} & $\begin{array}{c}\text { Energy Value } \\
\text { (MMBtu/ year) }\end{array}$ & $\begin{array}{c}\text { Delivered } \\
\text { Cost } \\
\text { (\$/ton) }\end{array}$ & $\begin{array}{r}\text { MC\% } \\
\text { Delivered Cost } \\
\text { (\$/MMBtu) }\end{array}$ \\
\hline Supplier 1 & Trim ends & 72 & 979 & $\$ 1.11$ & 20 & $\$ 0.08$ \\
Supplier 2 & Trim ends & 36 & 490 & $\$ 51.03$ & 20 & $\$ 3.75$ \\
Supplier 3 & Ground wood & 10,000 & 122,400 & $\$ 47.50$ & 28 & $\$ 3.88$ \\
Supplier 4 & Ground wood & 14,100 & 151,725 & $\$ 61.63$ & 37 & $\$ 5.73$ \\
Supplier 5 & Bark, chips & 7,200 & 72,420 & $\$ 59.04$ & 41 & $\$ 5.87$ \\
Supplier 6 & Chips & 1,500 & 14,025 & $\$ 72.83$ & 45 & $\$ 7.79$ \\
Supplier 7 & Sawdust, chips, bark & 2,000 & 18,700 & $\$ 74.06$ & 45 & $\$ 7.92$ \\
\hline Total/weighted average & $\mathbf{3 4 , 9 0 8}$ & $\mathbf{3 8 0 , 7 3 9}$ & $\mathbf{\$ 5 8 . 1 1}$ & $\mathbf{3 6}$ & $\$ \mathbf{S 5 . 3 3}$ \\
\hline
\end{tabular}

As with the previous two multipliers, the load scale multiplier just moves the entire annual load up or down by the amount specified, without changing the load shape or distribution. Any change in the actual load could alter the load chronology. For example, decreased summer hot water use will reduce the overall annual thermal energy use and shift the load distribution, which will reduce the accuracy of calculations of the derived relationship between biomass system size, capacity factor and contribution factor.

\footnotetext{
${ }^{28}$ [NREL] In this report, names of potential suppliers have been replaced with generic identifiers. See the unpublished Antares report for names.
} 


\subsubsection{Remaining parameters}

The final three parameters include O\&M costs, biomass system efficiency and natural gas system efficiency.

Table 8: Remaining parameters

\begin{tabular}{|c|c|c|}
\hline Advanced parameters & Units & Value \\
\hline Capital cost multiplier & -- & 0.70 \\
\hline Wood cost mulitplier & -- & 1.50 \\
\hline Load scale multiplier & .- & 1.00 \\
\hline O\&M costs & $\$ / y r$ & 5,000 \\
\hline Biomass system efficiency & $\%$ & $75 \%$ \\
\hline Natural gas system efficiency & $\%$ & $70 \%$ \\
\hline
\end{tabular}

In conversations with Fort Carson personnel, it was decided that the existing boiler plant operators would operate and maintain any biomass system connected to Building 1860, but that any additional hardware costs would need to be accounted for. We have estimated these costs at about \$5,000 dollars per year, but have made this an adjustable cell, for performing "what-if" analysis.

Biomass system efficiency depends on system design factors and on the moisture content of the fuel. We have used the estimated moisture contents from the biomass survey, and typical values for a high-efficiency biomass boiler, in our initial calculations, but have left the option for useradjustability so that effects of higher- and lower-efficiency systems, and differing fuel moisture contents, can be investigated. The default value for biomass system efficiency is $75 \%$.

According to data provided in the 1860 boiler logs, the efficiency of the natural gas generators varies between $54 \%$ and $86 \%$, depending on outdoor conditions and which generator is being used. We have set the default value at $70 \%$, but have left this value adjustable.

\subsubsection{Outputs and linked values}

In addition to the charts, the dashboard provides the values shown in Table 9. Note that these values are for a specific combination of parameter and advanced parameters discussed above, while the tables tend to provide outputs for a range of input values.

The values shown in Table 9 are for the default inputs. Note that SIR is less than one, simple payback period is greater than 30 years, and NPV, IRR, and ROI are all negative. This indicates that, under the current conditions, adding a biomass system is not economically attractive. 
Table 9: Outputs and linked values

\begin{tabular}{|c|c|c|}
\hline Outputs and linked values & Units & Value \\
\hline Discount rate & $\%$ & $3 \%$ \\
\hline Project life & years & 25 \\
\hline Adjusted thermal load & MMBtu/yr & 150,000 \\
\hline Biomass contribution factor & $\%$ & $49 \%$ \\
\hline Biomass capacity factor & $\%$ & $83 \%$ \\
\hline Biomass thermal output & MMBtu/yr & 73,400 \\
\hline Adjusted wood cost, year one & $\$ /$ ton & 52.22 \\
\hline Adjusted wood cost, year one & \$/MMBtu & 3.84 \\
\hline Wood consumption & green ton/yr & 7,200 \\
\hline Wood expenditures, year 1 & $\$ / y r 1$ & 376,000 \\
\hline Natural gas expenditures, year 1 & $\$ / y r 1$ & 437,700 \\
\hline Adjusted Project Costs & $\$$ & $3,400,000$ \\
\hline \multicolumn{3}{|l|}{ Financial metrics } \\
\hline SIR, 25 year, discounted & & 0.51 \\
\hline Simple payback period & years & 30 \\
\hline NPV, 25 year & $\$$ & $(1,632,000)$ \\
\hline IRR, 25 year, discounted & $\%$ & $-1.67 \%$ \\
\hline ROI, 25 year, discounted & $\%$ & $-48 \%$ \\
\hline
\end{tabular}

\subsection{Examples}

Dashboard output provided above reflects current conditions, and does not result in a viable biomass project. The dashboard allows users to adjust parameters to see what conditions will provide a better outcome. For example, if first year natural gas prices increase to $\$ 5.00$ per million Btu, payback and SIR will meet or exceed the minimum conditions (20-yr and 1.0) for biomass systems between approximately 7- and 20-MMBtu/hr. The optimum system would be around 14-MMBtu/hr.

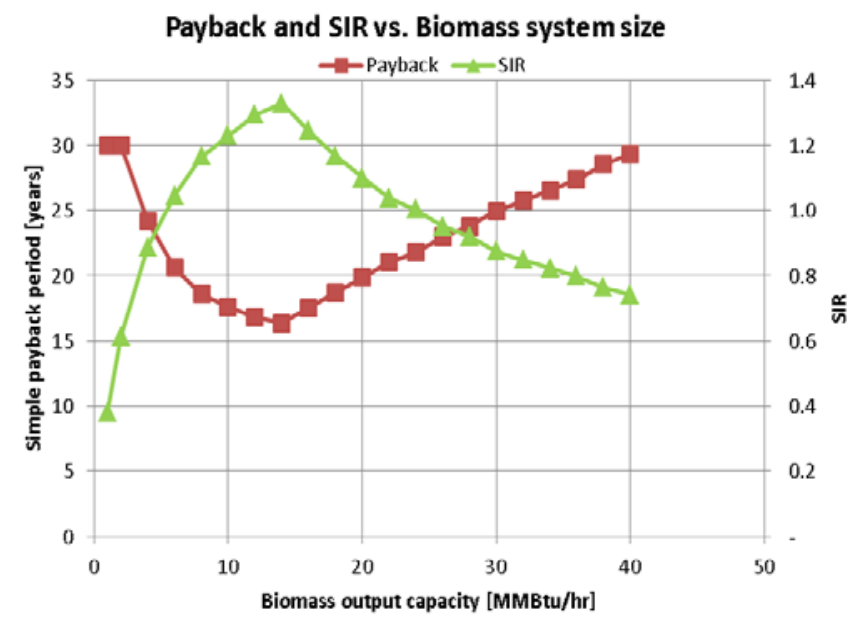

Figure 39: Payback and SIR with first year gas prices of $\$ 5.00 / M M B t u$ 
Figure 40 provides three more economic factors - IRR, ROI and NPV_-versus biomass system size. Again note the peak at 14-MMBtu/hr, which is explained next.

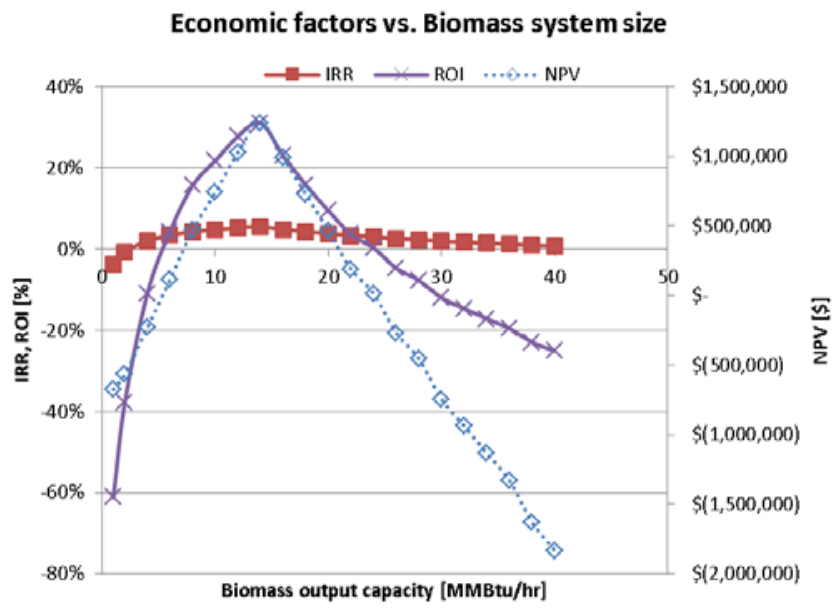

Figure 40: IRR, ROI and NPV with first year gas prices of $\$ 5.00 / M M B t u$

Figure 41 shows the thermal production and average wood cost for a range of biomass system sizes. This chart does not change with changing gas costs, but it will change with changing first year wood costs.

Note that average wood costs increase for systems above 14-MMBtu/hr, which is the reason that that size shows up as the best option. The cost increase looks minor, but it's enough to have a strong impact on economic feasibility. Even with significantly higher first year gas prices, 14$\mathrm{MMBtu} / \mathrm{hr}$ looks like the best option for this application.

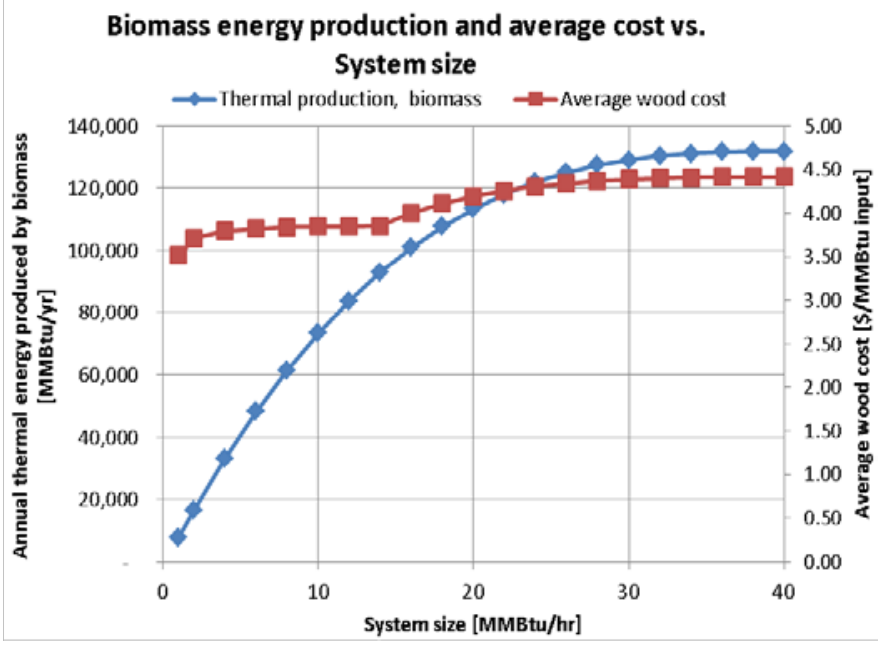

Figure 41: Thermal production from biomass and average wood cost as a function of biomass system size 
Figure 42 presents the projected wood and gas prices over a 30 -year period, with a starting gas price of $\$ 5.00$ per MMBtu. Note that natural gas prices are projected to be a little bit more volatile than wood prices.

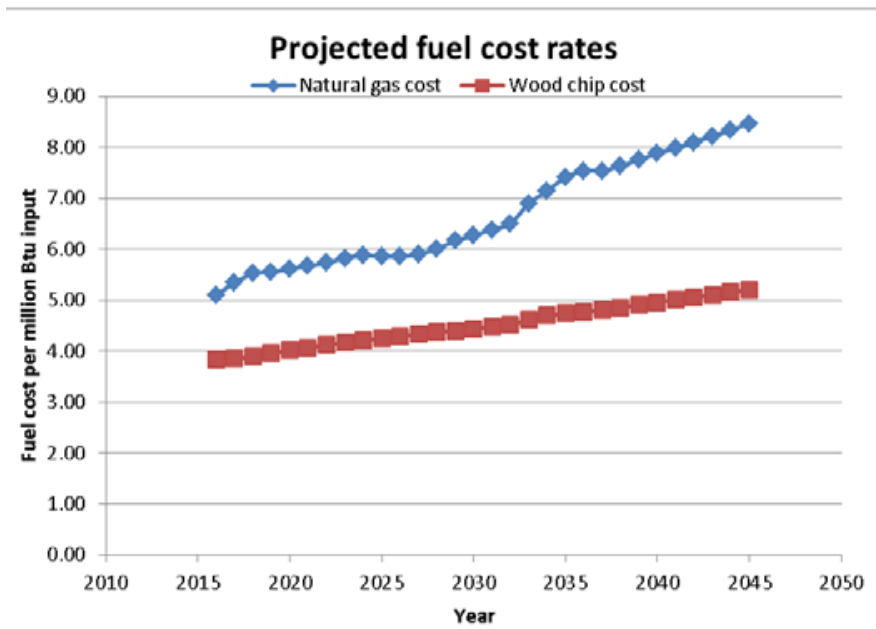

Figure 42: Projected gas and wood prices, at a first year gas price of $\$ 5.00 / M M B t u$ 


\section{Appendix A Potential Wood Contaminants}

Colorado Springs Utilities (CSU) is concerned about levels of contaminants - including chlorine and chlorides - within wood chips that they were considering for co-firing in their Drake plant. They performed analyses of biomass samples, and provided us with the results. Chlorine is presented in the following tables both as chlorine and as $\mathrm{HCl}$ - hydrogen chloride — and in various units.

Values are reported for the wood as received (AR) - meaning the wood is green - and dry, for samples of various types and sources. The purpose of the dry measurement is to eliminate the variability imposed by moisture content. For the Rocky Top samples, chlorine varies from 150 to $240 \mathrm{micrograms} /$ gram (i.e. parts per million by weight) dry. The forest samples had much lower chlorine levels - from less than 10 up to 73 ppm dry. The highest chlorine measurements were for pallets (302 ppm) and micro materials (up to $355 \mathrm{ppm}$ ).

In terms of energy values, chlorine ranges between 0.020 (or less) and 0.061 pounds per MMBtu for the wood samples tested. By comparison, typical coal values, presented in Section A1, range from 0.009 to 0.130 pound per MMBtu, as shown in Table 14, with coal from Wyoming and Montana on the low end of the range.

\section{A1. Wood Data}

Table 10 provides chlorine and mercury levels for five samples from Rocky Top and one from Black Forest. Results are presented as microgram per gram, relative to both as received (i.e. green) and dry bases. The last two columns present chlorine levels in micro grams per gram, and hydrogen chloride in pound per million Btu.

Table 10: CSU Wood Sample data for chlorine and mercury

\begin{tabular}{|c|c|c|c|c|c|c|}
\hline Sample Source & Date & $\begin{array}{l}\text { Dry } \\
\text { Chlorine } \\
\mathrm{ug} / \mathrm{g}\end{array}$ & $\begin{array}{l}\text { Basis } \\
\text { Mercury } \\
\text { ug/g }\end{array}$ & Moisture & $\begin{array}{l}\text { As R } \\
\text { Chlorine } \\
\mathrm{ug} / \mathrm{g}\end{array}$ & $\begin{array}{l}\text { eceived } \\
\mathrm{HCl} \\
\mathrm{lb} / \mathrm{MMBtu}\end{array}$ \\
\hline \multirow{5}{*}{ Rocky Top } & $3 / 3 / 2014$ & 240 & $<0.02$ & 18.06 & 197 & 0.032 \\
\hline & $3 / 4 / 2014$ & 150 & $<0.02$ & 18.21 & 123 & 0.020 \\
\hline & $3 / 6 / 2014$ & 220 & $<0.02$ & 18.84 & 179 & 0.029 \\
\hline & $3 / 7 / 2014$ & 200 & $<0.02$ & 18.84 & 162 & 0.026 \\
\hline & $3 / 8 / 2014$ & 190 & $<0.02$ & 23.66 & 145 & 0.023 \\
\hline Blackforest & $12 / 17 / 2014$ & 630 & 0.06 & 45.81 & 341 & \\
\hline
\end{tabular}


Table 11 is focused on chlorine measurements from pallets and micro material. ${ }^{29}$ Here data is presented as parts-per-million (by weight) — which is the same as microgram per gram — and as pounds of chlorine per MMBtu of energy content.

Table 11: Rocky Top Samples January 20, 2015—chlorine measurements

\begin{tabular}{|l|cr|rr|rr|}
\hline \multirow{2}{*}{ As-Received Chlorine } & \multicolumn{2}{|c|}{ Pallets } & \multicolumn{2}{c|}{ Pallets } & \multicolumn{2}{c|}{ Micro } \\
& ppm lb/MMBtu & ppm & lb/MMBtu & ppm & lb/MMBtu \\
\hline Min & 205 & 0.028 & 178 & 0.025 & 149 & 0.027 \\
Max & 302 & 0.042 & 213 & 0.034 & 355 & 0.061 \\
Avg & 262 & 0.036 & 192 & 0.031 & 245 & 0.041 \\
\hline
\end{tabular}

Table 12 provides additional data for chlorine, mercury - dry and as received (AR) — and sulfur. Note that sulfur values are in percent, but chlorine and mercury are in parts-per-million. This data is for samples taken from unprocessed forest wood.

Table 12: 2015 Forest Samples

\begin{tabular}{|l|l|l|l|l|l|l|}
\hline Sample ID & $\begin{array}{l}\text { Moisture } \\
\%\end{array}$ & $\begin{array}{l}\text { Dry } \\
\text { chlorine } \\
\text { ug/g }\end{array}$ & $\begin{array}{l}\text { AR } \\
\text { chlorine } \\
\text { ug/g }\end{array}$ & $\begin{array}{l}\begin{array}{l}\text { Dry } \\
\text { mercury } \\
\text { ug/g }\end{array} \\
\text { North Slope East Limber Pine }\end{array}$ & $\begin{array}{l}\text { AR } \\
\text { mercury } \\
\text { ug/g }\end{array}$ & $\begin{array}{l}\text { AR } \\
\text { sulfur } \\
\%\end{array}$ \\
North Slope East Ponderosa Pine & 48.60 & 15 & 8 & $<0.02$ & $<0.02$ & 0.02 \\
North Slope West Englemann Spruce & 14.72 & 15 & 8 & $<0.02$ & $<0.02$ & 0.02 \\
North Slope East Engleman Spruce & 11.55 & 12 & 20 & $<0.02$ & $<0.02$ & 0.03 \\
North Slope East Doug Fir & 3.65 & $<10$ & 11 & $<0.02$ & $<0.02$ & 0.04 \\
South Slope East Englemann Spruce & 14.59 & 20 & 17 & $<0.02$ & $<0.02$ & 0.03 \\
South Slope East Ponderosa Pine & 67.94 & 17 & 5 & $<0.02$ & $<0.02$ & 0.03 \\
South Slope East Aspen & 58.97 & 73 & 30 & $<0.02$ & $<0.02$ & 0.01 \\
\hline
\end{tabular}

Data in Table 13 is for a number of material samples around Fort Carson, including some pallet samples and some micro materials. Units for some of the measurements were not provided. We've highlighted the row with hydrogen chloride $(\mathrm{HCl})$, which shows a range from 0.025 to $0.061 \mathrm{lb} /$ MMBtu.

Table 13: Rocky Top Samples January 20, 2015-ultimate and proximate analysis

\begin{tabular}{|l|rrrrrrrrrrr|}
\hline Parameter & \multicolumn{1}{|c|}{ Pallet E } & Pallet S Pallet W & Carson N Carson E Carson S Carson W & Micro N Micro E Micro S Micro W \\
\hline Moisture & 11.28 & 11.46 & 11.01 & 27.19 & 14.97 & 10.94 & 24.24 & 24.42 & 32.37 & 21.64 & 22.68 \\
Ash & 1.91 & 2.3 & 1.12 & 5.57 & 3.89 & 2.79 & 6.79 & 8.14 & 4.42 & 5.57 & 5.98 \\
BTU & 7495 & 7411 & 7500 & 5732 & 6961 & 7442 & 5958 & 6015 & 5681 & 6446 & 6322 \\
Sulfur & 0.01 & 0 & 0 & 0.01 & 0.01 & 0.01 & 0.01 & 0.04 & 0.02 & 0.03 & 0.04 \\
Dry Ash & 2.15 & 2.6 & 1.26 & 7.65 & 4.57 & 3.14 & 8.96 & 10.77 & 6.53 & 7.11 & 7.74 \\
Dry BTU & 8448 & 8371 & 8428 & 7873 & 8187 & 8536 & 7865 & 7958 & 8400 & 8226 & 8176 \\
Dry Sulfur & 0.01 & 0 & 0 & 0.02 & 0.01 & 0.01 & 0.01 & 0.05 & 0.03 & 0.03 & 0.05
\end{tabular}

\footnotetext{
${ }^{29}$ Micro material is composed primarily of branches, with some logs and stumps mixed in.
} 


\begin{tabular}{|l|rrrrrrrrrrr|}
\hline Parameter & Pallet E & \multicolumn{1}{c|}{ Pallet S Pallet W } & Carson N Carson E Carson S Carson W & Micro N Micro E Micro S Micro W \\
\hline MAF BTU & 8634 & 8594 & 8536 & 8526 & 8579 & 8627 & 8639 & 8919 & 8987 & 8855 & 8862 \\
lbs Ash & 2.55 & 3.1 & 1.5 & 9.72 & 5.59 & 3.76 & 11.39 & 13.54 & 7.77 & 8.64 & 9.7 \\
lbs Sulfur & 0.01 & 0 & 0 & 0.02 & 0.01 & 0.01 & 0.02 & 0.06 & 0.03 & 0.04 & 0.06 \\
lbs SO2 & 0.02 & 0 & 0 & 0.04 & 0.02 & 0.02 & 0.03 & 0.12 & 0.07 & 0.08 & 0.12 \\
Dry Chlorine & 340 & 270 & 230 & 250 & 250 & 200 & 260 & 470 & 220 & 300 & 310 \\
AR Chlorine & 302 & 239 & 205 & 182 & 213 & 178 & 197 & 355 & 149 & 235 & 240 \\
AR HCl & 0.041 & 0.033 & 0.028 & 0.033 & 0.031 & 0.025 & 0.034 & 0.061 & 0.027 & 0.038 & 0.039 \\
lb/MMBtu & & & & & & & & & & & \\
Dry Mercury & $<0.02$ & $<0.02$ & $<0.02$ & $<0.02$ & $<0.02$ & $<0.02$ & $<0.02$ & $<0.02$ & $<0.02$ & $<0.02$ & $<0.02$ \\
AR Mercury & $<0.02$ & $<0.02$ & $<0.02$ & $<0.01$ & $<0.02$ & $<0.02$ & $<0.02$ & $<0.02$ & $<0.01$ & $<0.02$ & $<0.02$ \\
\hline
\end{tabular}

\section{A2. Coal Data}

For comparison, we've included analysis data for coal $^{30}$ in Table 14. The lowest chlorine values are found in coal from Montana and Wyoming — at 107 and 131 ppm dry, respectively. Coal used by CSU most likely comes from these sources.

Table 14: Coal data, including HHV, ash, sulfur, mercury and chlorine

\begin{tabular}{|l|rrrrrr|}
\hline State & \multicolumn{1}{l}{$\begin{array}{l}\text { HHV } \\
\text { Btu/lb, (dry) }\end{array}$} & $\begin{array}{l}\text { Ash } \\
\text { (\% dry) }\end{array}$ & $\begin{array}{l}\text { Sulfur } \\
\text { (\% dry) }\end{array}$ & $\begin{array}{l}\text { Mercury } \\
\text { (ppm dry) }\end{array}$ & $\begin{array}{l}\text { Chlorine } \\
\text { (ppm dry) }\end{array}$ & $\begin{array}{l}\text { Chlorine } \\
(\mathrm{lb} / \mathrm{MMBtu})\end{array}$ \\
\hline Illinois $^{1}$ & 12,992 & 9.9 & 2.6 & 0.083 & 1,691 & 0.130 \\
Pennsylvania $^{1}$ & 13,089 & 13.2 & 1.9 & 0.258 & 1,048 & 0.080 \\
Kentucky $^{1}$ & 13,153 & 11.2 & 1.9 & 0.104 & 1,054 & 0.080 \\
West Virginia $^{1}$ & 13,264 & 12 & 1.4 & 0.119 & 1,044 & 0.079 \\
Wyoming $^{2}$ & 12,033 & 8.1 & 0.6 & 0.053 & 131 & 0.011 \\
Montana $^{2}$ & 11,633 & 10 & 0.8 & 0.07 & 107 & 0.009 \\
North Dakota $^{3}$ & 10,603 & 14.4 & 1.3 & 0.097 & 159 & 0.015 \\
Texas $^{3}$ & 9,332 & 25.5 & 1.6 & 0.125 & 370 & 0.040 \\
\hline
\end{tabular}

1. Coals from Illinois, Pennsylvania, Kentucky and West Virginia are predominantly high volatile bituminous

2. Coals from Wyoming and Montana are mostly from the Powder River Basin and subbituminous in rank

3. Coals from North Dakota and Texas are mostly lignite

30 from

http://www.netl.doe.gov/File\%20Library/research/energy\%20analysis/publications/QGESS_DetailCoalSpecs_Rev4 _20130510.pdf 


\section{Appendix B System Size Vs, Load Served-Representative Examples}

We've previously discussed the negative impacts of having a system that's sized too large or too small for the loads. In this appendix we present some examples, complete with charts, to clarify this concept. We've provided figures that demonstrate the contribution of biomass to the annual load from three systems - sized at 12, 20 and $32 \mathrm{MMBtu} / \mathrm{hr}$ - as predicted by sizing method 1 discussed above. In each chart, daily loads are represented by blue markers; red markers indicate calculation of daily output of the biomass system. Note that two weeks of scheduled maintenance are planned to occur each year during the summer. Any load not met by biomass is served by natural gas.

1) $12 \mathrm{MMBtu} / \mathrm{hr}$ : This system operates all year, except for the annual maintenance period, but only supports a fraction of the winter load.

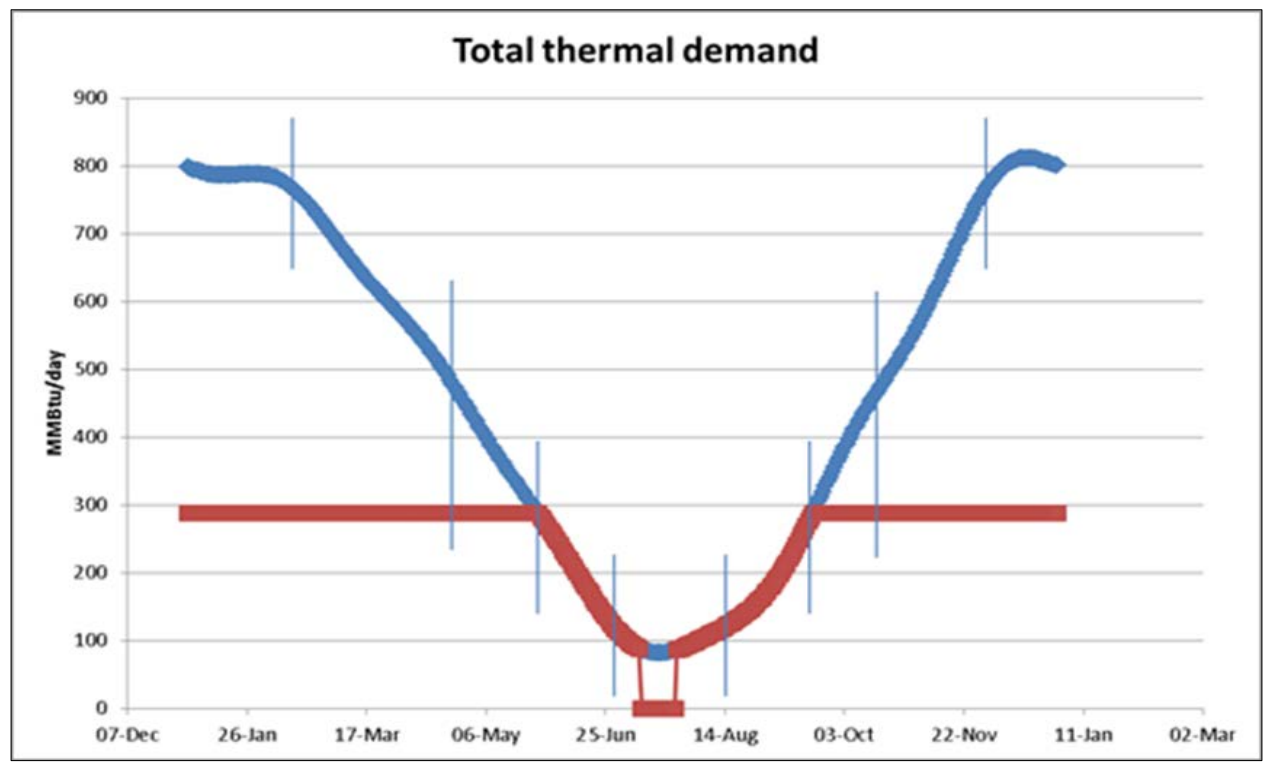

Figure 43: Example of thermal demand (blue) and output (red) from a 12-MMBtu/hr system using a single biomass boiler

2) $20 \mathrm{MMBtu} / \mathrm{hr}$ : This system also operates all year, except when the load is low in July and part of August. It provides a larger portion of the winter load, but a smaller portion of the summer load. 


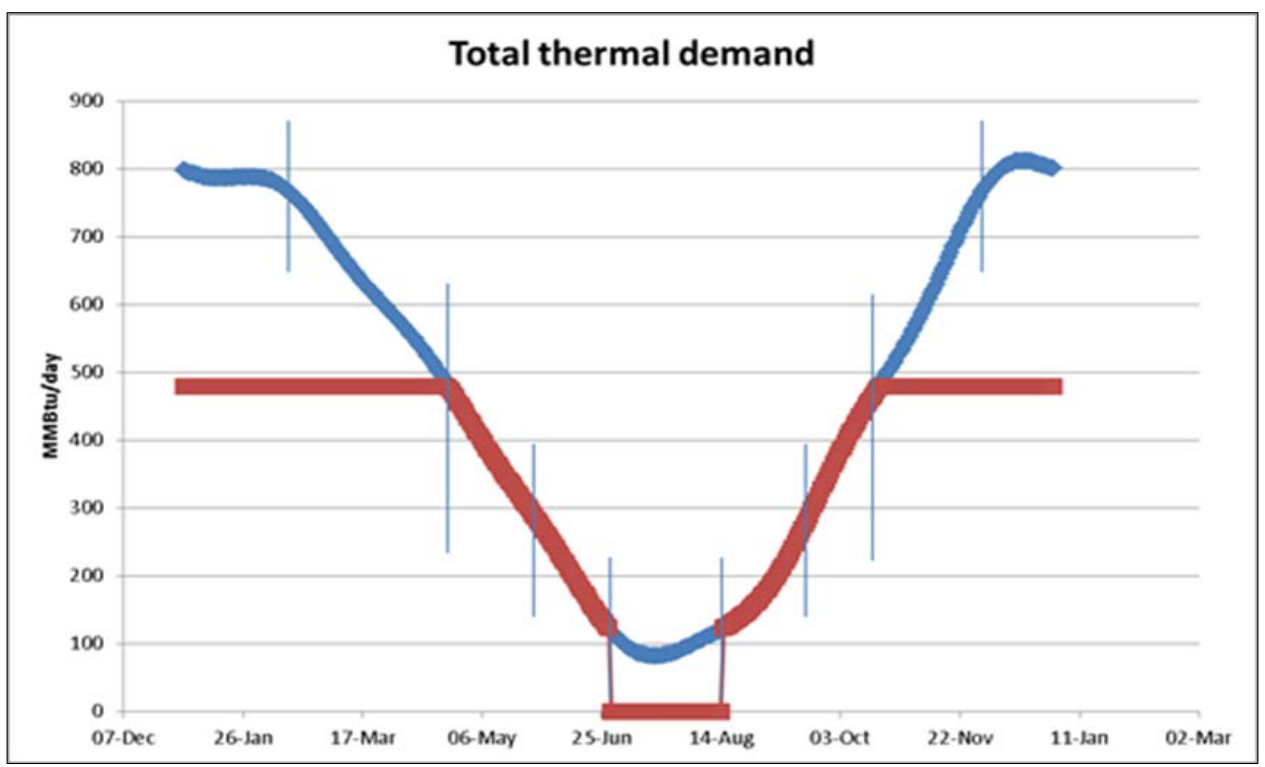

Figure 44: Example of thermal demand (blue) and output (red) for a 20-MMBtu/hr single biomass boiler

3) $32 \mathrm{MMBtu} / \mathrm{hr}$ : Compared to the 20-MMBtu/hr system, this system contributes even more in the winter, but less in the summer.

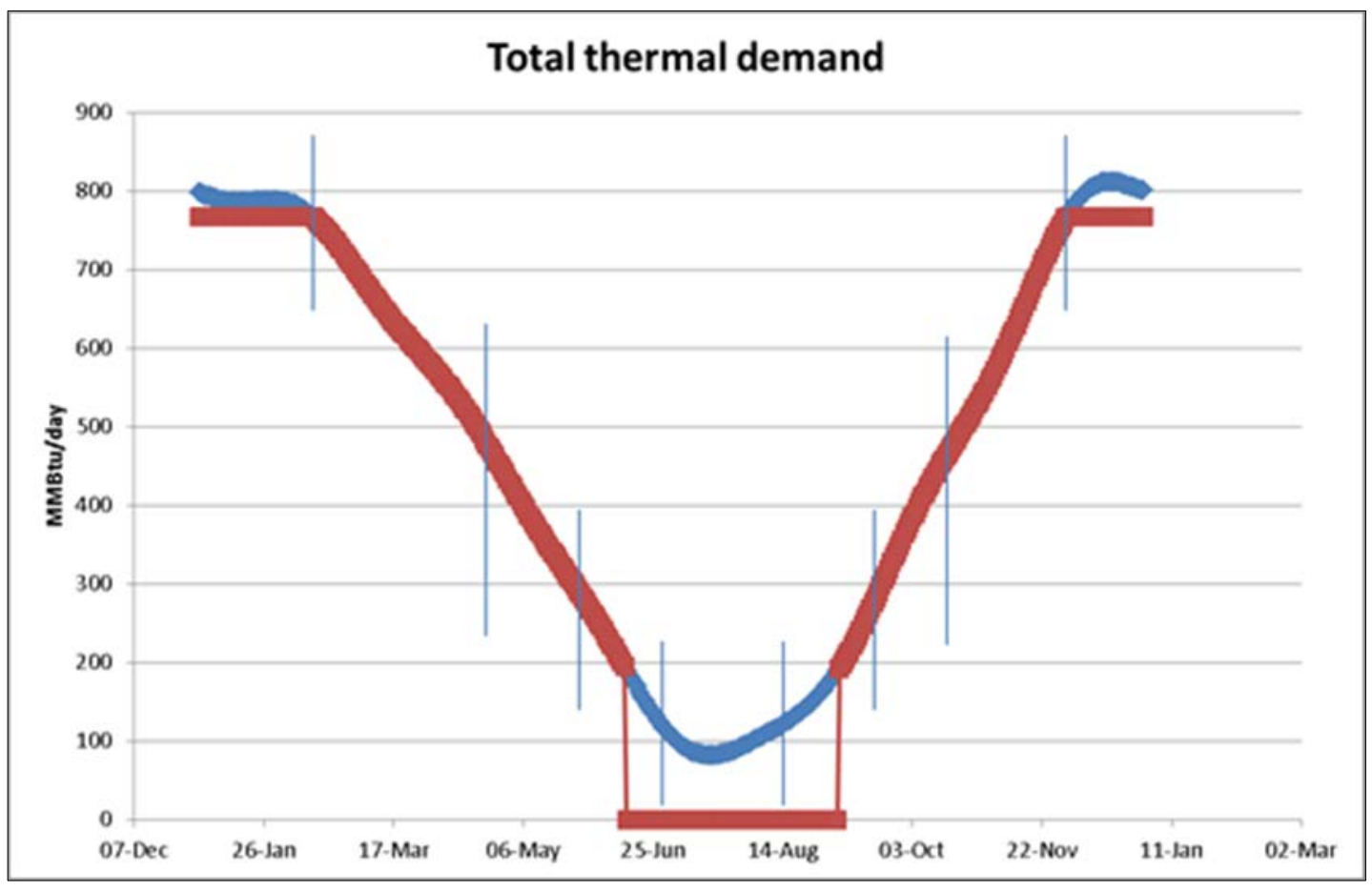

Figure 45: Example of thermal demand (blue) and output (red) for a 32-MMBtu/hr single biomass boiler 
(A better option to achieve a capacity of $32 \mathrm{MMBtu} / \mathrm{hr}$ might be to install two biomass units, for example a 12- and a 20-MMBtu/hr system. This would provide more operating flexibility and would have the advantage of eliminating summer downtime, if the boilers can be scheduled properly.)

The above charts don't account for daily load variations, which would look something like Figure 46 (with a single 32-MMBtu/hr boiler). In a practical application, the biomass system wouldn't be cycled on-and-off. Instead, the biomass boiler would be shut-down for the entire summer - and parts of the spring and fall—which means that a high percentage of the annual load would be met by natural gas. A smaller system could be operated all summer.

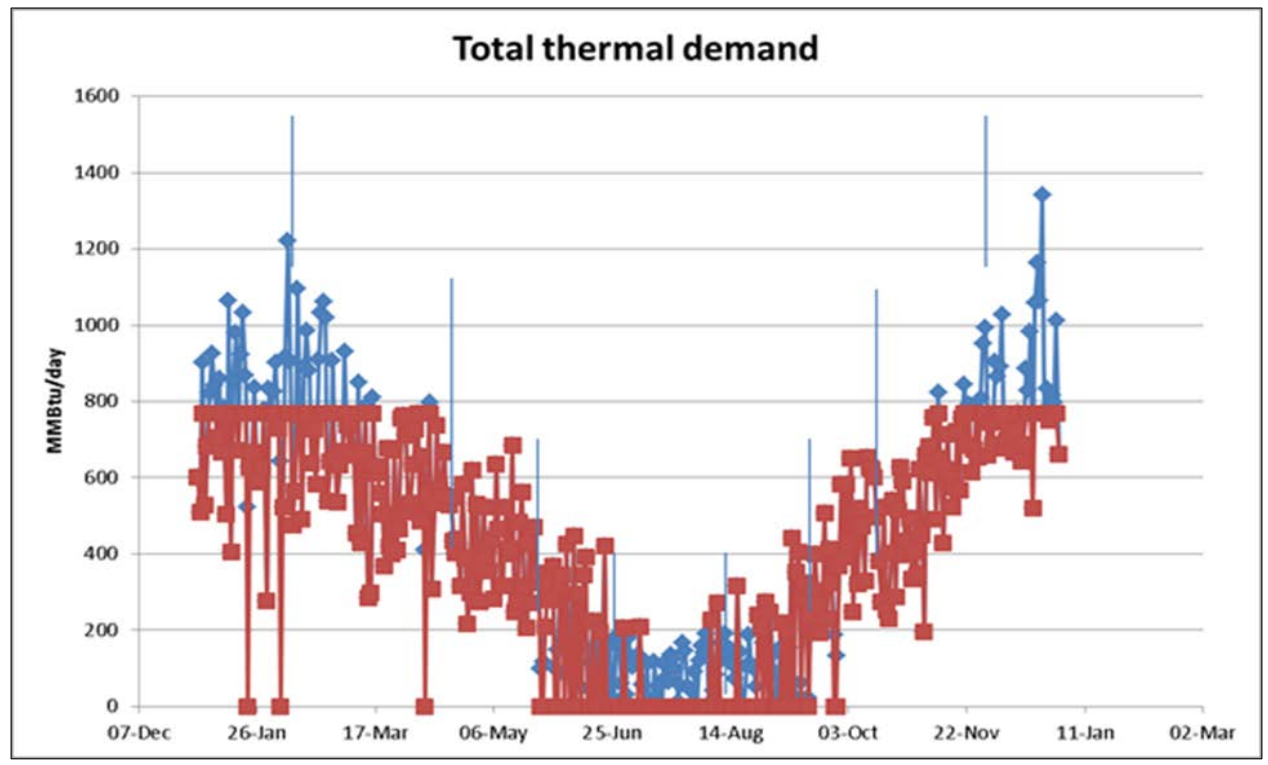

Figure 46: Thermal demand (blue) and output (red)—with daily variations—for a 32-MMBtu/hr single biomass boiler 